\title{
Les Grands Esprits du Management
}

Scénarios de Jean Boisvert Assisté de Daniel Maltais 



\section{Les Grands Esprits du Management}


PRESSES DE L'UNIVERSITÉ DU QUÉBEC

2875, hou]. Laurier, Sainte-Foy (Québec) G1V 2M3

Téléphone: (418) 657-4399 • Télécopieur: (418) 657-2096

Courriel : secretariat@puq.uquebec.ca・Internet : www.puq.uquebec.ca

Distribution :

CANADA et autres pays

DISTRIBUTION DE LIVRES UNIVERS S.E.N.C.

845, rue Marie-Victorin, Saint-Nicolas (Québec) G7A 3S8

Téléphone: (418) 831-7474 / 1-800-859-7474 • Télécopieur : (418) 831-4021

\section{FRANCE}

DIFFUSION DE L'ÉDITION QUÉBÉCOISE

30, rue Gay-Lussac, 75005 Paris, France

Téléphone: 33143544902

Télécopieur: 33143543915

\section{SUISSE}

GM DIFFUSION SA

Rue d'Etraz 2, CH-1027 Lonay, Suisse

Téléphone: 0218032626

Télécopieur: 0218032629

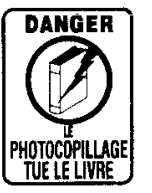

La Loi sur le droit d'auteur interdit la reproduction des oeuvres sans autorisation des titulaires de droits. Or, la photocopie non autorisée - le " photocopillage »-s'est généralisée, provoquant une baisse des ventes de livres et compromettant la rédaction et la production de nouveaux ouvrages par des professionnels. L'objet du logo apparaissant cicontre est d'alerter le lecteur sur la menace que représente pour l'avenir de l'écrit le développement massif du " photocopillage». 


\section{Les Grands Esprits du Management}

D’après une idée originale de Steve Allen

Scénarios de Jean Boisvert assisté de Daniel Maltais, professeur à l École nationale d'administration publique 
Données de catalogage avant publication (Canada)

Boisvert. Jean

Les grands esprits du management

Comprend des réf. bibliogr.

ISBN 2-7605-0771-8

1. Gestion - Philosophie. 2. Chefs d'entreprise - Attitudes.

3. Cadres (Personnel) - Attitudes. 4. Personnel - Direction.

5. Relations industrielles. 1. Maltais, Daniel, 1952- . II. Titre

HD38.B65 $1994 \quad 658^{\circ} .001 \quad$ C94-940763-1

Nous reconnaissons l'aide financière du gouvernement du Canada par l'entremise du Programme d'aide au développement de l'industrie de l'édition (PADIÉ) pour nos activités d'édition.

$\$$ Nous remercions le Conseil des arts du Canada

3 de l'aide accordée à notre programme de publication.

Révision linguistique: Monelle Gélinas

Conception graphique : CARON \& GOSSELIN COMMUNICATION GRAPHIQUE

123456789 PUQ 2000987654321

Tous droits de reproduction, de traduction et d'adaptation réservés (C) 1994 Presses de l'Université du Québec

Dépôt légal $-3^{\mathrm{e}}$ trimestre 1994

Bibliothèque nationale du Québec / Bibliothèque nationale du Canada

Imprimé au Canada 


\section{Préface}

C'est avec un certain étonnement que le lecteur, intéressé au développement du management et habitué à déchiffrer les austères traités sur la question, se laissera prendre par les rencontres passionnantes qu'il fera avec Les Grands Esprits du Management.

Passé un premier moment de scepticisme - de bon aloi chez des gens convaincus qu'on ne peut traiter que sérieusement des personnes et des idées sérieuses -, le lecteur découvrira la richesse de la confrontation des idées et le plaisir de l'humour, voire d'un certain cynisme, chez des auteurs dont les ouvrages sont parfois un peu froids et austères. La simple entrée en scène de Hyacinthe Dubreuil qui déclare solennellement, avant toute invitation à prendre la parole : "L'ouvrier n'a qu'une propriété, celle de son métier! » ou encore l'arrivée intempestive et les déclarations à l'emporte-pièce de George Elton Mayo en disent long sur la personnalité de ces Grands Esprits.

Mieux encore, la liberté que donnent aux auteurs la mise en scène et les règles de la théâtralité autorise des raccourcis et des rapprochements que la lecture linéaire de l'œuvre des auteurs ne permettra jamais. J'en veux comme illustration l'échange vif et nourri entre Dubreuil, Mayo, Barnard et Woodward sur la définition d'un cadre et les qualités qui lui sont indispensables. De distinctions en oppositions, le lecteur construit sa propre définition en puisant dans le riche vivier d'idées qui lui est rendu accessible. Ainsi est sûrement atteint un des buts de cet ouvrage qui cherche, avant tout, à développer une dialectique et à permettre au lecteur de se doter de sa propre doctrine managériale. 
Il faut souligner une autre vertu de cet ouvrage: la volonté de faire connaître l'histoire du management et d'en faire découvrir la mémoire. Il est stimulant de constater, une fois de plus, que toute forme de culture, fut-elle celle du management, repose avant tout sur la volonté de conserver les traces, de donner un sens à la sédimentation et au cumul des connaissances, en pratiquant la fertilisation croisée. Au fil des pages, nous découvrons bien sûr les oppositions, les contradictions entre des penseurs qui travaillent dans un même domaine de connaissances. Mais, plus encore, nous nous rendons compte que de l'un à l'autre de ces savants auteurs, des filiations peuvent être dégagées, des observations dessinent peu à peu un portrait d'ensemble de ce qu'est le management, des approches théoriques et pratiques s'enrichissent mutuellement.

Aujourd'hui, nous baignons plus que jamais dans un monde économique et social qui ne peut fonctionner efficacement qu'en pratiquant intensément l'interdisciplinarité. Qu'il s'agisse de la recherche scientifique, de la vie des appareils gouvernementaux, du développement de l'industrie ou des grandes entreprises financières, il n'y a plus de place pour les insulaires. seuls les continentaux peuvent survivre et se développer. En affirmant cela je voudrais répondre d'avance à qui m'objecterait que le Japon est un archipel! Oui évidemment, mais voilà des gens qui ont su profiter du meilleur de deux mondes en conservant leur culture séculaire et en parcourant tous les continents pour y repérer les meilleures idées, les meilleurs produits et les " adapter» à leurs besoins particuliers dans leurs usines et leurs institutions. Les grandes entreprises japonaises ne comptent-elles pas dans leur personnel des experts qui voyagent constamment et qui rendent compte de ce qu'ils ont $v u$, en produisant des "rapports d'étonnement»?

La rencontre des Grands Esprits emprunte à la richesse de l'interdisciplinarité car, tout en s'intéressant à un champ spécifique de la connaissance: le management, les personnages mis en scène proviennent d'horizons diversifiés et puisent dans des formations personnelles et des cultures nationales fort différentes. Entre Weber l'économiste et le philosophe, Taylor l'ingénieur. 
Follett la spécialiste en service social, Dubreuil l'autodidacte et Fayol le diplômé de l'École des mines, il devrait y avoir peu de choses en commun. Mais tous ces beaux esprits se sont intéressés, pour des raisons et dans des circonstances bien diverses, à l'organisation du travail, à la communication au sein des entreprises, à la croissance et à l'évaluation de la productivité. Plus encore, c'est au développement d'une pensée gestionnaire et d'une " science de la gestion " que ces hommes et ces femmes ont consacré, dans presque tous les cas, leur vie entière.

Un des aspects le plus intéressant de cette confrontation des Grands Esprits, c'est la filiation entre les grandes questions qui préoccupaient les penseurs du siècle dernier et du début du siècle actuel et celles qui sont au cour de la gestion actuelle des organisations. De toute évidence, les Grands Esprits ne vivaient pas dans ce contexte d'incertitude et de turbulence que connaissent les organisations de la fin du XX $X^{e}$ siècle. De toute évidence également, la dynamique des relations de travail, telle qu'elle s'est développée au cours des trente dernières années, était assez loin de leurs préoccupations, même si un homme comme Hyacinthe Dubreuil et une femme comme Mary Follett étaient plus avancés que leurs collègues clans leur vision du développement des personnes et de leur rapport aux entreprises. De façon générale, le discours est centré davantage sur l'entreprise et sur les conditions favorisant une productivité optimale. La présence du client. du consommateur est nulle: l'épanouissement de la ressource humaine se résume à une vague notion de bonheur des travailleurs. Ces valeurs appartiendront aux dernières années du siècle On les retrouvera chez des penseurs actuels du management qui ne sont pas encore inscrits au Panthéon. Il est intéressant par ailleurs d'entendre les Grands Esprits parler de l'autorité partagée, de la cohabitation des spécialités au sein d'une même unité de travail, de la nécessaire décentralisation, de l'importance du savoir ; autant de questions qui sont encore au cour des préoccupations des managers.

Enfin, comment ne pas se réjouir de la formule pédagogique empruntée et de l'exceptionnelle vivacité du texte. Il est rare que des universitaires expriment un tel intérêt pour la vulgarisation et la communication de leur discipline. On ne peut que s'en réjouir 
et souhaiter que des documents audio-visuels soient produits à partir de cet ouvrage. Ce qui lui donnerait tout son sens.

Le management, on le constate tout au long de la lecture de cet ouvrage sur les Grands Esprits du management, est moins une science qu'un assemblage de techniques et de savoir-faire ainsi que la capacité de faire la synthèse entre des domaines de connaissances très variés et d'en tirer les éléments qui soutiennent la décision : "Une esthétique plus qu'une logique », comme le fait remarquer Chester Irving Barnard.

La London Business School elle-même adhère à cette conception lorsqu'elle présente ainsi le principe fondamental de son programme de maîtrise : "La gestion peut être enseignée comme un ensemble unifié de connaissances essentielles que l'on peut appliquer à une organisation. " Le domaine de l'administration publique, mi je suis engagé depuis bien des années, m'a fourni maintes occasions de vérifier cette conception. Les meilleurs gestionnaires que j'y ai connus possédaient toujours une solide formation générale qui leur permettait de bien mener leur travail de généraliste. Ces gestionnaires possédaient également une formation spécialisée dans un domaine : le droit, la théologie, la géographie, les sciences politiques, la communication, la physique... Ce qui leur permettait de faire appel à un cadre conceptuel, un mode de lecture, une démarche éprouvée, sur laquelle ils se sentaient en contrôle, pour prendre des décisions dans des domaines tout autres.

L'ENAP et ses professeurs poursuivent inlassablement leur mission centrée sur le développement d'administrateurs publics compétents. En publiant un ouvrage qui facilite et encourage le retour aux classiques du management, cette école universitaire fait preuve de respect pour la pensée des pères fondateurs du management et d'intérêt pour la connaissance des sources et pour le retour aux racines. On ne peut que s'en réjouir et féliciter tous ceux qui ont rendu cet ouvrage possible.

Roland Arpin

Musée de la civilisation 


\section{Avant-propos}

Certains prennent plaisir à faire connaissance avec des personnages qui ont marqué l'histoire. En gestion, malheureusement, rares sont ceux et celles qui s'attardent à comprendre les points de vue des gestionnaires, des chercheurs et des penseurs qui ont marqué la discipline, à moins qu'il ne s'agisse d'auteurs contemporains aux théories supposées avant-gardistes. Parmi les raisons qui peuvent expliquer ce désintéressement, on peut relever l'opinion assez répandue selon laquelle ce qui a été écrit ou prescrit il y a quelques dizaines d'années ne vaut plus en ces temps modernes, marqués par de nombreux développements technologiques, la mondialisation des échanges et la perméabilité des frontières nationales et culturelles. Une seconde raison, plus malheureuse encore, est le peu d'intérêt que suscitent les formes utilisées pour faire connaître ces points de vue. Le plus souvent, on aura effleuré une théorie ou la contribution d'un auteur en s'en tenant aux synthèses très souvent partielles et mêmes partiales contenues dans les ouvrages généraux de gestion. Dans d'autres cas, on se souviendra moins de la contribution réelle d'un auteur que du plaisir que prennent plusieurs à le pourfendre et, à la limite, à l'ostraciser. Par exemple, il y a fort à parier que le seul nom de Frederick Winslow Taylor évoque, chez la plupart d'entre nous, l'exploitation des ouvriers par les gestionnaires, la routinisation du travail ou encore la poursuite effrénée de la productivité. Sans nier que certains de ces énoncés soient en partie vrais, il n'en reste pas moins juste d'affirmer que la pensée de ces auteurs a été interprétée le plus souvent sans égard au contexte de l'époque. Pourtant, à notre avis, beaucoup de ces propos nous semblent, même aujourd'hui, d'une grande pertinence. 
Cet ouvrage n'a pas la prétention d'être exhaustif ni encore de traiter en profondeur certaines théories concernant la gestion. Il vise plutôt à faire connaître, selon une formule particulière, celle des " Grands Esprits », six penseurs et deux penseuses qui se sont intéressés à différents aspects de la gestion. Ils ont été choisis par un groupe de professeurs de l'École nationale d'administration publique (ENAP) parce que leur oeuvre était achevée et qu'ils représentaient des perspectives différentes - syndicale, patronale, académique, entre autres - dans leur contribution aux connaissances sur l'organisation et le management. Sur la base de tels critères, les huit « Grands Esprits » retenus sont : Chester Barnard, Hyacinthe Dubreuil, Henri Fayol, Elton Mayo, Mary Parker Follett, Frederick Winslow Taylor, Max Weber et Joan Woodward.

La formule privilégiée pour rendre compte de la pensée de ces auteurs devait se démarquer des façons plus orthodoxes de faire connaissance avec des auteurs et leurs théories. De plus, il fallait trouver une formule qui permette la confrontation des idées. C'est ce qui nous a amenés à choisir celle des " Grands Esprits », imaginée par Steve Allen et reprise par Jean Boisvert il y a quelques années dans une production de Radio-Canada. Plusieurs se souviendront de cette série dont les premiers épisodes furent diffusés à Radio-Canada à l'automne 1982. C'est d'ailleurs en écoutant une de ces émissions que me vint l'idée d'appliquer la formule aux « Grands Esprits » du management. Quelques années plus tard, lors de ma première rencontre avec Jean Boisvert, ce dernier accepta de travailler au projet. C'est avec enthousiasme et passion qu'il entama ses recherches avec le concours de professeurs de l'École nationale d'administration publique (ENAP). Cette équipe d'experts, comme il se plaisait à les appeler, était constituée de Gérard Éthier, Michel Leblanc, Michel Paquin et Adrien Payette. Le résultat ne s'est pas fait attendre : deux scénarios, de deux heures chacun, où huit " Grands Esprits 》 de la gestion dialoguent en compagnie d'un animateur. Le premier scénario réunit Henri Fayol, Mary Parker Follett, Frederick Winslow Taylor et Max Weber alors que le second vous fait rencontrer Chester Barnard, Hyacinthe Dubreuil, Elton Mayo et Joan Woodward. Ces " Grands Esprits » de la gestion parlent tour à tour de leurs idées et de leurs travaux concernant la gestion des organisations. 
En dépit des nombreuses démarches entreprises, il nous a été impossible, à ce jour, de trouver les ressources nécessaires pour produire visuellement les « Grands Esprits », objectif ultime de notre projet. Cela nous a incités à recourir au médium de la publication pour accélérer leur utilisation, sans pour autant renoncer à notre projet de les faire produire par une troupe de théâtre ou de les rendre disponibles sur vidéocassettes.

En attendant un tel dénouement, nous croyons que cet ouvrage peut déjà constituer une alternative à l'enseignement magistral trop souvent pratiqué pour faire connaitre ces auteurs et leurs théories. Voici quelques suggestions pratiques. On pourra faire jouer ces scénarios, in extenso ou en partie, par les étudiants qui, avec l'aide du professeur, pourront commenter, expliquer et même critiquer la pensée des auteurs rencontrés. Les plus créatifs pourront ajouter des personnages et faire des ajustements au contenu de cet ouvrage en vue de répondre à des objectifs spécifiques d'enseignement ou d'apprentissage. Par ailleurs, il est possible d'utiliser le contenu de cet ouvrage sans faire " jouer » les scénarios. Ainsi, après leur lecture attentive, le professeur pourra questionner les étudiants sur les apports de tel ou tel penseur à des problématiques de management d'aujourd'hui. On constatera, à la lecture des scénarios, qu'ils contiennent des propos qui sont, encore aujourd'hui, d'une grande actualité. Cette façon de faire a, selon nous, le mérite de laisser l'étudiant faire part de sa propre perception de la pensée des auteurs en l'actualisant dans des problématiques contemporaines.

Ce livre s'adresse également à ceux et à celles qui désirent se rafraîchir la mémoire et s'amuser à voir dialoguer à la même table les Taylor, Fayol, Weber et Follett ou encore les Mayo, Barnard, Dubreuil et Woodward. En fait, ces scénarios constituent une confrontation d'idées qui, sans déterminer de gagnants ni de perdants, permet de mieux connaitre ces penseurs et leur contribution à la discipline de la gestion. Même aujourd'hui, la pertinence de leurs propos ne fait qu'ajouter à la tentation de les lire et de les comprendre. Si ce livre peut concourir à cette tentation, notre tâche n'aura pas été vaine.

Daniel Maltais

Professeur à l'École nationale d'administration publique 



\section{Remerciements}

Le principal artisan des textes que contient ce livre est bien sûr Jean Boisvert. Sans lui, sans ses talents de scénariste et de réalisateur, sans son enthousiasme à comprendre des points de vue théoriques qui au départ ne lui étaient pas familiers, cet ouvrage n'existerait tout simplement pas. D'ailleurs cette publication veut lui rendre hommage. Bien que Jean soit allé rejoindre les « Grands Esprits » en octobre 1991, tous ceux et celles qui l'ont côtoyé dans le cadre de ce projet en conservent un souvenir impérissable.

Par ailleurs, nous voulons remercier les autorités de l'École nationale d'administration publique et en particulier son directeur général, monsieur Pierre DeCelles, d'avoir accepté d'appuyer financièrement la production des textes des " Grands Esprits ». Sans cet appui financier de même que celui de quelques-uns d'entre nous qui avons cru à cette aventure, elle n'aurait pu se matérialiser.

Jean Boisvert avait exigé, comme condition principale de son engagement, de pouvoir compter sur la collaboration et les avis de professeurs en gestion. Il ne fut pas déçu de l'appui de Gérard Éthier. Michel Paquin et Adrien Payette, tous trois professeurs de l'ENAP. En son nom et en mon nom personnel, je tiens à leur exprimer toute notre gratitude et toute notre reconnaissance et à leur souhaiter de devenir euxmêmes de Grands Esprits de la gestion! Il me faut également souligner la contribution spéciale de Michel Leblanc, ex-cadre à l'ENAP et chargé de cours, dont les encouragements ont été déterminants dans la poursuite (le nos efforts à produire ces textes.

Deux autres «Énapiens » ont collaboré à la production finale des textes. Il s'agit de mon confrère Albert Dumas, professeur à 1'ENAP, dont les commentaires et les propositions d'amélioration 
du texte ont été d'une très grande pertinence. Je veux également remercier Éric Manseau, étudiant à l'ENAP qui, à titre d'assistant de recherche, a produit la bibliographie et proposé des corrections qui ont contribué à l'amélioration des textes. Le texte s'est aussi enrichi des corrections proposées par Monelle Gélinas, réviseure linguistique.

Enfin, mes derniers remerciements vont à Angèle Tremblay, directrice générale des Presses de l'Université du Québec, qui nous a encouragés à publier les scénarios des « Grands Esprits ».

Il ne me reste plus qu'à vous souhaiter une bonne lecture en attendant que vous puissiez voir les "Grands Esprits » dans le cadre d'une production théâtrale ou télévisuelle.

Daniel Maltais

Professeur à l'École nationale d'administration publique Juillet 1994 


\section{En hommage à}

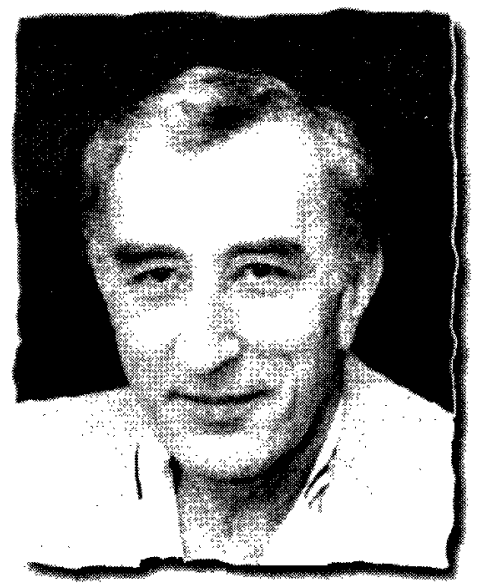

JEAN BOISVERT

$1923-1991$

Scénariste et réalisateur 



\section{Table des matières}

Préface de Roland Arpin ....................................................................... VII

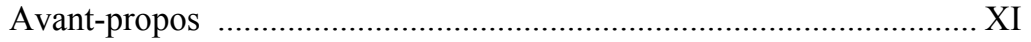

Remerciements .....................................................................

Rencontre avec

Max Weber

Henri Fayol

Frederick Winslow Taylor

Mary Parker Follett

Premier épisode 3

La présentation des invités - Les formes d'autorité • L'exercice de l'autorité - La bureaucratie - Les fonctions de gestion - Le management scientifique - Certains fondements psycho-logiques pour comprendre la gestion - La résolution de problèmes • La division du travail et la spécialisation.

Deuxième épisode 35

L'amélioration de la productivité • Les salaires • La coordination

- L'intégration - Les syndicats - Les programmes d'action (la planification) $\bullet$ Le contrôle $\cdot$ Les méthodes de Taylor. 
Rencontre avec

Hyacinthe Dubreuil

Joan Woodward

Chester Irving Barnard

George Elton Mayo

Troisième épisode 67

La présentation des invités - Les aspirations des travailleurs • La théorie et la pratique - La communication - L'organisation comme système coopératif $\bullet$ Les habiletés sociales et techniques $\bullet$ L'incident d'Hawthorne - La rémunération • La liberté du travailleur • L'effet des technologies sur les structures $\bullet$ La coopération • Le leadership - Les grèves - Les conditions de travail et l'enthousiasme des travailleurs.

Quatrième épisode 99

La décentralisation - Une nouvelle organisation du travail - En faveur de nouveaux administrateurs - L'organisation comme système coopératif - Différentes approches à l'étude des organisations • Les qualités d'un cadre - Sur les façons d'acquérir des connaissances à propos des organisations $\bullet$ À propos du progrès - De l'État et de la démocratie - L'exercice de l'autorité - La moralité et la responsabilité des cadres $\bullet$ La prise de décision $\bullet$ La théorie de la contingence $\bullet$ « Les mots de la fin ».

Épilogue

Bibliographie 


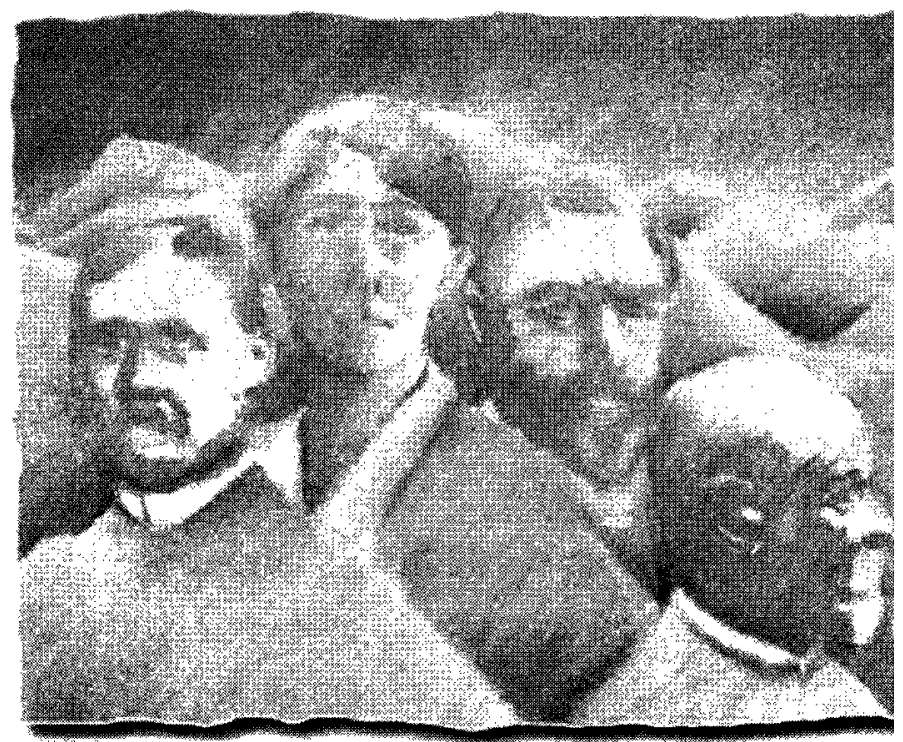

\title{
Rencontre avec
}

\author{
Max Weber \\ Henri Fayol \\ Frederick Winslow Taylor \\ Mary Parker Follett
}

Premier épisode

La présentation des invités $\bullet$ Les formes d'autorité - L'exercice de l'autorité - La bureaucratie - Les fonctions de gestion - Le management scientifique - Certains fondements psychologiques pour comprendre la gestion $\cdot \mathrm{La}$ résolution de problèmes $\cdot \mathrm{La}$ division du travail et la spécialisation.

Deuxième épisode

L'amélioration de la productivité - Les salaires $・$ La coordination

- L'intégration - Les syndicats - Les programmes d'action (la planification) $\bullet$ Le contrôle $\bullet$ Les méthodes de Taylor. 



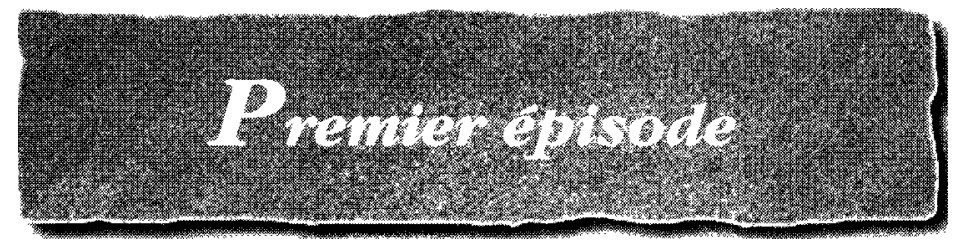

L'hôte arrive parmi le public, par l'allée qui fait face à son fauteuil et se rend jusque derrière son. fauteuil.

L'hôte Bonjour et bienvenue à cette rencontre avec quatre « Grands Esprits » du management.

Quand les personnes que nous allons rencontrer sont nées, la lampe électrique, le téléphone, l'automobile, la radio et l'avion n'existaient pas. Le Larousse universel de l'époque définissait le mot gestion ainsi : (Il prend une feuille sur la table et lit.) « Action de gérer ; administration active. " (Il pose la feuille.) Quant au mot anglais management, son utilisation remonterait au $\mathrm{XVI}^{\mathrm{e}}$ siècle selon l'Oxford Dictionary et le terme to manage serait né d'une confusion dans l'emploi du mot anglais manage qui renvoyait à l'art d'entraîner les chevaux et du mot français « manage », du verbe « mener ».

Quand ces mêmes personnes ont quitté notre Terre, l'ordinateur, la navette spatiale et la télévision n'avaient pas encore été inventés. Vous êtes donc en droit d'imaginer qu'elles seront extrêmement étonnées de se retrouver toutes ici, autour de la même table, et de discuter en votre compagnie grâce à la magie télévisuelle ${ }^{1}$. Eh bien, détrompez-vous ! Comme ce sont tous des Grands Esprits... du management, ils sont restés curieux, même dans l'Au-delà, et c'est vous qui serez étonnés de constater que leurs propos dans le domaine du management sont toujours d'actualité et parfois même avant-gardistes. 
Nous vous les présentons pour que ceux d'entre vous qui s'intéressent au management et qui prendront connaissance un jour prochain de leurs ouvrages les situent et les comprennent mieux. Cependant, le temps est limité et nous ne pourrons pas vous faire connaître à fond ces Grands Esprits ni leur pensée. Nous ne pouvons qu'espérer que vous les aurez trouvés assez attachants pour faire plus ample connaissance avec eux par la lecture, puisque les livres par eux et sur eux sont nombreux. Cela dit, je vais, sans plus tarder, vous présenter notre premier invité.

\section{Il s'assoit, prend une feuille et lit.}

Max Weber est né à Erfurt, en Allemagne, en 1864, d'un père avocat, actif en politique, et d'une mère très religieuse dévouée aux causes humanitaires. Max Weber connaît une vie d'abondance clans une famille très active socialement et politiquement, ce qui ne l'empêche pas d'avoir à faire son service militaire comme tous les jeunes Allemands de l'époque. Puis, il se distingue comme étudiant en droit aux universités d'Heidelberg et de Berlin, après quoi il devient professeur d'économie politique à l'Université de Fribourg. Mais, de faible constitution, il connaît de nombreux épisodes de maladie nerveuse et doit abandonner l'enseignement.

(Il lève les yeux de sa feuille et s'adresse à la caméra, l'air narquois.) Le rêve de bien des professeurs peut-être ? (Temps) Hélas pour eux, ils ne sont pas tous indépendants de fortune comme Max Weber ! (Il revient à ses feuilles.) Il voyage, lit, écrit, se soigne... (à la caméra) j'espère ! (retour aux feuilles)... et vingt ans plus tard, reprend l'enseignement à l'Université de Munich. Mais l'argent ne donne pas la santé ! Celle de Weber est restée chancelante et au sommet de sa carrière, la mort l'emporte à l'âge de 56 ans.

Nombreux furent les sociologues, les économistes et mêmes les philosophes à acclamer Max Weber et à vouloir en faire un des leurs, lui qui se défendait pourtant d'appartenir à une quelconque chapelle ! En fait, c'était un sociologue doté d'un esprit analytique, d'un savoir encyclopédique et d'une grande érudition. Pour lui, toute recherche doit reposer sur des bases rigoureusement 
scientifiques, même s'il faut pour cela faire abstraction de ses convictions personnelles, quand la recherche scientifique démontre, ou semble démontrer qu'elles sont fausses. (À la caméra qu'il ne quittera plus durant le reste de la présentation de Weber.) Il nous intéresse, notamment, parce que ses idées sur les différentes formes d'autorité jettent une lumière intéressante sur le fonctionnement des organisations.

On raconte qu'il sait provoquer des éclats, des révoltes, que c'est un volcan en constante éruption qui garde en son for intérieur un calme qui ajoute au désarroi de ses interlocuteurs. Nos autres invités et moi-même n'avons donc qu'à bien nous tenir, sans quoi c'est nous qui serons affligés d'une maladie nerveuse ! Mesdames et messieurs, Max Weber !

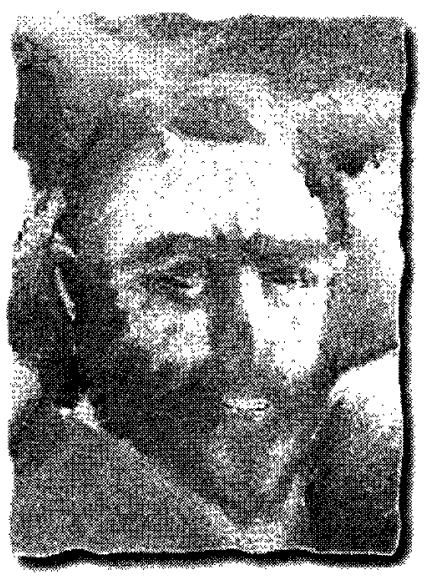

MAX WEBER

$1864-1920$

Weber entre par l'allée derrière l'hôte, va jusqu'à lui, salue le public. Ils se serrent la main durant son entrée. 
Weber Gittten tag Herr²... (nom de l'hôte)

L'hôte Bonjour Herr Weber et bienvenue à notre table ronde.

Weber Je suis très heureux d'y être!

L'hôte Ah oui! Pourquoi?

Weber (Humour) Parce que c'est terriblement ennuyant là-haut tout est parfait!

L'hôte (Humour) Une vraie bureaucratie! (Ils rient.) je suis certain qu'ici bas nous allons pouvoir remédier à tant de perfection! (Ils rient de plus belle.) Veuillez vous asseoir.

L'hôte lui indique le fauteuil à sa gauche et tous deux s'assoient.

L'hôte Monsieur Weber, vous nous avez laissé bien des idées, bien des écrits, dont votre apologie de la bureaucratie qui vous a valu de nombreux éloges et aussi... bon nombre de critiques.

Weber Les critiques ont tort (sourire) ... comme d'habitude ! Au-delà de mes opinions personnelles, ces mêmes critiques conviendront que la bureaucratie est la forme d'organisation la plus répandue clans les États occidentaux modernes. Cela étant dit, j'ai aussi indiqué que la bureaucratie n'était pas sans défaut et qu'elle pouvait avoir des aspects détestables.

L'ôte Je veux bien, mais étant donné l'esprit rationnel et scientifique qui vous caractérise, vous comprendrez que je vous demande de nous le démontrer.

Weber Avec plaisir. Premièrement, la bureaucratie existe depuis longtemps : on en trouve des formes diverses dans l'Égypte ancienne ; chez les Chinois, depuis l'époque de Shih Huang-ti ; chez les Romains, depuis l'ère de Dioclétien et clans l'Église catholique romaine depuis le XIII ${ }^{\mathrm{e}}$ siècle, et deuxiè...

L'hôte (Il le coupe.) Je constate qu'on a raison de dire que vous êtes érudit !

Weber (Sans se laisser interrompre) ... mement, voici comment je suis arrivé à la bureaucratie. Le rang social et le népotisme régissaient la société clans laquelle je vivais. Pour devenir officier de l'armée prussienne ou occuper un poste important clans le gouvernement ou l'industrie, il fallait être aristocrate. 
L'hôte Oh, vous savez, le népotisme existe encore de nos jours !

Weber Hélas ! L'humanité n'apprend pas vite ! En tout cas, je trouvais que c'était injuste, inefficace et... un pitoyable gaspillage de ressources humaines. On obtenait un poste, non pas selon « ce que "l'on connaissait, mais selon « qui » l'on connaissait ! C'était l'ineptie et la corruption institutionnalisées. J'ai longuement réfléchi et... conclu que la solution était la bureaucratie.

L'hôte La solution à un problème de gestion publique, pour régir les employés de la fonction publique.

Weber À l'origine, oui !

L'hôte Telle que vous l'avez conçue, c'était une utopie, (l'air condescendant) une vue de l'esprit!

Weber Bien sûr, parce que j'ai conçu la bureaucratie idéale, comme la plupart des choses que je concevais : l'idéal-type, l'idéale-société, etc. Je sais fort bien que c'est une abstraction, une simplification, un modèle, une vue de l'esprit comme vous dites.

L'hôte Il $y$ a bien des gens qui ne s'en sont pas rendu compte !

Weber Il serait temps qu'ils comprennent ! Je pose toujours l'idéal comme hypothèse parce qu'il permet une analyse objective. Reste que l'expérience a démontré que la bureaucratie a permis de professionnaliser l'administration et qu'au point de vue technique, elle est la forme la plus rationnelle d'administration des masses. Vous allez comprendre pourquoi quand je vous énoncerai les principes de la bureaucratie.

L'hôte J'ai hâte de les entendre, mais je crois que ce serait plus intéressant et plus profitable pour notre auditoire d'attendre nos autres invités et de leur donner la chance d'en discuter avec vous.

Weber À la bonne heure! J'adore la polémique !

L'hôte Qu'à cela ne tienne ; je commence par monsieur Fayol. Vous, monsieur Weber, vous êtes connu pour avoir écrit plusieurs ouvrages, monsieur Fayol, lui, est connu principalement pour un livre sur la gestion, mais autrement, vous avez de nombreux points communs. 
(Il prend une feuille et lit.) Max Weber et Henri Fayol ont tous deux vécu en Europe durant la deuxième moitié du $\mathrm{XIX}^{\mathrm{e}}$ siècle et le début du $\mathrm{XX}^{\mathrm{e}}$ et ont beaucoup contribué à l'enrichissement des connaissances sur l'organisation et le management. L'un (regard vers Weber) était sociologue, l'autre ingénieur. L'un a conçu une théorie de l'organisation : la bureaucratie, l'autre une théorie du management ; la valeur de leurs deux théories respectives n'a été reconnue que longtemps après que l'un et l'autre nous aient quittés.

Henri Fayol est né à Constantinople, en 1841, d'une famille française bourgeoise. (À la caméra) Pourquoi Constantinople ? (Haussement des épaules) Nous ne le savons pas; pas plus que nous ne savons grandchose sur sa vie personnelle, aussi bien durant son enfance que durant sa vie adulte. Par contre, nous connaissons bien ce qui nous importe : sa vie professionnelle. (Retour aux feuilles) Sorti ingénieur de l'École des Mines de Saint-Étienne à 19 ans, le plus jeune diplômé de sa classe, il a été immédiatement embauché comme ingénieur aux mines de charbon de Commentry-Fourchambault. Vingt-huit ans plus tard. alors que l'entreprise était au bord de la faillite, il en est devenu directeur général à l'âge de 47 ans. En quelques années, il a remis la société sur pied et a conservé son poste jusqu'à sa retraite, en 1918, à 77 ans. (À la caméra) On pourrait le comparer à Lee Iacocca qui a également redonné vie à une société géante agonisante : la Chrysler.

(Retour aux feuilles) Durant sa longue carrière, Henri Fayol a observé et noté les événements et les incidents quotidiens et en a tiré les règles générales et l'enseignement qu'il nous a légués dans son livre : Administration industrielle et générale. Il était donc méthodique mais pas pressé, puisque son oeuvre n'a été publiée qu'en 1916, deux ans avant sa retraite. Mesdames et messieurs, Henri Fayol.

Fayol entre par l'allée à la gauche de l'hôte, va jusqu'à lui, salue le public, poignée de main. Durant ce temps, Weber s'est levé. 


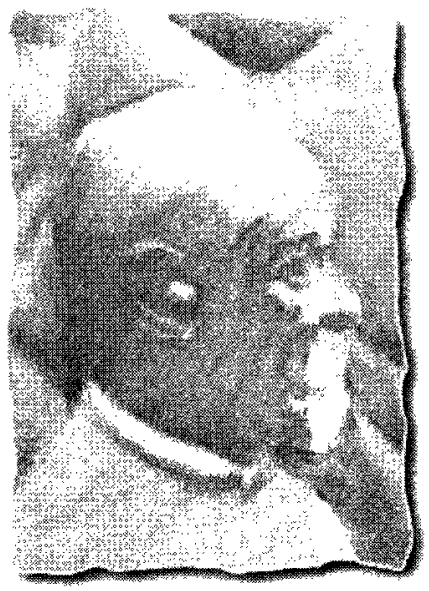

HENRI FAYOL

$1841-1925$

L'hôte Bonjour monsieur Fayol. (Regardant tour à tour le public et Weber, l'hôte continue.) Nous sommes tous ravis de vous accueillir à ces « Grands Esprits » du management.

Fayol Mais c'est moi qui suis ravi de faire votre connaissance, monsieur (nom de l'hôte) (Il se tourne vers Weber et lui tend la main.) et celle de monsieur Weber. Enchanté!

Weber Herr Fayol! Es lehe Frankreich ${ }^{3}$ !

L'hôte (Il indique à Fayol le fauteuil voisin de celui de Weber.) Je vous en prie, prenez place.

Tout le monde s'assoit.

Monsieur Fayol, vous avez intitulé votre livre Administration industrielle et générale ; considérez-vous l'administration comme la fonction la plus importante d'une entreprise ?

Fayol Pas du tout ! Administrer n'est qu'un des six groupes d'opérations ou fonctions dont la direction doit assurer la bonne marche. Il ne faut surtout pas confondre administrer et gouverner.

L'hôte Qu'est-ce que c'est, gouverner? 
Fayol Gouverner, c'est conduire l'entreprise vers son but en cherchant à tirer le meilleur parti possible de toutes les ressources dont elle dispose : c'est assurer la marche des six fonctions essentielles.

Weber Qui détermine le but de l'entreprise?

Fayol Celui qui gouverne : le patron.

Weber Seul?

Fayol Non! Collectivement avec son état-major.

L'hôte (Étonné) Son état-major ! Parlez-vous d'une entreprise ou d'une armée ?

Fayol D'une entreprise, mais dont la structure s'inspire de celle de l'armée. L'état-major est un organe de pensée, d'étude et d'observation qui élabore les stratégies de l'entreprise en fonction de ses prévisions.

Weber Très bien ! Les modalités sont quelque peu différentes, mais le principe est le même que clans ma bureaucratie.

Fayol À savoir?

Weber C'est le chef qui décide. Mais comme il ne peut pas tout savoir, il décide à partir de renseignements que lui ont fait parvenir les spécialistes des divers échelons de l'entreprise.

Fayol Et quelle est cette différence dans les modalités dont vous parliez ?

Weber En bureaucratie, les informations partent d'en bas et montent par les échelons hiérarchiques jusqu'au chef qui les reçoit, les analyse puis décide, seul!

Fayol Pourquoi pas collectivement?

Weber Les décisions collectives institutionnalisées minent l'autorité du chef.

Fayol On voit que vous êtes prussien!

Weber Et vous, travailleur social ou mère de famille ? Mein God $^{4}$ ! il faut qu'il y ait une autorité clans toute organisation! Nein?

4. $\quad$ En français : « Mon Dieu !». 
L'hôte (Il le coupe pour empêcher le ton de trop monter.) Monsieur Fayol, vous avez dit que " gouverner ", c'était assurer la marche de six fonctions essentielles : pouvez-vous nous en dire quelques mots?

Fayol Bien sûr.

- Premièrement, il y a les opérations techniques de production, de fabrication et de transformation ;

- puis, deuxièmement, les opérations commerciales d'achat, de vente et d'échange ;

- troisièmement, les opérations financières telles la recherche et la gérance des capitaux ;

—quatrièmement, les opérations de sécurité comme la protection des biens et des personnes ;

— cinquièmement, les opérations de comptabilité touchant par exemple les inventaires, le bilan, l'établissement du prix de revient. la production de statistiques ;

—et, sixièmement, les opérations administratives de prévoyance, d'organisation, de commandement, de coordination et de contrôle.

Que l'entreprise soit petite, moyenne ou grande, simple ou complexe, ces six regroupements d'opérations sont toujours essentiels.

L'hôte Si j'ai bien compris, dans votre livre, vous avez traité surtout d'administration, de management et presque pas de la gouverne au sens où vous venez de la définir. Pourquoi ?

Fayol Parce que le management, l'administration est ce que je connais, ce que j'ai fait pendant une bonne partie de ma vie. Et puis, à mon époque, c'était une fonction qui n'était pas très bien définie, pas reconnue au même titre que les cinq autres fonctions. J'étais personnellement convaincu que c'était une erreur et qu'il fallait corriger les choses en prescrivant ce en quoi devait consister l'exercice de cette fonction. J'étais aussi d'avis que ces prescriptions et leur application pouvaient être transmises, qu'elles pouvaient s'enseigner.

L'hôte Vous voulez dire qu'avant, la gestion s'apprenait, comment dire ? sur le tas? 
Fayol C'est exact. Je crois bien avoir été l'un des premiers à proposer que manager ou administrer pouvait s'enseigner et devait être enseigné. Encore fallait-il savoir quoi enseigner, d'où les cinq sous-fonctions, si je puis dire, que j'ai énumérées plus tôt. Je me suis également intéressé aux qualités que devaient posséder les managers. Les qualités physiques, intellectuelles, morales... enfin tout cela constitue une doctrine...

L'hôte Nous reviendrons plus tard (vers Fayot) à votre doctrine du management et (vers Weber) $\grave{a}$ votre bureaucratie : c'est maintenant le moment de rencontrer notre prochain invité.

(Il prend une feuille et annonce avec grandiloquence.) Mesdames et messieurs, voici l'histoire étonnante de Frederick Winslow Taylor, l'homme qui a donné son nom au taylorisme. (Ton normal à la caméra) Ce n'est pas un roman, c'est la pure vérité !

(Il lit.) Il naît à Germantown, Pennsylvanie, en 1856. Avocat prospère, son père fait partie de l'austère secte des Quakers. Sa mère, puritaine, retrace sa généalogie jusqu'à un ancêtre qui a débarqué à Plymouth en 1629 , neuf ans après les célèbres Pèlerins, les premiers immigrants britanniques arrivés aux États-Unis, à bord du Mayflower. Sa culture «puritano-quaker» le marque profondément et explique sans doute en grande partie un trait dominant de sa personnalité qui l'orientera toute sa vie vers la recherche de la vérité, l'observation méticuleuse des faits et l'étude expérimentale des procédés.

Weber L'importance de l'éthique protestante !

L'hôte Pour expliquer le capitalisme... comme vous l'avez écrit! (Retour aux feuilles) Il est attiré par la mécanique et, dès sa tendre enfance, s'amuse à démonter et remonter toutes sortes de jouets, d'objets et de machines, $(\grave{a}$ Weber) ce qui dénote un esprit plus scientifique que capitaliste !

(Retourà la feuille) Ses études le familiarisent avec les classiques, le français, l'allemand et l'Europe où il fait quelques voyages. Dans ses temps libres, (à la caméra) on se demande où il les prend (feuille), il arrive à faire une étude analytique du jeu de croquet et à déterminer la manière la moins fatigante de faire des randonnées clans la nature. (À la caméra) Il a commencé jeune à faire l'étude des mouvements ! (Feuille) Ses parents le destinent au droit, 
comme son père ; il passe haut la main son examen d'entrée à Harvard, mais n'y entre pas ! Pourquoi ? Certains prétendent que c'est à cause de sa santé délicate, d'autres, à cause de sa vue affaiblie par les longues études nocturnes, d'autres encore, que c'est en réaction contre le fait que ses parents ne l'aient pas laissé choisir lui-même sa carrière, mais tout ça ne nous concerne pas vraiment!

À 18 ans, il entre comme apprenti modeleur-machiniste à la Enterprise Hydraulic Works de Philadelphie. Il mène une vie d'ascète, ne fume pas, ne boit ni alcool, ni thé, ni café, mais apprend à jurer comme les ouvriers, une habitude qu'il ne perdra jamais ! Il termine son apprentissage quatre ans plus tard et se fait embaucher comme simple ouvrier à la Midvale Steel Works, toujours à Philadelphie.

Tout en travaillant à plein temps (à la caméra) ce qui voulait dire dix heures par jour à l'époque, (feuille) il obtient son diplôme d'ingénieurmécanicien du Stevens Institute of Technology en suivant des cours du soir pendant deux ans, patente de nombreuses inventions et, avec un ami, gagne le championnat américain de tennis amateur double messieurs. D'ouvrier, il passe à commis, à machiniste, à chef des machinistes, à contremaître de l'atelier d'ajustage, à responsable des réparations et de l'entretien et finalement, six ans seulement après son entrée comme simple ouvrier, il est nommé ingénieur-chef de toute l'entreprise à 28 ans et se marie !

(À la caméra) Étrange coïncidence, Frederick Taylor a élaboré sa doctrine en même temps qu'Henri Fayol puisque son livre The Principles of Scientific Management est paru en 1911, cinq ans avant celui de monsieur Fayol. Ces deux "Grands Esprits » ont autre chose en commun : on a dit d'eux qu'ils étaient « les deux grands théoriciens du management $\gg$.

Si vous voulez en savoir plus long sur le mariage de Frederick Taylor, sur les trois enfants qu'il a adoptés et sur le reste de sa vie, je vous recommande sa biographie ! Quant à ses activités professionnelles, vous les apprendrez de la bouche même de... Frederick Taylor!

Taylor entre par l'allée à la droite de l'hôte, va jusqu'à lui ; Weber et Fayal se lèvent. 


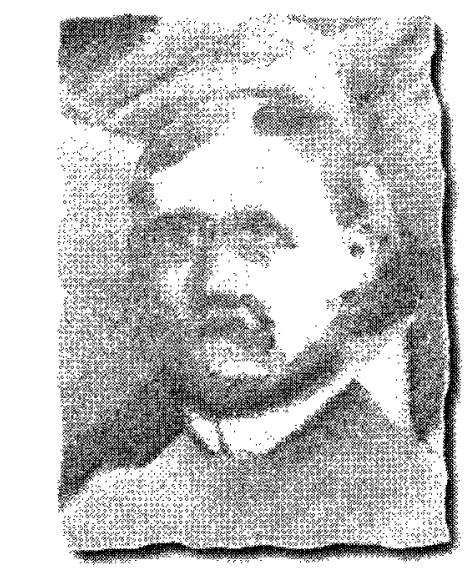

FREDERICK WINSLOW TAYLOR 1856- 1915

Avant même d'arriver à la table, depuis l'allée, Taylor lance.

Taylor Good afternoon! (rendu à la table, poignée de main) Bonjour monsieur (nom de l'hôte), que c'est gentil de m'avoir invité, quel plaisir d'être parmi vous tous!

L'hôte Quelle chance pour nous que vous ayez accepté de venir de si loin! Soyez le bienvenu.

Taylor Merci. (Sans traverser de leur côté, il salue les deux autres.) Herr Weber, monsieur Fayol.

Weber Good afternoon Mister Taylor.

Fayol Bonjour monsieur. J'ai étudié avec soin votre système basé sur les principes du management scientifique.

Taylor (Étonné) Ah oui ! Et qu'est-ce que vous en pensez ?

Fayol Votre idée de renforcer le rôle des chefs d'atelier et des contre-maîtres au chapitre de l'analyse du travail me paraît excellente; en revanche, la négation du principe de l'unité de commandement me paraît erronée et dangereuse.

Taylor Mais je suis sûr...

L'hôte (Il le coupe.) Je vous donnerai l'occasion d'en discuter tout à l'heure. 
Il indique son fauteuil à Taylor et tous s'assoient.

L'hôte Monsieur Taylor, vous avez enseigné à des ouvriers, qui faisaient ce travail depuis des années, comment transporter des lingots de fonte.

Taylor Oui, et c'est habituellement le premier exemple que je donne de l'étude des temps et des mouvements. (Facétieux) On en parle tellement qu'il y a des gens qui pensent que le management consiste à enseigner comment manipuler des lingots de fonte !

L'hôte (Rires. Sourires. Réaction au choix.) Vous avez écrit que vous pourriez entraîner un gorille à faire ce travail plus efficacement qu'un homme.

Taylor Oui et alors ?

L'hôte C'était très méprisant pour les ouvriers, humiliant même ! Descendre du singe, passons, mais que le singe soit plus efficace que nous, c'est trop !

Taylor Le premier homme qui a utilisé un cheval pour tirer des charges trop lourdes pour un humain était-il méprisant pour ses congénères ?

L'hôte Non.

Taylor Au contraire, il a rendu un immense service à l'humanité, n'est-ce pas ?

L'hôte C'est juste.

Taylor Alors, votre gorille (un temps), c'est la même chose !

Fayol Vous n'avez pas dû vous faire d'amis non plus quand vous avez écrit que les porteurs de lingots étaient comme les bœufs...

Taylor (Le coupe) ... lourds physiquement et mentalement ! Je sais. Ce ne sont pas les porteurs de lingots qui me l'ont reproché : la majorité d'entre eux étaient des immigrants analphabètes !

Fayol Vous vous enlisez, mon cher Taylor !

Taylor Pas du tout, je suis réaliste ! Pour passer sa vie à transporter des lingots de fonte d'une cinquantaine de kilos, c'est essentiel d'être fort comme un bœuf... mais nuisible d'être intelligent comme vous !

Fayol Si vous me prenez par les sentiments ! 
Taylor Ce serait du mauvais management de vous demander de trimbaler des objets lourds, tout comme de demander aux « bœufs » ou (regardant l'hôte) aux « gorilles » de " manager » une entreprise. On n'atteint pas un rendement maximum en demandant à quelqu'un de faire plus que ce qu'il peut faire, mais en l'aidant à faire au maximum ce dont il est capable.

Fayol Ça, c'est très juste !

Taylor (À l'hôte) Il est temps que je vous dise. cher hôte, que vous avez abordé le management comme un acheteur de cheval qui ne connaît pas les chevaux.

L'hôte C'est-à-dire ?

Taylor Par la queue... au lieu de commencer par lui examiner la tete, le corps et les pattes!

L'hôte Par où fallait-il commencer?

Taylor En me demandant ce qu'est le management scientifique.

L'hôte Bon, d'accord, qu'est-ce que c'est ?

Taylor Une révolution!

Weber Vous êtes révolutionnaire!

Taylor Mentalement, oui ! Le management scientifique est une révolution mentale.

Weber Dans quel sens?

Taylor Aujourd'hui comme clans mon temps, les patrons, d'une part, et les employés et leurs représentants syndicaux, d'autre part, ont une idée fixe...

L'hôte Ah oui ! et laquelle?

Taylor Leur idée fixe, c'est le partage des surplus. La révolution mentale du management scientifique les oriente vers l'augmentation des surplus; une augmentation telle qu'il n'y aura plus de querelles au sujet de leur partage. Une révolution qui substitue la paix à la guerre, la coopération fraternelle aux querelles, la confiance mutuelle à l'espionnage, transforme les ennemis en amis et amène patrons et ouvriers à travailler ensemble vers un même but.

Weber Vous n'êtes pas révolutionnaire mais utopiste! 
Taylor Absolument pas, je suis réaliste ! C'est exactement ce que j'ai accompli dans la plupart des entreprises où j'ai installé le management scientifique et je peux vous affirmer que durant les trente premières années de son application, il n'y a pas eu de grèves dans les entreprises qui ont adopté le système Taylor. On y vivait des relations paisibles !

Weber Durant le premier siècle de l'existence des États-Unis, les relations étaient également paisibles entre les maîtres et leurs esclaves !

Taylor Si vous jugez que le fouet est paisible... (S'il n'y a pas de rires, il ajoute.) j'aurai une piètre opinion de votre jugement !

Weber (Il rit.) Bravo, vous n'avez pas mordu à mon hameçon! Sérieusement, je sais fort bien que votre système était très populaire et que même les Soviétiques l'ont installé chez eux. Étiez-vous au courant, monsieur Taylor?

Taylor Oui, oui, bien sûr. Même qu'un certain Aleksei Gastev, dans les années vingt, s'est fait le promoteur de mon système. Staline y était moins sympathique, dit-on. Il préférait le stakhanovisme...

L'hôte Le quoi?

Taylor Le stakhanovisme. Du nom d'Aleksei Stakhanov, un mineur de charbon à la productivité légendaire qui, dans les années 1935-1936, est devenu le modèle à suivre en Union soviétique.

Weber Ils ont aussi adopté la chaîne d'assemblage...

Taylor (Il le coupe.) Ça, ça ne vient pas de moi ! C'est une invention de monsieur Olds, qui a donné son nom à la Oldsmobile, invention perfectionnée plus tard par Henry Ford qui a implanté dans son usine la chaîne d'assemblage mobile.

Weber Ne digressons pas, restons-en au taylorisme que certains accusent de ne pas tenir compte de l'humanité des travailleurs.

Taylor Pas le taylorisme ! Les gens qui ont tenté de l'appliquer sans le comprendre et qui ont ignoré l'aspect humain de mon système. $\mathrm{Au}$ lieu de lire les auteurs qui m'ont commenté et critiqué, vous devriez lire mes propres écrits. (À la caméra) Et vous aussi! (Retour à Weber) Vous y verriez que j'insiste d'abord pour que les managers expliquent aux employés concernés la nature et les raisons des changements proposés et, ensuite, pour qu'aucun changement ne soit effectué avant que les employés aient exprimé leurs points 
de vue et accepté le changement. D'ailleurs, la plupart des théoriciens du changement et des gestionnaires contemporains confirmeront que c'est là la façon appropriée d'implanter le changement dans les organisations.

Weber N'empêche que vous et vos acolytes étiez autour d'eux comme des pions avec vos chronomètres!

Taylor Je ne vois pas comment on peut connaître le temps que prend une opération sans la minuter !

Weber J'en conviens, mais pour employer une comparaison qui vous est familière, vous admettrez qu'ils devaient se sentir comme des chevaux de course !

Taylor Non, je n'admets pas ! La plupart des ouvriers étaient, je le répète, des immigrants analphabètes, mais on les traitait comme des humains et non comme des esclaves ou des bêtes. Après nos explications, ceux qui s'objectaient n'étaient pas forcés de participer. Ainsi, au Watertown Arsenal où j'ai mené une étude, un machiniste récalcitrant a continué de travailler durant toute notre recherche sans s'y soumettre et sans être chronométré. Les ouvriers participants savaient que ce que je voulais le plus, c'était confier à chacun la plus haute tâche que son intelligence et son physique lui permettaient d'atteindre.

L'hôte Monsieur Taylor, je commence à me demander si vous êtes un manager, un apôtre ou un travailleur social... ce qui m'amène à notre prochaine invitée, puisqu'elle a commencé sa carrière comme travailleuse sociale.

(Il prend une feuille et lit.) Issue d'une bonne famille de Boston, Mary Follett a eu la chance d'avoir parmi ses premières maîtresses, à l'école primaire, une femme intelligente et humaine qui est aussi devenue son amie. Elle l'a persuadée de la nécessité d'adopter une méthode d'étude rigoureuse, l'a stimulée intellectuellement et lui a inculqué le goût de la philosophie et d'une vie simple. Mary Follett a poursuivi ses études au Radcliffe College, où elle a choisi comme options l'économie, les sciences politiques et... la philosophie, bien sûr ! Elle a obtenu son diplôme en 1898 avec la mention summa cum lande - (à la caméra) pour ceux qui n'ont pas fait de latin, ça veut dire : avec très grande distinction! 
Fait important, elle a entrecoupé ses six années à Radcliffe d'une année à Cambridge, en Angleterre, où elle a étudié l'histoire, le droit et les sciences politiques. Elle a aimé la vie et les coutumes anglaises et s'est fait de nombreux amis qui sont devenus la base des liens étroits qu'elle a toujours conservés avec l'Angleterre où elle a d'ailleurs passé les cinq dernières années de sa vie. Avant, durant et immédiatement après ses études universitaires, Mary Follett a consacré trente ans de sa vie au service social. Dès 1900, elle a convaincu les autorités municipales de Boston d'ouvrir les écoles le soir, pour y offrir des activités éducationnelles et sociales ; louer d'autres lieux à ces fins ou ne pas utiliser les écoles vides, le soir, aurait été du mauvais management, disait-elle ! En 1912, elle fit ouvrir par la ville de Boston le premier " Placement Bureau Committee » auquel elle a participé activement, ce qui l'a mise en contact avec les travailleurs et des représentants de l'industrie et l'a fait s'intéresser de plus près aux relations industrielles, puis aux problèmes sociaux et, finalement, à l'organisation et à l'administration industrielles.

Elle est devenue une experte-conseil dont beaucoup de grandes sociétés s'arrachaient les avis. Plusieurs de ses points de vue faisaient autorité chez ceux et celles qui s'intéressaient à la gestion, à l'exercice du pouvoir, du contrôle et des responsabilités dans les organisations. Elle a en outre prescrit une nouvelle manière de gérer les conflits.

À maints égards, sa conception de la gestion était en avance sur ce qui se pratique encore aujourd'hui dans bien des organisations (à la caméra) ce qui n'est peut-être pas très flatteur pour les praticiens actuels, vous en conviendrez. (Feuilles) Elle constate que les fondements psychologiques du management sont négligés et même, parfois inconnus. Cette constatation nous apparaît tout aussi juste aujourd'hui que lorsqu'elle l'a faite dans les années vingt, hélas ! (̇̀ la caméra) Mesdames et messieurs, Mary Parker Follett.

Elle arrive par l'allée face à l'hôte qui va à sa rencontre; les trois autres se lèvent. 
L'hôte Mademoiselle Follett, bonjour et bienvenue parmi nous.

Follett Bonjour monsieur (nom de l'hôte). Je suis très heureuse de rencontrer enfin ces trois messieurs que j'admire, même si je ne suis pas toujours d'accord avec eux. ('̀ l'hôte) Quant à vous, je suis enchantée de faire votre connaissance, mais je préférerais que vous m'appeliez Mary.

L'hôte Comme vous voulez, Mademoiselle. Je conclus que vous ne vous êtes pas mariée ?

Follett Jamais! Je n'ai compté sur personne pour gagner ma vie.

L'hôte Indépendante et solitaire !

Follett Indépendante oui, solitaire non. À Boston, j'ai vécu trente ans avec une amie très chère, Isobel Briggs. Après sa mort, j'ai habité avec une amie londonnienne, Katherine Furze, qui s'occupait activement du mouvement des « Guides ».

L'hôte C'est clair et net !

Follett J'aime que les choses soient claires : on sait à quoi s'en tenir !

L'hôte Moi de même. Je vous en prie, asseyez-vous.

Follett Merci. (Elle se tourne vers les trois autres.) Messieurs!

Fayol et

Weber Mademoiselle! 
Taylor Hi Mary!

Tous s'assoient.

L'hôte $\quad$ Mademoi... euh, Mary, vous avez écrit de nombreux livres...

Follett (Elle le coupe.) Pardon, j’ai écrit peu de livres...

L'hôte Pourtant, on en...

Follett (Elle le coupe encore.) En 1933, peu après son ouverture et peu avant ma mort, la London School of Economics m'a invitée à faire une série de conférences. Plus tard, des disciples ont colligé ces conférences et d'autres papiers que j'avais écrits et les ont publiés. Ce sont là la plupart des «livres» qu'on m'attribue et qui concernent à proprement parler la gestion.

L'hôte Voilà une autre chose claire et nette ! (À la caméra) Ces écrits, fascinants pour tous ceux qui s'intéressent au management, sont également passionnants pour les profanes à cause de la grande humanité dont ils sont imprégnés ; je ne saurais trop vous recommander de les lire. ( $\grave{A}$ Mary) Pourquoi vous êtes-vous intéressée aux conflits?

Follett Parce que je les chéris!

Weber Vous êtes batailleuse!

Follett Surtout pas !

Fayol Parce que vous avez maîtrisé l'art du compromis ?

Follett Encore moins!

L'hôte (Drôle) Je sais ! Vous êtes masochiste !

Follett Jamais !

L'hôte Alors ?

Follett Réglons d'abord le cas du compromis que j'exècre parce qu'il sacrifie l'intégrité de l'individu : personne n'aime céder, même partiellement, une chose à laquelle il tient.

Fayol Non, mais c'est une preuve d'humilité !

Follett Non, non, non. L'humilité consiste à ne pas réclamer plus que ce que l'on mérite, que ce à quoi l'on a droit. Avec l'humilité, on conserve son intégrité, mais il faut insister pour recevoir ce qui nous est dû. L'humilité n'a rien à voir avec le compromis.

Taylor Admettons, mais le compromis aide à régler le problème. 
Follett Absolument pas ! Il ne fait que reporter le problème. Le compromis est futile et temporaire parce qu'il repose sur la croyance populaire et erronée que la vérité se situe « entre » deux points de vue différents ; le compromis est une solution factice qu'il faut éviter parce qu'elle se contente de réarranger ce qui existe au lieu de produire des nouvelles valeurs.

Weber Accepter un compromis, c'est faire preuve de compréhension et ainsi aider à...

Follett Pardon ! Le compromis n'est pas de la compréhension, c'est de la suppression, la bête noire de la psychologie moderne !

Weber Hélas ! la psychologie n'est pas mon fort : quand je suis né, Freud n'avait que huit ans!

Follett Je vais vous expliquer : dans un compromis. pour avoir la paix, deux individus abandonnent leurs points de vue respectifs, font chacun une suppression ; une soustraction en somme. Ceux qui croient au compromis doivent donc croire à une certaine magie qui fait que deux soustractions égalent une addition!

L'hôte Bon! Vous n'admettez pas les compromis et vous n'êtes pas batailleuse, alors pourquoi vous plonger dans les conflits?

Follett Parce qu'on peut en tirer une plus-value si l'on sait bien les gérer et transformer les opposants en « cocréateurs » qui vont engendrer des nouvelles valeurs grâce à l'intégration et au « comportement circulaire ».

Taylor Le ...« comportement circulaire », qu'est-ce c'est ? Tourner en rond ?

Follett (Dérision) Funny!

Taylor (Il mouille son index sur sa langue et, avec l'index, fait un trait vertical dans l'air.) 1 à 0 pour moi !

Follett (À Taylor) Si vous insistez!(À tous) Pour comprendre le comportement circulaire, il faut d'abord comprendre une notion de base en psychologie des relations humaines.

Taylor J'écoute.

Follett Quand je dialogue avec vous, je ne réagis pas à vous, mais à vous plus moi, à vous avec moi et vice versa ; (geste à l'appui) à chaque étape de ce va-et-vient, de l'échange, chacun d'entre 
nous est graduellement transformé ; c'est ce que j'appelle le comportement circulaire. Vous me suivez?

Taylor Oui, oui. Moi qui suis né la même année que Freud, je suis encore moins versé en psychologie que Herr Weber mais...

Follett (Elle le coupe.) On n'a qu'à étudier le système Taylor pour s'en rendre compte ! (Même geste que Taylor plus tôt) 1 à 1 !

Taylor O.K.! Continuez!

Follett Notre rencontre nous transforme tous les cieux parce que (geste circulaire) nous nous ajoutons mutuellement quelque chose. À chacune de vos interventions, je m'enrichis de vos idées, de vos connaissances, j'évolue, je progresse, et vous de même à chacune des miennes. Le comportement circulaire engendre une croissance humaine exactement de la même manière que l'intérêt composé engendre une croissance pécuniaire.

Taylor (Farceur) Je suis donc capital!

Follett (Riant) Comme moi! Et chaque échange entre nous est de l'intérêt composé qui s'ajoute immédiatement au capital, le fait croître et donne donc une valeur plus grande à l'échange suivant.

Taylor Et à la fin de la rencontre, on est devenu tous les deux millionnaires !

Follett En valeurs humaines... probablement !

Weber (Évidemment) C'est mon vieux principe du bewirkt und wirkend!

Follett (Perplexe) Pardon?

Weber Bewirkt und wirkend, c'est-à-dire tout ce qui est produit, produit à son tour une action. C'est ainsi qu'un effet peut devenir une cause et qu'une cause peut parfois être considérée comme un effet.

Follett Vous prétendiez plus tôt que ce n'était pas votre fort, mais voilà de la psychologie !

Fayol (Spirituel) Pardon mademoiselle, bewirkt und wirkend c'est de l'allemand!

Taylor (Tous rient de ce trait!) Mais non, voyons, c'est de la philosophie!

Weber Ce n'est ni de la psychologie ni de la philosophie, c'est de la sociologie! 
Follett Rien de tout ça ; c'est simplement le comportement circulaire qui intègre les divers éléments et nous fait passer de ce qui était à quelque chose de nouveau. C'est une expérience progressive, c'est la voie du développement individuel et social.

Fayol (Il reprend le geste circulaire de Follett en l'agrandissant.) Ainsi soitil !

Weber Mademoiselle, tout ce temps-là, vous nous parlez de psychologie et non pas de management qui devait être le sujet de notre rencontre !

Follett Monsieur Weber! En me présentant tout à l'heure, monsieur (nom de l'hôte) vous a dit que j'avais constaté que les fondements psychologiques du management étaient négligés et même inconnus. Aujourd'hui, j'ai l'intention de vous le démontrer... si vous me laissez continuer.

Weber Je vous en prie.

Fayol Pour nous aider à mieux vous comprendre, qu'entendez-vous par « intégration »?

Follett L'intégration, c'est le principe actif des relations humaines, la seule manière valable de régler un conflit. L'abandon ou la victoire d'une des parties est évidemment indésirable, de même que le compromis, j'espère vous en avoir convaincus ; il reste l'intégration. Mais, commençons par le commencement.

Taylor Ça, c'est généralement une bonne idée ! (Geste) 2 à 1 !

Follett C'est généralement ce que j'essaie d'avoir : des bonnes idées ! (Geste) 2 à 2 ! Quand il y a conflit, c'est qu'il y a différence, mais ce qu'on veut éliminer, ce n'est pas la différence.

Fayol Ah non ! Il me semble qu'une fois la différence éliminée, le conflit cesse d'exister!

Follett Vous avez raison, mais croyez-vous que les gens abandonnent facilement leurs convictions ? Spécialement dans le contexte d'un conflit?

Fayol Non, je ne le crois pas.

Follett Voilà ! Éliminer la différence serait une tâche presque impossible. Ce qu'il faut éliminer, c'est la confusion que la différence engendre. Or, pour y arriver, il faut d'abord s'assurer qu'on a toute l'information pertinente, tous les faits, les « vrais » faits. 
Weber Ce qui n'est pas facile : dans l'examen d'un problème, il y a tellement de points de vue spécifiques qu'on ne les a jamais tous épuisés.

Follett Je reconnais là votre recherche de l'idéal : après l'idéal-type et l'idéalesociété, voici maintenant l'idéal-problème : celui qui est le plus complexe ! Dans la pratique du management, les problèmes sont généralement plus simples, sinon c'est à nous de les ramener à une forme simple. Par exemple, si je pense que ce que j'aperçois est un serpent, tandis que vous pensez que c'est une branche morte, notre dialogue sera insensé. Une fois établi que c'est un serpent, nous ne serons pas forcément d'accord sur ce qu'il faut en faire, mais au moins nous parlerons de la même chose ; notre différence sera significative, notre conversation, intelligente.

Fayol Voilà établie la nécessité de l'information exacte. Ensuite ?

Follett Ensuite, il faut s'assurer que l'interprétation des faits est correcte et impartiale.

Weber Vous avez raison : toute analyse doit se soumettre aux règles de la vérification, du contrôle et de la preuve. Je suis sûr que vous avez un exemple à nous donner !

Follett Certainement! Vous voyez un homme gifler un ami. (Temps) Ne le jugez pas avant de vérifier s'il n'a pas plutôt tué un moustique qui allait piquer son ami ! De plus, et je ne vous apprends rien, j'en suis certaine, il faut se méfier des interprétations influencées par ses propres désirs.

Weber Je vois. Ensuite?

Follett C'est maintenant que la psychologie et le travail créateur peuvent commencer. Avant que vous me le demandiez, je vais vous donner des exemples. Un jour, j'étais dans une petite salle de la bibliothèque d'une université. Un homme qui était là voulait ouvrir la fenêtre, je la voulais fermée. Conflit!

Première étape : l'information, les faits.

-Pourquoi voulez-vous ouvrir la fenêtre ?

- Pour avoir plus d'air.

-Moi aussi j'aimerais avoir plus d'air mais je ne veux pas qu'il arrive directement sur moi. 
Les faits sont connus : nous voulons tous les deux la même chose, ça facilite la résolution du problème.

Deuxième étape : création et intégration.

Comment lui donner son air sans me l'envoyer clans le dos ? En ouvrant la fenêtre de la salle voisine ! Pas de compromis ! L'intégration c'est trouver une troisième manière qui va inclure les désirs de $\mathrm{A}$ et ceux de $\mathrm{B}$ sans qu'aucun des deux n'ait à faire de sacrifice.

Fayol C'est très clair et ça me paraît très efficace, mais il s'agit d'un problème personnel ; or, il est rare que les problèmes d'une organisation soient d'ordre individuel!

Follett J'ai aussi un exemple d'ordre organisationnel ! Une prospère et paisible coopérative de laitiers a presque péri à cause d'un problème apparemment bénin. La laiterie était située au milieu d'une côte. Les laitiers qui arrivaient du haut de la côte disaient qu'ils n'avaient pas à attendre dans une pente avant de décharger leurs bidons de lait sur la plate-forme de la laiterie. Ils exigeaient la préséance sur leurs confrères qui arrivaient du bas de la côte. Ceux-ci prétendaient à la même préséance, ne voulant pas non plus attendre dans ladite pente. Le conflit s'était envenimé à tel point que la coopérative songeait à se démembrer. Ses membres ne voyaient que deux possibilités : priorité aux ascendants ou priorité aux descendants. Un consultant a suggéré de déplacer la plateforme de sorte que les ascendants et les descendants puissent décharger leurs bidons de lait en même temps. La suggestion a été acceptée par les deux parties, toutes deux heureuses, mais pas parce qu'elles avaient gagné leur point : parce que le consultant avait inventé une troisième solution. L'intégration nécessite de la créativité. Il ne faut jamais se laisser emprisonner dans « ou bien ceci, ou bien cela ». Il faut inventer une troisième situation qui apportera satisfaction aux parties.

L'hôte Mademoiselle Follett, merci de cet exposé qui nous a tous éclairés. (Se tourne vers Weber.) Monsieur Weber, j'ai dû vous interrompre plus tôt alors que vous étiez lancé sur la bureaucratie ; maintenant que tout le monde est là, c'est le moment de continuer. 
Weber Merci. Je veux d'abord établir que la bureaucratie, telle que je l'ai conçue et tout utopique qu'elle soit, est en fait un modèle d'organisation ; modèle qui a de nombreux points communs avec celui que monsieur Fayol nous propose dans son Administration industrielle et générale. La bureaucratie veut assurer deux qualités essentielles à toute organisation : l'efficacité et la continuité. Pour y arriver, j'ai appuyé l'exercice de l'autorité et le fonctionnement de la bureaucratie sur les principes de la rationalité et de la légalité.

Taylor De la dictature ! C'est vous qui le dites !

Weber La bureaucratie est autoritaire mais pas dictatoriale ! Elle est, au contraire, fondamentalement démocratique.

Taylor Ah oui ? Comment ça ?

Weber (Il déplie un doigt (*) à chaque raison.) En donnant aux fonctionnaires (*) un statut légal officiel, (*) la sécurité d'emploi ; $(*)$ en les recrutant dans toutes les classes de la société et, détail important, (*) par concours; $\left(^{*}\right)$ en les rémunérant à salaire fixe et selon une échelle prédéterminée $(*)$ accompagné d'un fonds de retraite et $\left(^{*}\right)$ en soumettant l'avancement des fonctionnaires à un comité guidé par des critères précis au lieu de le laisser à l'arbitraire des autorités.

Taylor Ouais ! C'est pas mal! Mettons que je n'ai rien dit.

Weber (Humour) C'est vous qui le dites !

Fayol La sécurité d'emploi a le désavantage... d'empêcher de mettre à l'écart un employé quand c'est nécessaire.

Weber Dans ces cas-là, il y a toujours le leurre d'une retraite prématurée et avantageuse ! C'est une tactique courante en temps de compressions budgétaires !

Fayol Et quand le budget, justement, ne le permet pas ou que... le poisson ne mord pas?

Weber (Haussement désespéré des bras) C'est le prix qu'il faut parfois payer pour avoir une organisation rationnelle et démocratique.

Fayol Peut-être, mais c'est une entorse à l'efficacité que la bureaucratie veut assurer. 
Weber Je ne peux que répéter : c'est le prix qu'il faut parfois payer pour avoir une organisation rationnelle et démocratique.

L'hôte La bureaucratie permet d'offrir des services spécifiques avec efficacité et efficience, en instaurant une division poussée des tâches, ce qui entraîne inévitablement la «robotisation» des fonctionnaires !

Weber On pourra revenir sur vos robots, mais je dois vous répondre que la division des fonctions mène à la spécialisation, à laquelle personne autour de cette table ne s'objecte... sauf vous!

Follett Pas moi en tout cas! Déjà au XVIII ${ }^{\mathrm{e}}$ siècle, Adam Smith avait constaté que la spécialisation permettait à une dizaine d'hommes de produire 48000 épingles par jour alors qu'un artisan, travaillant seul, n'en faisait qu'une vingtaine dans le même temps. Un autre précurseur du management, Charles Babbage, écrivait au début du XIX ${ }^{\mathrm{e}}$ siècle que les nations les plus civilisées devaient leur avance à la division du travail.

Fayol Et l'on peut observer que la division du travail est naturelle dans le monde animal où, plus l'être se perfectionne, plus il développe d'organes chargés de fonctions différentes. Dans notre monde, la division du travail permet de produire plus et mieux sans augmenter l'effort.

L'hôte Voulez-vous expliquer pourquoi à tous les profanes comme moi?

Fayol Avec plaisir ! L'ouvrier qui fait toujours la même pièce, le chef qui traite constamment des mêmes affaires, acquièrent une habileté, une assurance, une précision qui accroissent leur rendement.

L'hôte Mais oui, c'est évident, j'aurais dû y penser !

Fayol Chaque changement d'occupation entraîne un effort d'adaptation qui diminue la production. En revanche, la division du travail permet de réduire le nombre d'objets sur lesquels l'attention et l'effort doivent se porter; elle permet donc d'augmenter la production.

Taylor Moi, je n'ai qu'une chose à vous dire : si l'homme moyen d'aujourd'hui vit aussi bien que le roi d'il y a 250 ans, c'est à cause de la division du travail et de la spécialisation qu'elle entraîne ! 
L'hôte (Bras élevés comme une victime de hold-up) Bon, ça va ; j'ai compris les avantages de la spécialisation! (’̀ Weber) Vous avez aussi insisté pour que le patron conserve le contrôle du travail.

Weber Évidemment, c'est le privilège implicite de l'employeur, mais toujours par souci de justice et de démocratie, en bureaucratie, ce contrôle est luimême contrôlé par une commission de discipline. Enfin, dernier principe de la bureaucratie, j'insiste pour qu'il y ait séparation complète entre la fonction et la personne qui l'occupe.

Fayol Tiens! Pourquoi?

Weber Parce qu'aucun fonctionnaire ne saurait être propriétaire de sa charge !

Fayol N'est-ce pas évident? Pourquoi l'avez-vous spécifié ?

Weber En réaction contre une coutume que le népotisme et le favoritisme avaient engendrée et qu'il fallait faire disparaitre.

Fayol Mais en affirmant ce principe, n'encouragez-vous pas la mobilité des employés qui s'identifient moins à leurs fonctions ? Par ailleurs, cette mobilité accrue coûte cher si l'on tient compte du temps que met tout agent à s'initier à une fonction nouvelle.

Weber Sans que cela ait été mon intention, je conviens que ce principe peut se traduire par une plus grande mobilité. Mais n'est-ce pas souhaitable ? Cette plus grande mobilité pourra profiter à l'entreprise qui veut remanier ses opérations puisqu'elle est susceptible d'améliorer les possibilités d'avancement des employés.

Taylor Ce qui est une forte source de motivation et qui, de plus, combat l'impression de robotisation que la spécialisation peut faire naître chez certains employés, comme le soulignait notre hôte tout à l'heure.

Weber (À Taylor) Très juste! (Retour à Fayol) Je ne dis pas que la bureaucratie est parfaite, mais...

L'hôte (Il le coupe tout en cherchant parmi ses feuilles; il trouve au bon moment.) Non, mais vous en avez fait une apologie dithyrambique que j'ai apportée et que je vais... (Il se reprend.) ou plutôt non : vous l'avez écrite, lisez-la! (Il lui tend la feuille.) 
Weber (Il prend la feuille.) Qu'est-ce que c'est ? (Il jette un coup d'oeil puis, réjoui.) Ah, oui! (Ravi, à l'hôte) Merci beaucoup ! (Il lit.) L'expérience tend universellement à démontrer que l'organisation bureaucratique de l'administration est, du point de vue purement technique, capable d'atteindre le plus haut degré d'efficience. Dans ce sens, c'est le moyen le plus rationnel d'exercer un contrôle impérieux sur les êtres humains.

(Follett et Taylor rouspètent en grommelant; Weber se contente d'élever légèrement le ton.) Elle est supérieure à tout autre moyen par sa précision, sa stabilité, la rigueur de sa discipline et par... (Follett et Taylor rouspètent encore, Weber élève encore le ton et répète le dernier mot avec plus d'assurance.) ... par la rigueur de sa discipline et par sa fiabilité. C'est ainsi qu'elle permet un degré particulièrement élevé de calculabilité des résultats pour les chefs d'organisations. Finalement, elle est supérieure à la fois par l'intensité de son efficacité et par l'étendue de ses opérations et elle peut s'appliquer à toutes les sortes de tâches administratives, publiques ou privées. (Il rend la feuille à l'hôte en s'adressant à lui.) Merci. Je suppose que nous allons aborder plus tard la question d'autorité et de pouvoir?

L'hôte En effet!

Weber (À Follett et à Taylor) Nous verrons à ce moment-là ce que vous avez à dire sur le contrôle impérieux et la discipline rigoureuse qui vous ont fait réagir pendant que je lisais. (Temps) Je me suis davantage intéressé à la fonction publique lorsque j'ai élaboré le modèle bureaucratique, mais avec l'industrialisation, les techniques et l'économie modernes de la production des biens et services, la bureaucratie est inévitable même dans le domaine privé. D'ailleurs, on la trouve maintenant dans toute entreprise d'envergure, publique ou privée, qu'elle soit américaine, française, russe, chinoise ou sud-américaine. Enfin, voyez l'essor qu'elle a donné à l'éducation!

Taylor (Incrédule) À l'éducation?

Weber Mais oui : la demande croissante, par l'État et les entreprises, de plus en plus d'employés, de plus en plus spécialisés, a nécessité le développement de l'enseignement secondaire et universitaire, amené la multiplication des collèges et des universités 
et surtout, la création des grandes écoles. Grâce à quoi ? Grâce à... (Il les incite à répondre.)

Tous

ensemble La bureaucratie!

Weber Merci, vous êtes de bons élèves !

L'hôte Merci à vous Herr Weber et bravo! Moi qui ai tellement maugréé contre la bureaucratie, je n'aurais jamais cru qu'un jour je lui trouverais des qualités ou, à tout le moins, des justifications!

Weber Danke 5 .

L'hôte J'avais l'intention de revenir à la doctrine du management de monsieur Fayol, mais il ne nous reste pas assez de temps. Nous en parlerons durant notre second entretien. Passons donc plutôt à l'autorité. Monsieur Weber, vous aviez quelque chose à dire là-dessus ?

Weber Oui. Il faut d'abord poser que l'ordre social est vital ; sinon, c'est la confusion, l'anarchie et même la révolution, vous êtes bien d'accord ?

Fayol Évidemment.

Taylor Sans aucun doute.

Follett Absolument.

Weber Pour que l'ordre essentiel puisse exister, il faut qu'il y ait domination.

Follett Ça, c'est moins certain !

Taylor Comment définissez-vous la domination?

Weber Comme la probabilité qu'un subalterne obéira à un commandement spécifique ; plus cette probabilité est grande, plus grande sera la domination qui pourra en résulter. Ce qui m'amène à définir l'autorité, ou le pouvoir si vous préférez, comme la probabilité qu'une personne va pouvoir accomplir sa volonté en dépit de l'opposition des autres.

Follett Venant de vous, ces deux définitions ne m'étonnent pas !

Weber Et je conclus que l'autorité est une nécessité socio-psychologique. 
Fayol Prussien!

Follett Imbu d'autoritarisme !

Weber Au contraire! À la suite de mon voyage aux États-Unis en 1904,j'ai écrit que l'autoritarisme était une faillite partout, sauf dans l'Église.

Follett Bon, je retire mon accusation d'autoritarisme, mais vous, continuez-vous d'affirmer que l'autorité est une nécessité socio-psychologique?

Weber Absolument! La preuve : les autorités existantes ne sont renversées que pour être remplacées par des nouvelles. Cela ne peut être que parce que les humains que nous sommes permettent à certains d'entre nous d'être en autorité. J'en conclus que cela répond à des besoins humains et sociaux fondamentaux.

Follett Votre raisonnement ne me convainc pas, quoiqu'il m'amène à conclure que nous allons continuer à chercher une autorité extérieure et arbitraire tant que nous n'aurons pas appris à diriger nos recherches vers la loi de la situation.

L'hôte Quelle est votre définition de l'autorité ?

Follett L'habileté à obtenir que les choses soient faites. Et cela dépend presque uniquement du succès qu'on a à persuader les gens de travailler « avec » soi. Dans les démocraties modernes, l'idée que quelqu'un est « sous l'autorité » de quelqu'un d'autre entraîne habituellement un refus de coopérer. C'est pourquoi il faut abandonner l'idée d'exercer du pouvoir «sur » les gens et tenter de l'exercer « avec » eux. En d'autres mots, contrairement à ce qu'implique la subordination, à savoir que le pouvoir est concentré chez le dominateur, on peut penser que le pouvoir est partagé, inégalement peut-être, mais partagé tout de même. Le défi consiste donc à convaincre les gens de mettre en commun le pouvoir qu'ils ont.

L'hôte Et pour vous, monsieur Fayol, qu'est-ce que c'est que l'autorité ?

Fayol Le droit de commander et le pouvoir de se faire obéir. Je distingue l'autorité statutaire, qui tient à la fonction, de l'autorité personnelle faite d'intelligence, de savoir, d'expérience, de valeur morale, etc. L'autorité personnelle est le complément indispensable de l'autorité statutaire, et ni l'élection à un poste ni la propriété d'une entreprise ne la confèrent. 
L'hôte Finalement, vous, monsieur Taylor?

Taylor Dans mon système, l'autorité s'appuie sur la connaissance indépendamment de la fonction ; je m'intéresse davantage à développer des façons de faire qui feront autorité plutôt qu'à l'exercice de l'autorité sur des bases dont beaucoup m'apparaissent arbitraires et discutables.

Weber Mademoiselle Follett prône le pouvoir « avec » et monsieur Taylor, l'autorité basée sur l'expertise. Sans partager leurs points de vue, je considère que pour que l'autorité et le contrôle fonctionnent, il faut que le subalterne accepte ne serait-ce que minimalement son état de soumission.

Taylor Ce qui n'est pas vraiment nécessaire dans mon système, puisque le supérieur ne donne pas d'ordres au travailleur en vertu de l'autorité inhérente à sa position dans la hiérarchie, mais bien selon la connaissance approfondie et spécialisée qu'il a d'un aspect du travail de l'employé.

Fayol Cet aspect de votre théorie a ses mérites, mais en pratique, elle signifie que chacun de vos travailleurs aura plusieurs supérieurs immédiats, chacun spécialiste d'un aspect, ce qui fait que l'ordre, l'autorité, la discipline et la stabilité sont menacés.

Taylor Pas du tout, et c'est vous-même qui expliquez pourquoi.

Fayol Ça m'étonnerait : l'unité de commandement est une des choses auxquelles je tiens le plus !

Taylor Oui, oui, tout le monde sait ça! Mais vous avez écrit : « Pour une action donnée, un agent ne doit recevoir d'ordres que d'un seul chef. »

Fayol Justement, chacun de vos agents a deux, trois et même quatre chefs !

Taylor En tout, oui, mais un seul chef pour chaque aspect particulier de sa tâche : la vitesse de sa machine, son entretien, les réparations nécessaires éventuellement, etc. Exactement comme vous dites : un seul chef pour une action donnée !

L'hôte Mary, il vous reste à peine une minute pour conclure.

Follett Je suis d'accord, du moins partiellement, avec monsieur Taylor. Je crois que l'autorité provient de l'expertise et de sa pertinence 
dans une situation donnée. Mais l'autorité est beaucoup trop complexe pour pouvoir clarifier le phénomène en une minute, voire en une heure.

L'hôte Mademoiselle...

Follett (Index accusateur) Non, non, non !

L'hôte Oh, pardon! Mary, messieurs, merci pour cette intéressante session et à bientôt pour la seconde. ('̀ la caméra) Mesdames, mesdemoiselles, messieurs, merci d'être venus nous rencontrer. Je suis convaincu que vous aurez trouvé nos invités tellement fascinants que vous ne voudrez pas manquer le seconde heure que j'aurai le plaisir de passer avec eux. À bientôt, au revoir. 


\section{Deuriente eprote}

Les invités causent, sotto voce, autour de la table, Follett et Taylor à gauche, Weber et Fayol à droite. L'hôte arrive par l'allée derrière son fauteuil, vient jusqu'à son fauteuil.

L'hôte Bonjour et bienvenue à ce deuxième épisode des Grands Esprits du Management qui accueille les mêmes invités que la dernière fois. Je les présente brièvement pour le bénéfice de ceux qui n'auraient pas assisté à leur première rencontre. D'abord, mademoiselle Mary Follett. Sans bruit, dès le début du siècle, cette femme s'était déjà taillé une place enviable dans le monde du management. Ses connaissances en psychologie lui ont permis d'émettre, sur le fonctionnement des organisations, des opinions qui étaient avant-gardistes à son époque et qui, de l'avis de plusieurs, le sont encore aujourd'hui. Étonnant, pas flatteur pour nos contemporains, mais vrai. Mesdames, mesdemoiselles, messieurs, Mary Follett !

Follett (Au public) Bonjour.

Pendant qu'elle salue et que le public applaudit, l'hôte tire son fauteuil, puis elle s'assoit.

L'hôte Voici maintenant l'homme qui a établi et promu l'étude scientifique des temps et des mouvements de ceux qui exécutent des tâches et dont le système de management porte le nom. Il a commencé sa carrière comme apprenti avec les cols bleus qui lui ont appris à travailler et à jurer, deux habitudes qu'il n'a jamais perdues. On l'a critiqué, on le critique encore, mais vous verrez qu'il a les connaissances, la conviction et... le caractère qu'il faut pour se défendre : Frederick Winslow Taylor ! 
Taylor (Au public) Good afternoon, bonjour.

Après les applaudissements, il s'assoit; l'hôte se tourne vers sa gauche.

L'hôte À ma gauche maintenant, un homme qui se défend d'être philosophe ou psychologue ; il se dit sociologue. Même s'il ne s'est pas penché sur le management comme tel, ses études, ses analyses et sa conception des modes de fonctionnement des organisations sociales font de lui un penseur qui a grandement influencé leur gestion : Max Weber !

Weber (Au public) Bonjour.

Après les applaudissements, il s'assoit.

L'hôte (Vers Fayot) Pendant la cinquantaine d'années où il a été directeur des mines de charbon de Commentry-Fourchambault, en France, notre dernier invité a observé, noté et réfléchi, ce qui nous a valu son livre Administration industrielle et générale. On a dit que monsieur Taylor et lui étaient les deux grands théoriciens du management. Voici donc Henri Fayol!

Fayol Mesdames, mesdemoiselles, messieurs, bonjour.

Après les applaudissements, Fayol et l'hôte s'assoient.

L'hôte Monsieur Fayol, vous et monsieur Taylor avez été deux grands théoriciens du management, mais ce qui est moins connu, c'est que vous, monsieur Fayol, vous vous êtes intéressé à l'organisation dans son ensemble et plus particulièrement à ce que devaient faire les managers qui la dirigeaient...

Fayol En effet.

L'hôte Tandis que monsieur Taylor s'est bien davantage occupé des ouvriers au bas de l'échelle, ceux-là mêmes qui sont associés directement à la production des biens.

Fayol Aux prolétaires en quelque sorte.

L'hôte Voilà une différence dont nous pourrons peut-être discuter plus tard. Pour le moment, il y a une question que j'ai envie de vous poser depuis notre dernière rencontre : Pourquoi avez-vous choisi d'écrire sur le management? 
Fayol Parce que l'État français avait fait les plus grands efforts pour répandre et perfectionner les connaissances techniques, mais rien, ou presque, pour préparer les futurs chefs à exercer les fonctions commerciales, financières et administratives ou de management de l'entreprise.

Taylor Les connaissances administratives, comme vous dites, aussi bien que techniques s'acquièrent à l'atelier !

Fayol Au contraire, les deux doivent d'abord s'acquérir à l'école, puis s'appliquer à l'atelier.

Taylor Alors, pourquoi votre État enseignait-il la technique dans ses écoles mais pas le management?

Fayol À cause de l'absence d'une doctrine du management, d'une doctrine issue de la discussion publique et consacrée.

Taylor Qu'est-ce que vous voulez dire par doctrine?

Fayol Un ensemble de principes, de règles, de méthodes, de procédés éprouvés et contrôlés par l'expérience.

Taylor Des principes concernant notamment l'autorité et la discipline ne manquaient pourtant pas à la France de la fin du XIX ${ }^{\mathrm{e}}$ siècle ; l'État n'avait qu'à les proclamer et à les appliquer au monde du management !

Fayol Il faut croire que la proclamation ne suffit pas. La lumière des principes, comme celle des phares, ne guide que ceux qui connaissent le chemin du port ! Un principe, sans le moyen de le réaliser, ne mène nulle part !

Taylor Étant donné l'état de choses en France à votre époque, qu'est-ce que vous comptiez accomplir avec votre livre?

Fayol Établir un courant qui serait suivi par d'autres managers, apporter un concours utile à la constitution d'une doctrine.

Taylor Et ensuite, une fois la doctrine établie ?

Fayol L'enseigner pour qu'il y ait des gens qui connaissent le chemin du port. Je crois que l'enseignement du management doit être universel : rudimentaire dans les écoles primaires, un peu plus étendu dans les écoles secondaires, très développé dans les écoles supérieures et les universités. 
L'hôte Monsieur Fayol, vos voeux n'ont peut-être pas encore été exaucés pour ce qui est des écoles primaires et secondaires, mais dans de nombreuses écoles supérieures et universités, on enseigne le management maintenant.

Fayol Dieu merci ! J'espère qu'elles vont se multiplier !

L'hôte Pourquoi établir une doctrine du management plutôt qu'une doctrine traitant de l'exécution technique des tâches, comme a fait monsieur Taylor?

Taylor Parce qu'il n'a pas compris que ça ne sert à rien d'établir des prévisions, des plans et des buts si les ouvriers ne savent pas accomplir leurs tâches de la manière la plus efficace possible !

Weber Parce que monsieur Fayol n'a pas compris que c'est la tête qui mène et dicte la marche à suivre !

Follett Parce qu'il a pressenti que c'est la responsabilité de la direction de voir à ce qu'il y ait coordination, l'intégration et le comportement circulaire dans une organisation, de sorte que chacun de ses éléments contribue au succès de l'entreprise.

L'hôte Maintenant que tout le monde a répondu à votre place, monsieur Fayol, voulez-vous nous dire pourquoi vous avez créé une doctrine du management au lieu d'une doctrine concernant l'exécution technique des tâches?

Fayol Parce que, comme je vous le disais lors de notre première rencontre, gouverner, c'est conduire l'entreprise vers son but en cherchant à tirer le meilleur parti possible de toutes les ressources dont elle dispose, et que coordonner, c'est mettre de l'harmonie entre tous les actes d'une entreprise pour en faciliter le fonctionnement et le succès. Vous conviendrez avec moi, monsieur Taylor, que ce sont là des mesures que les ouvriers ne peuvent ni déterminer ni inculquer à une entreprise !

Taylor Peut-être pas, mais il n'y a pas a Jesus-Christ of a man qui va me...

Follett (Outrée) Fred, how are you ? On ne respecte pas le deuxième commandement de Dieu dans le système Taylor?

Taylor Oui, oui, oui, mais hélas Mary, je suis mal élevé !

Follett Que je ne vous y reprenne pas ! 
Taylor Excusez-moi ; je vais faire mon possible, mais faudrait pas trop me provoquer! Qu'est-ce que je disais?

Follett Ne le répétez surtout pas!

Taylor Non, non, non... Ah oui! Quels que soient les plans, les coordinations et les « tournages en rond » qu'une direc...

Follett (Elle le coupe.) Le « comportement circulaire»!

Taylor (Condescendant) O.K., le « comportement circulaire » qu'une direction puisse édicter, si les ouvriers décident de faire une grève du zèle, de flâner au travail, l'entreprise ne produira pas comme elle le devrait !

Fayol C'est pourquoi il est important d'avoir un management bien organisé, bien structuré, capable de constater l'existence d'un problème, de l'analyser et d'en trouver la solution.

Taylor Et de l'imposer, comme font vos modèles favoris : les militaires et leurs états-majors!

Fayol On peut s'inspirer de quelqu'un ou de quelque chose sans l'imiter servilement ! Il n'y a rien de rigide ni d'absolu en matière de management ; tout y est question de mesure. Les principes que j'ai énoncés, parmi lesquels on retrouve la division du travail, l'exercice responsable de l'autorité, l'unité de commandement et l'unité de direction, sont souples et peuvent être adaptés à tous les besoins. Il s'agit de savoir s'en servir. C'est un art difficile qui exige de l'intelligence, de l'expérience, de la décision et de la mesure. La mesure et la flexibilité sont faites de tact et d'expérience et sont cieux des principales qualités du manager. Il doit comprendre qu'un changement de situation peut déterminer un changement des règles de l'organisation qu'avait légitimées une situation initiale.

Taylor Donc vos règles peuvent changer au gré des événements !

Fayol En effet! La santé et le bon fonctionnement d'un corps social, ce qu'est toute entreprise, dépendent d'un certain nombre de conditions qu'on appelle indifféremment principes, lois ou règles. J'ai choisi le mot principe en le dégageant de toute idée de rigidité.

Taylor Qu'entendez-vous par corps social? 
Fayol On le comprend facilement, si l'on compare le corps social à l'animal.

Taylor Quel animal, le gorille ou le cheval?

Fayol (Après le rire) $\dot{A}$ votre guise ! N'importe quel animal peut servir à cette comparaison. L'homme joue dans le corps social un rôle analogue à celui de la cellule dans le corps de l'animal : cellule unique dans l'entreprise rudimentaire, millième ou millionième partie du corps social dans la grande entreprise.

Taylor Alors là, si vous nous entraînez dans la biologie cellulaire !

Fayol Je m'explique : le fonctionnement du système nerveux présente de grandes analogies avec le management. Ainsi le système nerveux recueille, un peu partout dans l'organisme, des sensations qu'il transmet, je vous fais grâce des intermédiaires, qu'il transmet donc au cerveau, à la direction. Du cerveau part ensuite le commandement qui, en sens inverse, va au membre ou au service qui doit exécuter le mouvement. Sans l'impulsion nerveuse, comme sans l'action managériale, l'organisme devient une masse inerte et dépérit rapidement.

L'hôte Merci monsieur Fayol, cette comparaison nous aide à comprendre votre conception du management et son application. (lise tourne vers Taylor.) Monsieur Taylor, parlez-nous du taylorisme, de ses méthodes, de ses buts.

Taylor Non!

L'hôte Comment, non ?

Taylor Non, je ne vous décrirai pas les méthodes d'étude des temps et des mouvements : je n'aurais pas le temps de vous en expliquer les nombreux et complexes détails. (À la caméra) Que ceux que ça intéresse lisent $L a$ direction scientifique des entreprises ou encore le compte rendu de mon témoignage devant le comité spécial du Congrès américain, ils y trouveront tout ce qui peut leur être utile.

L'hôte Alors, ses buts?

Taylor Le but ultime du taylorisme est la prospérité !

Weber Du patron capitaliste?

Taylor Non ! Le taylorisme contribue à la prospérité du patron, mais tel n'est pas son but ultime. 
Follett La prospérité des travailleurs?

Taylor Non plus ! Il améliore le sort du travailleur, mais ce n'est pas son but ultime non plus.

Fayol Reste l'entreprise?

Taylor Elle aussi bénéficie du taylorisme, mais sa prospérité n'en est pas le but réel. (Temps) C'est l'humanité tout entière qui est le plus grand bénéficiaire du management scientifique, comme elle l'a été de la machine et de l'avènement de l'ère industrielle. La production accrue permet au manufacturier de baisser les prix, donc de rendre son produit plus accessible au public qui voit ainsi son bien-être augmenté. Henry Ford en a fait la preuve.

L'hôte La croyance populaire veut que la machine ait pris la place de l'homme et entraîné l'accroissement du chômage.

Taylor Erreur ! La machine améliore le rendement, diminue les coûts de production, élargit le marché, augmente la demande et, conséquemment, la production, engendre la prospérité et enraye le chômage.

L'hôte Ça fait une belle jambe aux pauvres journaliers ignorants et sans métier !

Taylor Peut-être pas, mais ça leur a fait des beaux pieds !

L'hôte Comment ça?

Taylor La mécanisation des manufactures de chaussures a fait augmenter la production, baisser les prix et mis les souliers à la portée des journaliers qui, depuis, vont travailler chaussés au lieu de pieds nus. La prospérité de l'humanité est le résultat de la plus grande productivité des hommes et des machines.

Weber N'avez-vous pas recommandé une augmentation inflationniste des salaires proportionnelle à l'augmentation de la productivité ?

Taylor Oui, mais la prospérité, celle d'un peuple, ne se mesure pas au coût du travail, mais à la valeur de ce qui est produit, à la richesse qui est créée dans le monde.

Weber Et qu'est-ce que c'est, la richesse, pour vous ?

Taylor La richesse, ce n'est pas l'argent ; la richesse, c'est ce qui vient de la terre plus ce qui est produit par les hommes. J'ai vu tout ce que l'humanité perdait par son inefficacité et j'ai voulu y 
remédier par le management scientifique qui repose sur des lois, des règles ou... des principes, comme vous diriez, mon cher Fayol !

Follett Vous vouliez donner la prospérité à tout le monde !

Taylor Absolument ! À l'employeur aussi bien qu'à l'employé. Pour l'employeur, le maximum de prospérité ne veut pas dire uniquement des gros dividendes, mais le développement maximum de toute son entreprise de sorte que sa prospérité soit permanente.

Follett Et pour l'employé ?

Taylor Un salaire plus élevé, mais aussi son développement personnel maximum, d'où la possibilité de se voir confier le plus haut niveau de travail que lui permettent son talent et ses capacités. C'est ça qui devrait être le premier but de toute entreprise : produire des hommes de première classe qui accéderont le plus rapidement possible aux plus hauts échelons.

Weber À vous entendre, le taylorisme, c'est le paradis !

Taylor Terrestre!

Weber Vraiment?

Taylor Indiscutablement! Les pays développés, qui ont adopté le management scientifique, sont au moins cinq à six fois plus productifs et ont proportionnellement moins de chômage que ceux du tiers-monde.

Weber Il y a quelque chose d'irrationnel dans votre système : si vous diminuez le nombre d'employés, vous mettez des hommes dans la rue!

Taylor Mais non! À l'intérieur d'une entreprise donnée, certains employés sont promus, d'autres sont réaffectés. Les mécontents, les incapables, enfin ceux qui abandonnent, finissent par se trouver du travail ailleurs parce que c'est toute la société qui bénéficie de la prospérité et qui a besoin de plus en plus de main-d'œuvre. Vous vous êtes intéressé à l'histoire, Herr Weber, vous devez savoir qu'elle nous démontre que la consommation croît au rythme de la production!

Weber Oui, c'est juste. Mais il y a autre chose que ma raison n'admet pas : si une industrie dépense de l'argent pour acheter des machines qui minimisent le travail, les salaires qu'elle paie devraient baisser en conséquence. 
Taylor Non, le plus souvent, on observe exactement le contraire. C'est dans les entreprises fortement mécanisées qu'on retrouve les emplois les mieux rémunérés. (Regard vers Fayol) D'ailleurs ceci s'explique aisément du fait que les travailleurs sont amenés à exercer des tâches plus complexes et requérant un meilleur entraînement. Ils sont donc rémunérés en conséquence.

L'hôte Oui, mais le taylorisme demande aux ouvriers de dépenser plus d'énergie pour augmenter la production.

Taylor Pas du tout ! Le taylorisme rationalise le travail et minimise la demande énergétique. Cela dit, il faut augmenter la production : le monde souffre de la sous-production qui est responsable des bas salaires et prive les pauvres de logements, de vêtements et de nourriture.

Weber Donc, augmenter la production et conséquemment le profit. Connaissezvous les paroles de saint Thomas d'Aquin qui qualifie la recherche du profit de turpitudo, de turpitude ? Et il ne parle pas d'exploitation mais de profit raisonnable !

L'hôte Vous voulez nous engager dans une discussion philosophique et religieuse sur l'éthique du profit !

Weber Non, non, je ne veux pas en discuter, je veux simplement semer cette petite graine et la laisser germer dans vos « Grands Esprits ». Mais, monsieur Taylor a pris une tangente : il s'est déguisé en apôtre qui veut aider l'humanité souffrante tandis que je voulais aborder le problème des salaires.

Fayol Un problème ardu, car en matière de salaire, toutes les solutions sont précaires.

Weber Précaires?

Fayol Mais oui : à mesure que les circonstances changent, il faut changer les modes de rémunération.

Follett Exemple?

Fayol On commence par le salaire horaire ou journalier, puis, quand la routine s'est établie et que la production diminue, pour stimuler le zèle, on est tenté de passer au paiement à la pièce.

Taylor Je suis contre!

Weber Moi aussi! 
Fayol Et moi aussi, parce que le zèle ne dure qu'un certain temps et qu'un régime finit par s'établir qui, peu à peu, ramène ce mode de paiement à celui de la tâche journalière pour un prix fixé d'avance.

L'hôte Et vous monsieur Taylor, pourquoi êtes-vous contre le paiement à la pièce?

Taylor Pour les mêmes raisons que monsieur Fayol : quand un travailleur a vu le prix de la pièce diminuer deux ou trois fois en raison de l'accroissement de sa production, il ralentit son rythme, se met à traîner, à flâner au travail et la flânerie est un des plus graves problèmes des organisations.

Weber Vous avez raison. Le manque de conscience des ouvriers demeure un des principaux obstacles au développement du capitalisme. D'autant plus que c'est un mal qui ne tarde pas à atteindre tous les ouvriers de l'organisation, non pas par contagion, mais grâce aux méthodes intimidantes souvent utilisées par les traînards.

Taylor Tiens! vous êtes au courant de ce système?

Weber Bien sûr! il est pratiqué depuis longtemps. En Angleterre, au XVIII ${ }^{\mathrm{e}}$ siècle, les membres de la nouvelle secte anglicane appelée « méthodiste» étaient consciencieux et montraient trop d'ardeur au travail au goût des autres employés traînards. Devant le refus des méthodistes de ralentir leur rythme de production, leurs compagnons les ont pris en aversion, les ont persécutés et ont détruit leurs outils.

Follett Quelle conclusion tirez-vous de ces faits?

Weber Ils me rappellent le verset de saint Paul : «Si quelqu'un ne veut pas travailler, qu'il ne mange pas non plus!»

L'hôte Vous devez donc être contre le paiement à la pièce ?

Weber Oui, mais pas à cause de l'aventure des méthodistes ni des moyens violents utilisés encore aujourd'hui par les traînards.

L'hôte Alors, pourquoi ?

Weber Parce que le paiement à la pièce est une invention du capitalisme pour faire augmenter la productivité du travail humain par l'accroissement de son intensité. Or, partout où le capitalisme a essayé d'implanter cette méthode, il s'est heurté à la tradition précapitaliste. 
Taylor Ah ! the jesu... (Il regarde Follett et se reprend.) Le maudit traditionalisme!

L'hôte La tradition précapitaliste qui se manifeste comment?

Weber Par le réflexe presque naturel qu'ont les hommes à s'attacher à une façon traditionnelle de faire le travail ; qui les amène à régler leurs prestations qualitativement et quantitativement selon des résultats stéréotypés et en fonction de salaires auxquels ils croient avoir droit. L'homme ne désire donc pas gagner de plus en plus d'argent. Il désire tout simplement vivre selon son habitude et gagner autant d'argent qu'il lui en faut pour cela.

Follett Exemple?

Weber Les récoltes. La fragilité des produits agricoles et la menace des intempéries exigent qu'elles se fassent le plus rapidement possible. Dans mon temps, les agriculteurs avaient décidé d'élever le taux du paiement à la pièce pour accélérer l'engrangement de la récolte. Eh bien ! ce qu'ils ont obtenu, ce n'est pas une augmentation, mais une réduction du rendement, parce que les ouvriers ont réagi à l'augmentation de salaire par une diminution de production.

Fayol Vous avez des chiffres ?

Weber Mais oui! L'homme qui recevait 1 mark pour faucher un arpent fauchait deux arpents et demi par jour et recevait 2,5 marks par jour. Lorsque l'arpent est passé à 1,25 mark, il ne fauchait pas trois arpents comme on l'avait escompté, ce qui lui aurait permis de gagner 3,75 marks par jour ; il fauchait deux arpents seulement, ce qui lui permettait de continuer à gagner ses 2,5 marks habituels. Le gain supplémentaire l'intéressait moins que la réduction de son travail. Il ne se demandait pas: «Combien puis-je gagner si je travaille plus ? » mais : «Combien dois-je travailler pour gagner les 2,5 marks qui couvrent mes besoins courants? »

Fayol Comment les agriculteurs ont-ils réagi ?

Weber Ils ont recouru au procédé inverse !

Fayol C'est-à-dire ?

Weber Un abaissement du salaire pour contraindre les ouvriers à un rendement accru s'ils voulaient conserver le même gain. 
Fayol Ce qui ne fonctionne pas non plus!

Weber Pendant un certain temps, oui. À l'époque, il s'est même trouvé un soidisant penseur pour affirmer que « le peuple ne travaille que parce qu'il est pauvre et aussi longtemps que la nécessité l'y pousse ». Les bas salaires ne fonctionnent que dans un milieu limité : celui des ouvriers non spécialisés, et seulement pour un temps limité. À la longue, ils entrainent l'employeur dans un cul-de-sac dont le fond est la sélection des bons à rien.

Fayol Alors, quelle est la solution?

Weber La question que se pose l'ouvrier est : "Comment gagner un salaire donné avec un minimum d'effort ? ». Il faut lui faire comprendre que gagner de l'argent est le résultat de l'application et de la compétence au sein d'une profession. La solution, c'est de convaincre les ouvriers que le travail doit être accompli comme s'il était un but en soi, euh (Il cherche le mot.) ein beruf...

Je crois que vous diriez une vocation.

Taylor (Pouffe de rire.) Ah! ah! ah! Ou bien vous faites une farce, ou bien vous êtes encore plus utopiste que je ne pensais: vous faites un « idéal-rêve »!

Weber Ni l'un ni l'autre. Je sais fort bien qu'un tel état d'esprit n'est pas un produit de la nature ; il ne peut qu'être le résultat d'un long, d'un persévérant processus d'éducation des ouvriers.

Taylor Et ça, c'est pas de la tarte!

Weber (Sourire) Dans mon temps non, mais maintenant que le capitalisme est bien en selle et que le recrutement de la main-d'oeuvre est relativement aisé, je dirais même que c'est du gâteau! D'ailleurs, il devrait être facile de vous en convaincre : c'est exactement ce que vous avez fait pour implanter votre système. Vous avez éduqué, pour ne pas dire endoctriné, les ouvriers de votre usine.

Taylor Oui, oui, là-dessus, on est d'accord : vous parlez de... « brouf »? Je par...

Weber (Un peu piqué qu'on se moque de sa langue.) Beruf! J'avais cru entendre dire monsieur (nom de l'hôte) que vous saviez l'allemand ! 
Taylor Oui, mais il y a si longtemps que j'ai eu l'occasion de le pratiquer! Vous parlez de beruf, c'est-à-dire de vocation, et je parle de tâche, ça revient au même. L'idée de tâche est la plus importante du management scientifique.

L'hôte Du taylorisme?

Taylor Oui, que certains appellent « le management des tâches », mais mon idée des tâches n'était pas nouvelle. Chacun de nous se souvient qu'elle est utilisée avec beaucoup de succès à l'école. Chaque jour, l'instituteur demande à l'élève d'apprendre une leçon précise : telle partie de telle matière. C'est uniquement de cette manière que les élèves progressent systématiquement et c'est aussi uniquement de cette manière qu'on fait progresser des ouvriers.

Weber Et vos ouvriers s'y soumettaient?

Taylor Volontiers, mais à une condition, et là-dessus, vous et moi ne sommes pas d'accord : les hommes étaient prêts à apprendre leurs tâches et par conséquent à augmenter leur rendement pourvu qu'on leur assure une augmentation substantielle et permanente.

Weber Et vous leur assuriez une augmentation permanente?

Taylor Oui, parce que ça éliminait leur crainte de recevoir un salaire inférieur durant les périodes creuses.

Weber Une augmentation de quel ordre?

Taylor Entre $30 \%$ et $100 \%$ selon la tâche de chacun.

Follett Vous leur donniez des augmentations quand ils les avaient méritées et qu'ils vous les demandaient?

Taylor Pardon! Dans mon système, ils ont des augmentations sans les demander!

Follett Comment concevez-vous le salaire?

Taylor Comme une juste division des surplus résultant des efforts des patrons et des employés.

L'hôte Et voilà pour les salaires ! Merci messieurs. Mary, à part l'intégration et le comportement circulaire, vous vous êtes beaucoup intéressée à la coordination. Voulez-vous nous dire ce que vous entendez par coordination et nous en parler? 
Follett Je veux bien vous en parler, mais comme bien longtemps avant nous tous, monsieur Fayol a été le premier à la définir et à en faire une des fonctions du management, c'est à lui qu'il revient d'aborder ce sujet.

L'hôte Bon d'accord, quitte à ce que vous fassiez les mises au point qui s'imposeront sans cloute, compte tenu de l'évolution du management depuis que monsieur Fayol a écrit son livre.

Fayol Merci monsieur (nom de l'hôte). Mademoiselle, il me revient d'abord de vous remercier de votre... euh... galanterie... qui est pourtant un apanage masculin ! Pour bien nous comprendre, commençons par la définition : coordonner, c'est relier, unir, harmoniser tous les actes et tous les efforts de tous les membres de l'organisation pour en faciliter le fonctionnement et le succès.

L'hôte C'est plutôt lapidaire, pouvez-vous développer davantage ?

Fayol Volontiers; c'est tenir compte, clans chaque opération, des obligations et des conséquences que cette opération entraine pour toutes les fonctions de l'entreprise.

Follett Et c'est beaucoup plus important que dans votre temps, parce que maintenant il y a plus de responsables clans les entreprises : tout le long de la hiérarchie, plusieurs postes jouissent à divers degrés d'une certaine autorité et il y a de nombreux directeurs sous le directeur général.

Fayol C'est donc d'autant plus impérieux que la coordination remplisse ses fonctions essentielles, qui sont de proportionner rigoureusement les dépenses aux ressources financières, l'ampleur des immeubles et de l'outillage aux besoins de fabrication, les stocks à la consommation et les ventes à la production.

Weber Les ventes relèvent des vendeurs, pas du management !

Fayol Mon cher Weber, l'industrie privée n'est pas la bureaucratie ! La prospérité d'une entreprise privée dépend de la fonction commerciale autant que de la fonction technique et la coordination doit les englober toutes les deux. Si le produit ne s'écoule pas, c'est la ruine. Savoir acheter et vendre est aussi important que savoir fabriquer!

Follett Exact ! Une entreprise bien gérée, c'est une entreprise dont toutes les parties sont complètement coordonnées. Elles s'ajustent les 
unes aux autres comme les mailles d'un tricot, se tiennent les unes les autres comme les maillons d'une chaîne. Elles sont reliées, imbriquées et l'organisation coordonnée n'est pas un amas de pièces séparées, mais un tout, une unité.

Fayol D'accord ! C'est pourquoi j'ai toujours insisté sur l'unité de commandement.

Follett Pas d'accord! Non, non, non!

Fayol (Étonné : ça allait si bien!) Ah non! Pourquoi ?

Follett D'abord, parce que je ne parle pas de l'unité de commandement, et ensuite, parce que l'unité de commandement n'est plus possible aujourd'hui à cause de la multiplicité et de la complexité des fonctions et de l'état actuel de la société.

Fayol Voilà une affirmation qui me semble gratuite.

Follett Pas du tout, c'est une affirmation fondée et je vais vous le démontrer.

Fayol Je me demande bien comment! L'unité de commandement est une règle essentielle et quand elle est violée, l'autorité est atteinte, la discipline compromise, l'ordre troublé et la stabilité menacée. Il faut résister à la tentation d'installer la dualité ou la pluralité de commandement dans le seul but de justifier le partage des attributions entre associés. L'unité de commandement m'a toujours bien servi.

Follett Oui, sans doute ! (À mesure qu'elle énumère, il approuve de la tête et vocalement par des onomatopées.) Elle vous a servi vous, en 1850, en Europe militarisée, en France, dans une usine de charbon où l'organigramme prenait la forme d'une pyramide et la hiérarchie, celle d'une échelle.

Fayol Tout cela est juste. Et alors?

Follett Alors ? Nous arrivons au $\mathrm{XXI}^{\mathrm{e}}$ siècle. Seules quelques dictatures sont encore militarisées, la France est rendue à sa cinquième république et les grandes entreprises sont multinationales. Pour nous adapter à ces changements, nous avons ajouté un tapis roulant horizontal à votre échelle verticale, et votre pyramide traditionnelle, comme les pyramides égyptiennes, c'est de l'histoire ancienne, du moins dans bien des cas. D'ailleurs, certains prétendent qu'elle a davantage de sens... la tête en bas! 
Fayol C'est le monde à l'envers !

Follett Tout à fait, et comme vous avez si justement écrit : " les programmes doivent être constamment tenus en harmonie avec les circonstances ", nous avons pris votre modèle qui fonctionnait si bien dans vos circonstances et, selon votre conseil, nous l'avons transformé et adapté aux nôtres, à notre temps.

Fayol Dans le domaine de la coordination, (petit sourire) où nous nous entendons mieux que dans celui du commandement, qu'avez-vous changé ?

Follett Pour vous expliquer notre coordination, il me faudrait au moins une journée. Je vais donc me contenter de vous exposer les trois points qui, à mon avis, constituent aujourd'hui la base de l'unité d'une entreprise. Ne vous en déplaise, la coordination est à la base de l'unité, et je ne doute pas que vous aurez compris ce que j'entends par l'une et l'autre à la fin de mon exposé.

Fayol Je vous écoute.

Follett Le premier point est la collaboration étroite entre les différents services d'une organisation. Je prends comme exemple une compagnie de téléphone où j'ai mené une enquête. Quand la direction a décidé de diviser un central en deux, il a fallu déterminer si l'on allait couper les lignes au rythme de 35 par jour ou toutes les 500 lignes en une seule nuit. C'était une décision qui affectait quatre services : les communications téléphoniques, l'ingénierie, les ventes et le central lui-même. Les directeurs des quatre services se sont entendus pour faire le changement en une seule nuit.

Fayol S'ils ne s'étaient pas entendus?

Follett Ils auraient porté le problème plus haut verticalement dans l'échelle hiérarchique, aux surintendants de chacun des services concernés.

Fayol Voilà : la hiérarchie, l'échelle !

Follett Mais oui ! Je n'ai pas dit que nous avions éliminé l'échelle, mais que nous lui avions ajouté un tapis roulant horizontal. Saisis du problème, les surintendants en auraient discuté entre eux, horizontalement, comme leurs subordonnés l'avaient fait avant eux. 
Fayol Et si les surintendants n'avaient pas réussi à s'entendre?

Follett Ils seraient allés plus haut verticalement, et ainsi de suite jusqu'au directeur general.

Fayol Voilà !

Follett Voilà comment, grâce à une organisation mixte, c'est-à-dire à la fois verticale et horizontale, on n'est pas forcé de toujours grimper l'échelle. de toujours porter sur le pupitre du directeur des problèmes qu'on peut régler à un niveau inférieur.

Fayol Et comment on détruit la hiérarchie et l'autorité.

Follett Absolument pas! D'abord, je vous ai déjà dit lors de notre première rencontre que l'autorité n'est pas une question de domination et de subordination. Ensuite, nous n'avons pas détruit l'autorité, nous l'avons étalée horizontalement. Quant à la hiérarchie, nous l'avons conservée, puisque le cas échéant, on remonte jusqu'au directeur général, ce qui confirme d'ailleurs son autorité. Et songez à tout ce qu'on économise en temps et en énergie !

Fayot Que voulez-vous dire?

Follett Que partir des échelons inférieurs et remonter jusqu'à la tête pour des décisions d'importance secondaire implique du temps et de l'énergie à chaque échelon. De plus, notre modèle laisse au directeur général le temps de faire ce qu'il doit faire : diriger l'organisation.

Fayol (Concédant) Oui... j’y vois certains avantages...

Follett Entre autres, celui de mettre les gens en contact direct les uns avec les autres. Cela leur permet de discuter des difficultés entre eux et diminue les dangers d'incompréhension.

Fayol Alors là, très bien : je vous l'ai dit, je favorise les communications verbales. J'ai même déjà rêvé d'interdire les notes de service... mais je ne l'ai pas fait!

Follett Ce genre de communications m'amène au deuxième point: l'intégration. Je vous en ai parlé lors de notre première rencontre, je ne m'étendrai donc pas sur ce sujet. Je me contenterai de dire qu'il est beaucoup plus facile de régler des conflits internes, de concilier des points de vue différents par intégration et par comportement circulaire quand on est face à face pour en discuter. 
L'hôte Et votre troisième point?

Follett La forme fonctionnelle d'organisation, qui se rattache aux deux autres points est aussi importante.

L'hôte Et qu'est-ce que c'est, la forme fonctionnelle d'organisation ?

Follett Une organisation où l'on reconnaît certaines fonctions spéciales qui soutiennent et appuient les autres fonctions plus étroitement associées aux opérations principales.

L'hôte Comme ?

Follett Les achats, les relations de travail, l'équipement, etc. Autrefois, chaque service achetait le matériel qui lui était nécessaire. Maintenant, on voit de plus en plus souvent, dans les organisations, un service des achats qui se procure tout ce dont l'entreprise a besoin. De même, le service d'entretien s'occupe de toute la machinerie d'une usine et le service des relations humaines ou des relations de travail règle les problèmes humains de tous les services.

Fayol Quel avantage y voyez-vous ?

Follett Le sens de la responsabilité collective. Au lieu de décider seul de l'achat d'une pièce d'équipement, le chef de service en discute avec le directeur des équipements avant de faire une recommandation d'achat au directeur des achats. Avec la forme fonctionnelle d'organisation, la responsabilité est partagée et devient par le fait même collective. On peut alors se poser des questions comme : est-ce le chef de production ou le chimiste qui est responsable de la qualité d'un produit alimentaire... ou les deux ? Si une méthode se révèle un échec, à qui la faute ? À l'expert qui l'a suggérée, au chef de service qui l'a appliquée ou aux deux ?

Fayol En somme, chacun est forcé de prendre ses responsabilités.

Follett Oui, mais cela ne suffit pas. On croit généralement que si chacun de son côté fait sa part, tout ira bien. Or, tel n'est pas le cas. La responsabilité collective ne résulte pas de l'addition des diverses responsabilités, mais de la solidarité de toutes les personnes responsables concernées. La responsabilité collective n'est pas affaire d'agrégation mais d'intégration.

Fayol Et quand vous l'obtenez, qu'est-ce que vous avez de plus ? 
Follett Chaque employé, en plus de se sentir responsable de son propre travail, se sent aussi responsable du succès de toute l'entreprise.

Fayol Et vous avez alors trouvé l'unité rêvée !

Follett Non ; l'unité est une utopie, elle n'existe pas.

Fayol (Il ne comprend pas.) Alors pourquoi la recherchez-vous ?

Follett Je ne la recherche pas parce que je sais qu'elle ne dure pas. Pas une journée, même pas cinq minutes. Ce que je recherche, c'est que chaque membre d'une organisation sache et sente que son travail doit se conjuguer avec celui de tous les autres dans un esprit de coopération.

L'hôte Vous terminez avec l'idée de coopération, une idée louable et souhaitable sans cloute, mais une idée que détestent les plus chauds opposants du management: les syndicats.

Weber Ah! Les syndicats ! La plaie ! L’anarchie ! Le désordre !

L'hôte (Riant) Aurais-je touché une de vos cordes sensibles ?

Weber En plein dans le mille ! Les syndicats qui s'attaquent à l'autorité, garant de l'ordre et du bon fonctionnement de toute société, et au travail qui est le but même de la vie.

L'hôte Le travail est le but de la vie?

Weber Bien sûr : c'est un principe qu'on trouve partout dans les Écritures et je vous répète les mots de saint Paul : «Si quelqu'un ne veut pas travailler, qu'il ne mange pas non plus. »

L'hôte Mais les syndicats ne sont pas contre le travail, ils essaient de l'organiser, d'en améliorer les conditions.

Weber Ils essaient de le minimiser et quand ils n'arrivent pas à l'arrêter complètement par leurs grèves, ils le ralentissent par des grèves du zèle et par un tas d'autres procédés diaboliques. Voilà ce que je pense des syndicats et vous ne m'en ferez pas démordre.

L'hôte Je n'en ai pas la moindre intention : je suis convaincu que ce serait du temps perdu. Monsieur Taylor, cible favorite des syndicats, vous ne devez pas les porter dans votre cœur!

Taylor Je ne leur en veux pas.

Weber (Incrédule) Ah non ? 
Taylor Pas du tout : ils ont diminué les souffrances et amélioré les heures et les conditions de travail des salariés.

Weber Vous, leur victime, vous êtes en faveur des syndicats ?

Taylor Ce n'est pas ce que j'ai dit; j'ai dit qu'ils avaient rendu service...

Weber (Il le coupe.) Vous êtes pour ou contre?

Taylor Ni l'un ni l'autre.

Weber Ah! Ah ! Poule mouillée !

Taylor Non! Non! Tête froide ! Je reconnais ce que les syndicats ont accompli, mais je dis que mon système est infiniment supérieur à leur méthode qui règle les salaires et les conditions de travail de milliers d'employés par des négociations avec les employeurs.

Weber Pourquoi votre système est-il supérieur aux négociations ?

Taylor Parce qu'il stimule l'ambition de chaque travailleur en le payant selon sa valeur individuelle au lieu de l'engloutir clans l'anonymat des employés de sa classe. C'est une chose que les syndicats ne peuvent pas se permettre, parce que le traitement individuel est une menace pour le groupe.

Weber Donc, le taylorisme est supérieur au syndicalisme ?

Taylor Sans aucun doute : si le management scientifique remplaçait les négociations syndicales dans la détermination des salaires et des conditions de travail, les syndicats auraient beaucoup de mal à convaincre les travailleurs de leur payer de grasses cotisations !

L'hôte Un événement semble vous donner raison, monsieur Taylor: en 1989, les employés de l'usine Nissan à Smyrna, Tennessee, aux États-Unis, ont rejeté à $82 \%$ une demande d'accréditation par les Travailleurs unis de l'automobile.

Taylor Bravo! Et j'espère que ce n'est qu'un début!

Fayol Monsieur Taylor, vous venez de nous dire que votre système stimule l'ambition des travailleurs. Ai-je raison de conclure que leur plus grande ambition fait augmenter leur productivité ?

Taylor Mais oui!

Fayol À combien estimez-vous le pourcentage de l'augmentation de la productivité attribuable à la systématisation du travail et celui provenant de son accélération? 
Taylor Le taylorisme ne demande pas aux ouvriers d'accélérer leur travail ; il leur demande simplement d'éliminer les gestes inutiles et de ne pas traînasser ou flâner.

Fayol Comment peut-on déterminer s'il s'agit de flânerie ou d'une dépense normale d'énergie?

Taylor Par une étude scientifique, minutieuse, précise et honnête du travail à accomplir.

Weber N'est-il pas concevable que, par cupidité, l'employeur détermine une norme de travail supérieure au rendement normal et honnête d'un ouvrier?

Taylor Ça pourrait arriver.

Weber Comment l'ouvrier peut-il alors se protéger s'il est « taylorisé » plutôt que syndiqué ?

Taylor En refusant de travailler au rythme convenu, un remède qu'il peut utiliser sans perdre son salaire.

Follett Sans perdre son salaire?

Taylor Oui, parce que, sous le taylorisme, son salaire de base est garanti. Tout ce qu'il perd, dans un tel cas, c'est les $30 \%$ à $100 \%$ de prime qu'il recevrait en respectant le rythme convenu.

Follett Et l'employeur?

Taylor Il perd sa poule aux œufs d'or!

Weber Le syndicalisme et le taylorisme prétendent tous deux aider l'ouvrier ; quelle différence y a-t-il entre eux ?

Taylor Le management scientifique s'appuie sur la coopération, tandis que le syndicalisme repose sur l'affrontement.

Follett Et le syndicalisme repose sur l'affrontement parce que bien des gens n'aiment pas faire l'effort de se servir de leur intelligence; la recherche d'une solution qui satisfait les intérêts des deux parties exige parfois un travail long et ardu. C'est beaucoup plus facile pour le syndicat de se battre que de réfléchir pour essayer de solutionner les problèmes.

L'hôte Que vous tentez de régler par l'intégration?

Follett Oui, mais l'intégration demande de l'invention et pour inventer il faut penser, ce qui est fatigant et difficile ! Du moins, ça semble l'être, pour bien des chefs syndicaux ainsi que certains patrons d'ailleurs ! 
Fayol Leur attitude vient peut-être du fait que les conventions ne font qu'un temps : quand elles ne sont plus en harmonie avec les conditions économiques et sociales, il faut les renégocier.

Follett Non, non, non, c'est justement là qu'ils ont tort : le secret de l'arbitrage des conflits de travail ne réside pas dans l'ajustement aux circonstances, mais dans l'invention, dans la création de situations nouvelles.

L'hôte Monsieur Taylor, vous avez dit que...

Taylor Encore moi ? Mais vous ne me lâchez pas!

L'hôte Ce n'est ni Mary, ni monsieur Weber, ni monsieur Fayol qui ont attaqué les syndicats, c'est vous !

Taylor Pardon, ce n'est pas moi qui ai attaqué les syndicats, ce sont eux qui se sont acharnés contre moi, jusqu'à me traîner devant le Congrès américain.

L'hôte Où vous vous êtes bien défendu! Tout ce que je vous demande, c'est de continuer de vous défendre maintenant.

Taylor Bon, d'accord; sur quel point m'attaquez-vous?

L'hôte Vous dites que le traitement individuel est une menace pour le groupe syndical. L'ouvrier qui, pour des raisons physiques ou psychiques hors de son contrôle, n'est pas un bon travailleur, n'a-t-il pas le droit de vivre aussi bien que le bon travailleur?

Taylor Pas aussi bien que le bon travailleur.

L'hôte Ah, non?

Taylor Non, parce que cela voudrait dire que tous les humains ont le droit de vivre de la même manière, qu'ils travaillent ou pas, bien ou mal, un peu ou beaucoup, ce qui n'est pas le cas. Il a le droit de gagner sa vie, mais pas aussi bien!

L'hôte N'est-ce pas de l'injustice?

Taylor Non, c'est simplement l'application du jeu de l'offre et de la demande ou du rapport qualité-prix : le caviar coûte plus cher que les ailes de poulet et personne ne trouve ça injuste !

L'hôte (Riant) Laissons les poulets de côté et retournons à nos moutons, les syndicats. Dans vos entreprises " taylorisées », les syndicats ont-ils négocié des conventions collectives ou réglé des griefs ? 
Taylor Jamais ! Ce n'était pas nécessaire: dans mon système, les ouvriers peuvent, sans encombre, discuter personnellement de leurs problèmes avec Li direction.

L'hôte En somme... vous n'êtes pas contre les syndicats ?

Taylor Je suis pour ce qu'ils ont de bon et contre ce qu'ils ont de mauvais.

L'hôte Comme vous disiez : pas poule mouillée mais tête froide !

Taylor Toujours : quand je mange des ailes de poulet, je n'avale pas les os; quand je regarde les syndicats, je n'avale pas la flânerie !

L'hôte (Riant) Encore ! Si je vous laisse aller nous aurons besoin d'un barbecue! Mademoiselle Follett, qu'est-ce que vous pensez des syndicats en général ?

Follett Comme monsieur Taylor, mon avis est partagé sur ce sujet : les syndicats recherchent le pouvoir égal parce qu'il leur permet une lutte juste, c'està-dire à forces égales ; or, je suis persuadée que le management et les relations de travail ne sont pas une affaire de lutte ni de combat, comme je vous l'ai déjà dit. Dans ce sens-là, je suis contre l'attitude des syndicats.

L'hôte Ce qui laisse sous-entendre que, d'un autre point de vue, vous êtes pour?

Follett Oui : le fait qu'ils représentent la totalité des employés nous donne une unité fonctionnelle qui permet de transformer une situation où l'on se dispute le pouvoir en une situation où les détenteurs de pouvoirs collaborent.

L'hôte Je ne vois pas très bien la différence ?

Follett Par définition, la collaboration permet une unification qui admet les différences mais élimine les combats. De sorte que les rencontres entre managers et employés ne se passent plus clans une atmosphère de combat mais de coopération.

L'hôte À condition que les managers eux-mêmes aient un esprit de coopération.

Follett C'est ce qu'ils doivent avoir! Autrement, ils sont dans la même position que le mari qui dit au psychiatre : « Ma femme et moi sommes en désaccord, je vous en prie, soignez-la !» 
L'hôte (Riant) Et pour en finir avec les syndicats, le point de vue de monsieur Fayol.

Fayol Oh, vous savez, je ne suis pas un expert en la matière : les syndicats n'étaient pas aussi puissants que maintenant quand je gérais la Commentry-Fourchamhault ! Mon point de vue ? Ils constituent une circonstance avec laquelle nous devrons continuer de composer tant qu'elle continuera d'exister !

L'hôte Composer, c'est-à-dire faire des concessions, mais n'est-ce pas admettre que vous n'aurez pas su prévoir, l'un de vos principes, et que vous vous adapterez aux événements?

Fayol Je sais, mais un autre de mes principes, que mademoiselle Follett m'a servi tout à l'heure, c'est qu'il faut être en harmonie avec les circonstances, c'est-à-dire savoir s'adapter à ce qu'on n'a pas pu prévoir.

L'hôte Voilà une arme à deux tranchants : étant donné que les managers ne sont pas des devins, toute prévision est aléatoire! Dans ce contexte, prévoir, qu'est-ce que ça signifie pour vous?

Fayol Dans n'importe quel contexte, prévoir, c'est à la fois supputer l'avenir et le préparer. Prévoir, c'est déjà agir.

L'hôte Une action qui se traduit par?

Fayol Un programme d'action.

L'hôte C'est tautologique!

Taylor (Éberlué) Hein ? C'est quoi ?

L'hôte Tautologique, t-a-u-t-o-logique.

Taylor Un autre animal ?

L'hôte Il me semblait que vous aviez appris le français !

Taylor J'ai appris le français, mais je ne suis pas un dictionnaire!

L'hôte Une tautologie est une évidence, une vérité de La Palice. Quand monsieur Fayol me dit qu'agir, c'est faire un programme d'action, je réagis : « tautologie ! ».

Fayol Attendez que je vous définisse «programme d'action»!

L'hôte C'est ce que nous attendons tous! 
Fayol Un programme d'action est à la fois le résultat visé, la ligne de conduite à suivre, les étapes à franchir et les moyens à employer. C'est la marche de l'entreprise prévue et préparée pour un certain temps.

L'hôte Et sur quoi vous basez-vous pour prévoir et préparer?

Fayol Sur les ressources de l'entreprise, la nature des opérations en cours et les possibilités d'avenir.

L'hôte Une autre tautologie : la prévision est basée sur les possibilités d'avenir !

Fayol (Impatient) Mais vous confondez tout!

L'hôte (Insolent) Déconfondez-moi !

Fayol (Résigné) Bon ! (Un temps pour retrouver ses esprits) Prévoir, c'est d'abord considérer les possibilités d'avenir qui dépendent des conditions techniques, commerciales, financières, etc. Ensuite, c'est établir un programme d'action qui infléchit les possibilités d'avenir suivant le ou les buts de l'entreprise. C'est dans ce sens-là que je dis que prévoir, c'est agir.

L'hôte Tracer un programme d'action doit être une tâche énorme !

Fayol En effet, c'est une des opérations les plus importantes et les plus difficiles de toute entreprise ; elle met en jeu tous les services et tous les cadres, particulièrement le chef de la direction.

L'hôte Pourquoi le chef de la direction plus que les autres ?

Fayol Parce que, pour remplir vraiment et complètement sa fonction, il doit prendre l'initiative du programme d'action et décider de la ligne de conduite de l'entreprise. Avant d'agir, il faut savoir ce qu'on peut faire et ce qu'on veut faire ; c'est pourquoi un programme d'action et un manager efficace sont indispensables à toute entreprise.

Weber Très juste : prévoir est important et les bureaucraties doivent s'y intéresser.

Follett Ce qui permet de créer la prochaine situation au lieu de la subir. 
Fayol (Rectifiant) D'essayer de la créer : les prévisions ne sont pas des prophéties. Elles ne font que réduire la part de l'imprévu : le programme d'action le mieux étudié ne se réalise jamais exactement.

Follett Oui, oui, je sais, mais il faut quand même toujours avoir un programme d'action, parce que le management est un procédé continu à l'intérieur duquel il faut prévoir les problèmes à venir ; cet exercice devrait d'ailleurs être facile puisqu'il répond à la passion innée chez l'homme de vouloir maîtriser l'avenir.

Fayol Il ne faut jamais oublier que c'est précisément quand les problèmes surviennent que le programme d'action est nécessaire. Il défend l'entreprise contre les fâcheux changements d'orientation que pourraient provoquer des événements extérieurs ou la versatilité des autorités supérieures.

Taylor Mais, la versatilité est une qualité !

Fayol Et vous n'êtes pas un dictionnaire!

Taylor Je sais bien : je l'ai dit plus tôt, mais qu'est-ce que ça vient faire ici?

Fayol En anglais « versatile» veut dire qui a des talents divers et nombreux.

Taylor Mais oui, c'est ce que j'ai voulu dire.

Fayol Mais en français, « versatile » veut dire qui change brusquement d'idée, qui est exposé à des revirements soudains ; c'est un synonyme de " changeant », « inconstant »; en somme, les gens versatiles sont des girouettes, ce qui est un défaut !

Taylor Donc, un programme d'action protège contre les patrons qui changent d'idée?

Fayol On ne peut rien vous cacher!

Taylor Merci pour la langue française!

Fayol Je vous en prie.

L'hôte Monsieur Fayol, si vous aviez à résumer l'aspect positif d'un programme d'action, que diriez-vous ?

Fayol Qu'il facilite l'utilisation maximale des ressources et le choix des meilleurs moyens pour arriver au but ; qu'il supprime ou réduit les hésitations, les fausses manœuvres et les changements injustifiés 
d'orientation. En somme, il accomplit deux choses : il détermine à la fois le but et les moyens de l'atteindre.

Follett Dans ce sens, la prévoyance et le programme d'action ne sont pas des prophéties, comme vous me l'avez si justement souligné plus tôt, mais des instruments de contrôle.

Fayol Exact : le contrôle ne regarde pas vers le passé mais vers l'avenir.

Follett Et le contrôle doit être un procédé continuel permettant aux managers de découvrir des principes qui les guideront dans les circonstances futures semblables à celles qu'ils auront observées.

Weber Le contrôle, c'est l'autorité, le pouvoir.

Follett Plus maintenant ! Cette notion répandue dans le monde des sciences politiques ne fait que semer la confusion.

Weber Vous croyez?

Follett J'en suis certaine et je ne suis pas la seule. Le monde du management l'a compris, et le contrôle ne s'exerce plus sur les hommes, comme dans votre temps, mais sur les faits.

Weber Le centre de contrôle, c'est l'autorité, le président-directeur général !

Follett Plus maintenant! Dans le management scientifique, le centre de contrôle est une expression technique qui indique le moment, ou l'endroit, où la connaissance et l'expérience se rencontrent et se penchent sur un problème ou sur un sujet donné.

Weber Et l'autorité, qu'est-ce qu'on en fait ?

Follett L'autorité, c'est autre chose ; il ne faut pas la confondre avec le contrôle qui, lui, n'est plus, comme dans votre temps, une affaire d'influence « sur » des subalternes, mais bien une question d'activités « entre » cadres clans un esprit de coordination. Le contrôle central n'est plus le point d'où émanent les directives et l'autorité, mais le lieu de rencontre des nombreux contrôles qui existent à travers toute l'entreprise.

L'hôte Vous nous avez fait une esquisse de ce qu'est le contrôle, je vous demande maintenant quels sont les principes du contrôle?

Follett C'est comme si vous me demandiez quels sont les principes d'une entreprise ! 
L'hôte Comment ça ?

Follett Parce que le but de l'entreprise, c'est le contrôle, on pourrait même dire que l'entreprise, «c'est » le contrôle.

L'hôte (Perplexe) Ah?

Follett Mais oui, autrement on en serait resté à l'artisanat! L'activité organisatrice est une activité directrice, et l'organisme a le pouvoir de s'autodiriger du simple fait qu'il est un organisme. (Idée soudaine) Tiens! une définition succincte du contrôle serait : le pouvoir d'un organisme de s'autodiriger.

L'hôte Et comment s'autodirige-t-il, ou se contrôle-t-il, puisque vous nous dites que c'est la même chose?

Follett Par la corrélation fonctionnelle de ses diverses parties.

L'hôte Voilà une réponse... énigmatique !

Follett Bon ! Je m'explique et je réponds du même coup à votre question antérieure au sujet des principes du contrôle. Les quatre principes du contrôle sont : 1) la coordination, 2) la coordination, 3) la coordination et $4) \ldots$

L'hôte _... la coordination!

Taylor Ça, c'est tautologique!

Follett (Riant) En effet! Et voulu! Pour capter votre attention. Je vous ai déjà dit toute l'importance que $\mathrm{j}$ 'accorde à la coordination. Eh bien! c'est elle qui assure le contrôle, et c'est pourquoi la coordination est la fonction la plus importante d'une organisation.

Taylor Bon, allez-vous enfin nous dire quelles sont vos quatre coordinations tautologiques?

Follett Avec plaisir : 1) la coordination ou l'action de relier tous les facteurs qui affectent une situation donnée ; 2) la coordination par contact direct entre tous les cadres responsables de ces divers facteurs ; 3) la coordination dès les premières étapes du projet ou du problème ; et 4) la coordination en tant que procédé continu.

Fayol Les autres principes sont clairs, mais pourquoi la coordination dès les premières étapes? 
Follett Pour éviter que chacune des personnes concernées n'adopte un point de vue définitif sans avoir ceux des autres. Cela évite des prises de bec souvent pénibles et rend un accord éventuel plus facile et plus probable. De plus, ce principe ne s'applique pas uniquement aux discussions internes : plusieurs entreprises l'utilisent avantageusement dans leurs pourparlers avec les syndicats.

L'hôte En résumé, le contrôle...?

Follett Repose sur des activités concrètes et sur leur interdépendance. Il ne consiste pas seulement à évaluer chaque facteur, mais surtout à établir la relation entre eux et les effets qu'ils ont les uns sur les autres. En guise de conclusion, je veux vous dire que bien des gens pensent, à tort, que la réponse au " laisser-faire » c'est la force et la coercition. La vraie réponse au « laisser-faire », c'est le contrôle qui n'est pas coercition, mais coordination.

L'hôte La coercition! monsieur Taylor, il y a encore des gens qui accusent votre système d'être coercitif et dictatorial...

Taylor Bon, ça recommence!

L'hôte Non, non, je ne vais pas vous faire de procès, mais il y a deux objections qui reviennent souvent et auxquelles vous devez bien avoir réponse ! Je veux simplement vous donner l'occasion de vous défendre durant les quelques minutes qui nous restent.

Taylor O.K. ! I am ready!

L'hôte Il y a des gens qui disent que vous avez chronométré le temps que prenaient les ouvriers pour faire leur travail, que vous l'avez trouvé trop long...

Taylor (Il le coupe, irrité.) Ils sont tous pleins de... (S'arrête, regarde Mary, puis se reprend.) Ils sont tous pleins de colle! Bien d'autres avant moi ont mesuré le temps que les hommes mettaient à faire leur travail... ce n'est pas à ce chapitre que se situe l'originalité de ma contribution.

L'hôte Alors vous, qu'est-ce que vous avez mesuré ?

Taylor J'ai étudié et mesuré le temps qu'un travail devrait prendre, ce qui n'est pas du tout la même chose!

L'hôte Et qu'est-ce que vous avez découvert? 
Taylor Mes recherches ont démontré qu'il $y$ avait bien des efforts et des mouvements inutiles. Elles ont fait la preuve que pour chaque étape de chaque métier il y a une méthode et un outil plus rapides et plus efficaces que n'importe quel autre.

L'hôte Et c'est ce que vous leur avez imposé !

Taylor Non, non, non, non, non! À ceux qui ont librement consenti, j'ai fourni les outils appropriés et j'ai enseigné la méthode la plus efficace pour faire leur travail.

L'hôte $\quad$ Avec le résultat que...

Taylor (Le coupe.) Les gars étaient ravis parce qu'ils faisaient à la fois moins d'efforts et plus d'argent, et ça, c'est ni de la coercition ni de la dictature!

L'hôte Bonne réponse, merci ! Deuxième objection: rendus là, les gars répétaient exactement ce que vous leur aviez enseigné, sans se servir de leur tête, comme des robots !

Taylor Comme des chirurgiens! qui durant leurs années d'études apprennent dans le menu détail chaque geste et chaque mouvement qui rendra leur travail le plus efficace possible selon les connaissances de l'art à ce moment-là ; exactement comme les ouvriers entrânés selon le management scientifique. Ça fait des chirurgiens numéro un qui ne se considèrent pas comme des robots, pas plus que mes hommes! Y'en a d'autres?

L'hôte $\quad$ Euh... peut-être, mais il ne reste plus de temps! Juste ce qu'il faut pour vous remercier tous les quatre d'avoir accepté de participer à nos deux rencontres (à la caméra) et pour vous dire, chers spectateurs, que nous espérons vous avoir fait apprécier nos invités à leur juste valeur et vous avoir donné le goût de mieux les connaître et de les lire. Je profite de l'occasion pour vous recommander de ne pas manquer les deux autres heures de rencontre avec quatre autres " Grands Esprits du Management » : Chester Barnard, Joan Woodward, Hyacinthe Dubreuil et Elton Mayo. Au revoir à tous ! 


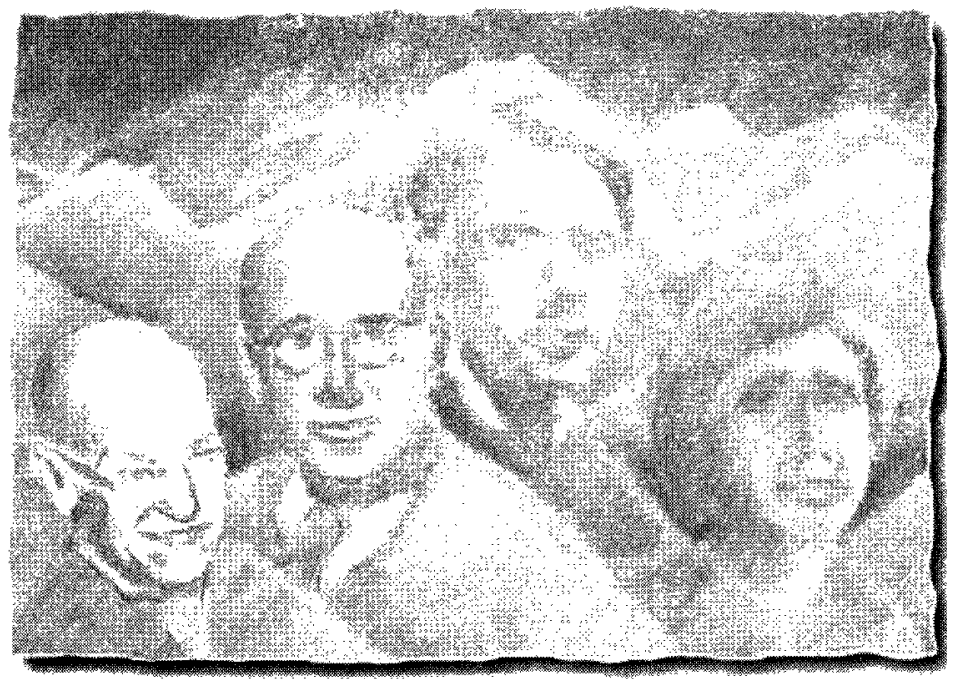

\title{
Rencontre avec
}

\author{
Hyacinthe Dubreuil \\ Joan Woodward \\ Chester Irving Barnard \\ George Elton Mayo
}

Troisième épisode

La présentation des invités - Les aspirations des travailleurs $\cdot$ La théorie et la pratique $\cdot$ La communication $\cdot$ L'organisation comme système coopératif - Les habiletés sociales et techniques - L'incident d'Hawthorne - La rémunération - La liberté du travailleur - L'effet des technologies sur les structures $-\mathrm{La}$ coopération $\bullet$ Le leadership $\bullet$ Les grèves $\bullet$ Les conditions de travail et l'enthousiasme des travailleurs.

\section{Quatrième épisode}

La décentralisation - Une nouvelle organisation du travail - En faveur de nouveaux administrateurs - L'organisation comme système coopératif - Différentes approches à l'étude des organisations • Les qualités d'un cadre • Sur les façons d'acquérir des connaissances à propos (les organisations $\bullet$ À propos du progrès - De l'État et de la démocratie - L'exercice de l'autorité - La moralité et la responsabilité des cadres $\bullet$ La prise de décision $\bullet$ La théorie de la contingence $\bullet$ «Les mots de la fin ». 



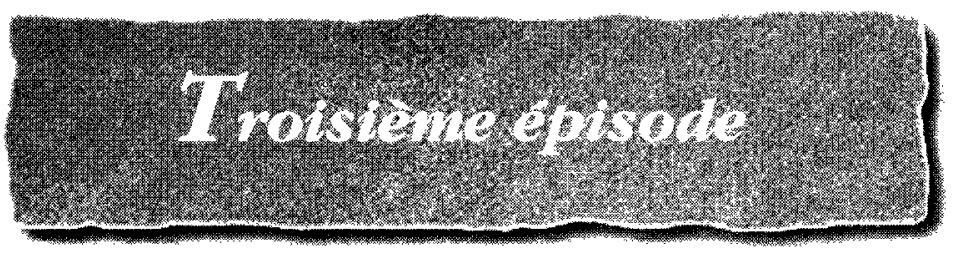

L'hôte arrive par l'allée faisant face à son fauteuil, s'y rend et, une fois les applaudissements terminés, salue la foule.

L'hôte Bonjour et bienvenue à ce troisième épisode des « Grands Esprits du Management ». (Un temps) Est-ce qu'il $y$ en a parmi vous qui n'ont pas vu les deux premiers épisodes?

(Temps, puis il enchaîne avec humour à condition qu'il y ait des bras levés.) Un bon conseil: empressez-vous de les regarder ! Vous allez bien vous amuser en plus d'apprendre un tas de choses intéressantes. Nous vous faisons rencontrer des gens que vous allez côtoyer durant vos études en management et probablement durant toute votre vie. Notre but? Vous familiariser avec eux, vous les faire connaitre, vous les faire aimer, vous rendre curieux à leur sujet, vous donner le goût de les lire pour les connaître à fond.

Dans les deux premières heures de cette série, nous vous avons présenté des pionniers du management aujourd'hui et dans l'épisode suivant, nous allons nous rapprocher sensiblement de notre époque pour rencontrer des « Grands Esprits » du management qui ont œuvré surtout durant le $\mathrm{XX}^{\mathrm{e}}$ siècle.

(Il prend une feuille et lit.) Le premier de nos invités, Hyacinthe Dubreuil, est né en 1883 à Bérou la Mulotière, en Eure-et-Loire, (à la caméra) une commune si petite que son nom n'apparaît même pas dans le Petit Robert! Pour les mordus de géographie, disons que c'est à l'ouest du bassin parisien, vaguement dans l'axe Paris-Chartres. 
(Retour aux feuilles) Ouvrier et syndicaliste, Hyacinthe Dubreuil a travaillé sur tous les plans de l'action syndicale, beaucoup écrit, séjourné quinze mois aux États-Unis en 1927-1928, été fonctionnaire au Bureau international du travail à Genève de 1931 à 1938 et fut durant les trentetrois dernières années de sa vie, consultant et conférencier spécialisé dans tout ce qui avait trait au travail, un consultant recherché par tous les milieux, même gouvernementaux. (Il pose ses feuilles.) Mesdames et messieurs, Hyacinthe Dubreuil.

Il se lève pour l'accueillir. Dubreuil arrive par l'allée à la gauche de l'hôte. se dirige vers lui, puis se retourne vers le public.

Dubreuil Bonjour. (Un temps, puis avec solennité) L'ouvrier n'a qu'une propriété, celle de son métier!

Il se retourne vers l'hôte et lui serre le main.

L'hôte Bonjour monsieur Dubreuil et bienvenue aux « Grands Esprits du Management ».

Dubreuil Bonjour monsieur... (II regarde autour de la table.) Sont pas nombreux vos Grands Esprits ! (ils rient.) 
L'hôte Faites-moi confiance, ça va venir! (Il lui indique son fauteuil.) Je vous en prie, asseyez-vous.

Les deux s'assoient.

Dubreuil Ah! quel plaisir de revenir en Amérique et surtout de pouvoir y parler français !

L'hôte Parce qu'aux États-Unis, vous parliez anglais.

Dubreuil Je n'avais pas le choix ! Mais avant de le parler, j'ai dû l'apprendre et je vous assure qu'apprendre l'anglais à 43 ans, c'est pas de la tarte!

L'hôte Vous ne l'aviez pas appris à l'école?

Dubreuil Hélas! non. De toute façon, j'ai quitté l'école à 14 ans !

L'hôte Quatorze ans! Ce n'est pas vieux!

Dubreuil En effet, mais je ne pouvais faire autrement: clans sa vie, mon père a eu trois emplois : le premier, manœuvre dans une fonderie, le deuxième, chômeur, et le troisième, palefrenier dans une auberge. Étant donné les salaires de famine que payent ces illustres emplois, le deuxième surtout, à 14 ans, il a fallu que je gagne ma vie.

L'hôte Qu'est-ce que vous avez fait?

Dubreuil D'abord, j'ai été apprenti !

L'hôte En quoi?

Dubreuil En bien des choses : en mécanique, en fabrication d'automobiles à vapeur, en fabrication d'obus pour la marine, comme chauffeur de chaudière de machines à vapeur et enfin, comme tourneur clans une usine de mécanique.

L'hôte Quel métier avez-vous finalement choisi ?

Dubreuil Mécanicien, et c'est en tant que tel que je me suis syndiqué.

L'hôte Une chose m'intrigue : vous n'avez complété que vos études primaires, ensuite vous avez fait vos nombreux apprentissages, puis vous vous êtes mis à travailler comme mécanicien ; comment diable êtes-vous devenu écrivain?

Dubreuil En livrant mes batailles syndicales.

L'hôte Contre les patrons ! 
Dubreuil Non ! contre la gauche syndicale. Au début du siècle, il y avait une guerre féroce entre les deux ailes de la grande centrale syndicale française dont je faisais partie. Pour exposer et défendre les idées de la droite, dont j'étais, je me suis mis à écrire dans La Bataille syndicaliste, le quotidien que publiait la centrale.

L'hôte Et vous êtes devenu journaliste !

Dubreuil Pour commencer, oui. J'ai écrit pour des journaux et des revues, puis au cours des ans, j'ai fait publier plusieurs bouquins.

L'hôte Et vous êtes devenu l'ami de plusieurs écrivains, entre autres de Paul Claudel dont l'éditeur vous a demandé d'écrire la préface et des notes pour son ouvrage intitulé Qui ne souffre pas?

Dubreuil En effet; ce fut un grand honneur.

L'hôte Vous étiez devenu l'« intello » du syndicalisme !

Dubreuil Que non! J'ai vertement critiqué les intellectuels !

L'hôte Ah tiens! Pourquoi?

Dubreuil À cause de leur trop grande influence sociale.

L'hôte Elle est pourtant souhaitable!

Dubreuil Parfois oui, mais je n'admets pas qu'ils se mêlent de vouloir régler le sort et la vie des ouvriers sans avoir jamais partagé leur misère quotidienne, sans avoir jamais mis les pieds dans une usine.

L'hôte Les syndicats s'ingénient à mettre en évidence et souvent à exagérer la misère des ouvriers.

Dubreuil C'est faux ! Ce sont les ouvriers eux-mêmes qui s'en plaignent. Par exemple, lors d'une grève à Chicago en 1910, des piqueteurs portaient des pancartes qui disaient : « Nous voulons du pain, et aussi des fleurs. »

L'hôte (Pas convaincu) 1910 ! Vous remontez loin!

Dubreuil L'ouvrier d'aujourd'hui a lui aussi besoin de fleurs ; il a droit au bonheur, à la joie clans son travail autant que celui de $1910 \ldots$ et autant que son patron!

L'hôte Votre obstination à réclamer la joie pour les ouvriers est bien connue et nous en reparlerons tout à l'heure... 
Dubreuil (Il le coupe, très sûr de lui.) Avec plaisir !

L'hôte ... $\quad$ mais pour le moment, il est temps de combler (montrant la table) ce vide de Grands Esprits que vous avez souligné plus tôt et de présenter notre prochaine invitée.

L'hôte (À la caméra) Les notices biographiques de Joan Woodward donnent l'impression qu'elle a été créée et mise au monde pour occuper les sièges des maisons d'enseignement.

(Il prend une feuille et lit.) Après ses études primaires et secondaires, elle complète, à 19 ans et avec distinction, ses études en politique, en philosophie et en économie aux universités de Durham et d'Oxford. À 21 ans, elle obtient sa maîtrise en philosophie médiévale et à 22 ans, son diplôme d'Oxford en administration sociale et publique. Ses 22 ans coïncident avec le début de la Deuxième Guerre mondiale durant laquelle elle se consacre à divers postes administratifs dans la fonction publique. Sitôt la guerre finie, elle commence une carrière d'enseignante et de chercheuse qui la mène aux universités de Liverpool, d'Oxford et finalement à l'Imperial College de Londres où elle devient la deuxième femme à obtenir le titre de professeur et la première à diriger la nouvelle faculté de sociologie industrielle. Très active, en plus d'enseigner et de faire de la recherche, elle a fréquemment répondu à l'appel du gouvernement britannique qu'elle a conseillé sur des sujets aussi divers que les postes, l'emploi, la productivité, les prix et salaires, l'administration des hôpitaux et des établissements industriels de l'État. Ceux qui l'ont connue de près s'accordent à vanter son vif esprit analytique, sa créativité, son humanité envers les étudiants et sa modestie qui n'était pas une marque de faiblesse mais de dignité. (Il pose ses feuilles.) Mesdames, messieurs, Joan Woodward!

Il se lève de même que Dubreuil. Elle entre par l'allée à la droite de l'hôte, s'avance jusqu'à la table, salue le public puis tend la main à l'hôte. 


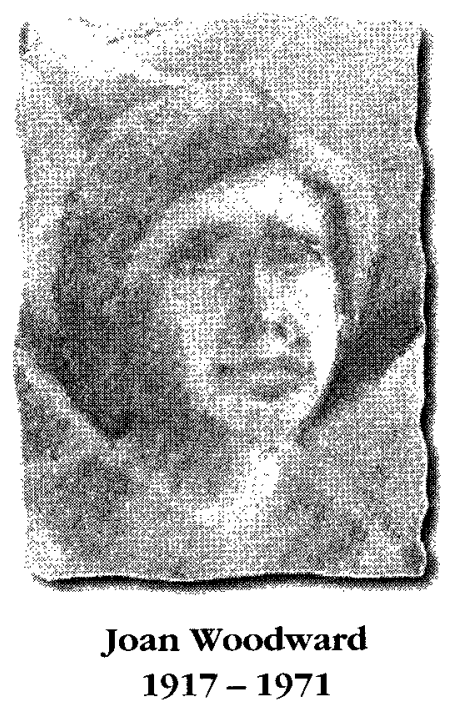

Woodward Bonjour monsieur (nom de l'hôte)

L'hôte Bonjour madame Woodward, soyez la bienvenue parmi nous.

Woodward Merci. (Elle se tourne vers Dubreuil souriante.) Monsieur Dubreuil.

Dubreuil Madame Woodward, je suis ravi de rencontrer une femme aussi charmante que vous, même si vous êtes une universitaire.

L'hôte tire sa chaise et dit rapidement pour tenter d'éviter la prise de bec.

L'hôte Veuillez vous asseoir.

Elle s'assoit puis Dubreuil et l'hôte en font autant.

Woodward Monsieur Dubreuil, je constate que vous n'êtes pas très porté vers les universitaires. Complexe d'infériorité ou jalousie?

Dubreuil Ni l'un ni l'autre madame, je suis autodidacte et je ne regrette absolument pas de ne pas avoir de doctorat. (Un temps) Vous êtes-vous déjà dit qu'il y a certainement eu des hommes intelligents avant qu'il y ait des livres ?

Woodward Euh... non, mais c'est sûrement vrai.

Dubreuil Et saviez-vous qu'Anatole France a dit qu'il est probable que l'humanité ignore les plus grands génies qu'elle a eus parce que ces génies ont négligé d'écrire.

Woodward (Souriant) Ce qui n'est pas votre cas ! 
Dubreuil J'ai écrit oui, mais avant d'écrire, j'ai travaillé, et le travail est une sorte de grand livre ; plus : le travail est une véritable université où l'on s'entraîne intellectuellement; (humour) c'est pourquoi l'on découvre avec étonnement qu'il y a des intellectuels qui s'ignorent !

Woodward Vous avez raison et c'est précisément pour ça que j'ai innové à l'Imperial College de Londres en exigeant que l'étude de cas réels dans les usines fasse partie des cours universitaires et complète l'enseignement traditionnel.

Dubreuil Donc, vous reconnaissez qu'il y a des lacunes dans l'enseignement universitaire?

Woodward Bien sûr, et dans ce sens je compare l'enseignement universitaire à la médecine.

L'hôte À la médecine?

Woodward Mais oui ! En médecine, alléger les symptômes est utile, mais ce n'est qu'après un diagnostic que le médecin est certain de recommander le bon traitement. Or, pour poser un diagnostic, il faut voir le patient, l'étudier, faire des analyses. Pour soigner une organisation, c'est la même chose : il ne suffit pas d'alléger les symptômes, il faut aller dans les ateliers voir le patient, l'examiner et analyser systématiquement toutes les conditions dans lesquelles il vit.

Dubreuil Alors nous sommes sur la même longueur d'onde! Il manque quelque chose aux uns et aux autres. Ceux qui n'ont reçu que l'éducation universitaire se basent sur des notions abstraites et arbitraires, tandis que ceux qui n'ont reçu que l'éducation du travail ont une vision des choses qui reste trop bornée et terre à terre, due à cette espèce d'exagération du sens pratique que leur donne le contact des choses de l'atelier.

Woodward D'accord, et c'est pourquoi j'ai décidé que notre enseignement ne serait pas confiné aux salles de cours, mais enverrait nos étudiants apprendre sur les lieux mêmes de l'action: dans les ateliers. (Sourire) Et voilà notre première querelle réglée... parce que nous nous sommes parlé.

Dubreuil Et compris !

Woodward En somme, parce que nous avons communiqué. 
L'hôte La communication! Un sujet extrêmement important en management et sur lequel notre prochain invité s'est longuement penché. Je m'en voudrais de l'aborder en son absence. (À la caméra) Je vais donc vous le présenter dès maintenant. Chester Barnard est l'auteur d'un des livres les plus cités dans l'étude des organisations: The Functions of the Executive. Malgré sa popularité et le fait qu'il fut publié en 1938, ce livre, hélas! n'a pas encore été traduit en français, en tout cas pas à notre connaissance. Deux choses intéressantes à noter au sujet de ce livre : il est précédé de la dédicace suivante : (Il prend un livre sur la table, trouve la page et lit.) " À mon père qui m'a appris dans ma jeunesse la sagesse de choisir : essayer et faillir, c'est au moins apprendre ; faillir d'essayer, c'est subir l'inestimable perte de ce qui aurait pu être. " (À la caméra) Il est également précédé, en exergue, d'un extrait de la Métaphysique d'Aristote qui commence ainsi (Il tourne une page du livre, puis lit) : " L'efficacité d'une armée vient en partie de l'ordre et en partie de son général ; mais surtout de ce dernier parce qu'il ne dépend pas de l'ordre tandis que l'ordre dépend de lui. » (À la caméra) Voilà qui donne une idée du personnage et de sa pensée ; pour le reste, nous allons le laisser dire lui-même ce qu'il voudra bien nous dire. Mesdames et messieurs, Chester Barnard.

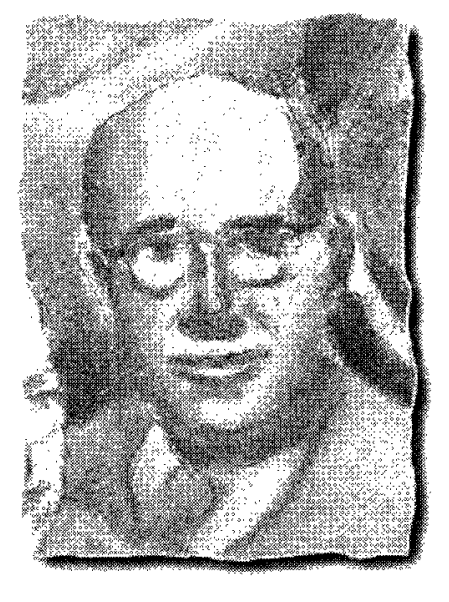

\section{CHESTER IRVING BARNARD}

$1886-1961$ 
L'hôte et Dubreuil se lèvent mais Woodward reste assise. Barnard entre par l'allée à la gauche de l'hôte, vient vers lui, lui tend la main.

Barnard Bonjour monsieur (nom de l'hôte)

L'hôte Bonjour monsieur Barnard, votre présence ici nous honore.

Il se retourne vers le public qu'il salue.

Barnard Merci. Mesdames, messieurs! (puis aux deux autres invités) Mrs. Woodward, I am pleased to meet you!

Woodward How do you do?

Barnard (Lui tendant la main) Monsieur Dubreuil, ravi de faire votre connaissance.

Dubreuil Moi de même.

L'hôte (Il lui indique son fauteuil, voisin de celui de Dubreuil.) Je vous en prie.

Les trois hommes s'assoient.

Monsieur Barnard, avant de deviser sur les communications, un de vos thèmes préférés, parlez-nous de vos origines, de votre jeunesse.

Barnard Je suis né à Malden, au Massachusetts, dans une famille modeste. Mon père était machiniste et c'est lui qui nous a élevés, mon frère et moi, après la mort prématurée de ma mère.

L'hôte Sévèrement ?

Barnard Non, intelligemment! Il nous a inculqué l'indépendance d'esprit, le pragmatisme, le respect de l'individu et l'industrie... euh... industrie dans le sens d'habileté à exécuter quelque chose.

L'hôte Comme tous les petits Américains, vous avez dû apprendre tôt à jouer au baseball et au football!

Barnard Encore une fois, non! (Il pointe vers ses lunettes.) Je suis né myope, ce qui rendait mon sens de l'équilibre précaire ; mes activités sportives et physiques étaient donc forcément limitées.

L'hôte Alors, comment le petit Chester s'est-il amusé ?

Barnard En devenant très tôt avide lecteur et pianiste.

L'hôte Un petit élève modèle !

Barnard Disons plutôt appliqué et très intéressé. 
L'hôte Votre père vous a fait poursuivre de longues études?

Barnard Il m'a encouragé à les poursuivre, mais il n'avait pas les moyens de me les payer.

Dubreuil Qui vous les a payées?

Barnard Je les ai gagnées moi-même!

Dubreuil Bravo! Comment?

Barnard Mes études collégiales, en travaillant sur la ferme du collège, et mes études universitaires, en tapant des thèses pour mes aînés et en dirigeant un orchestre de danse.

Woodward On dit que vous étiez un amateur de jazz, est-ce vrai ?

Barnard Oui et aussi de musique classique : plus tard dans ma vie, c'est moi qui ai fondé la Bach Society du New Jersey.

L'hôte C'est à Harvard, je crois, que vous avez terminé vos études et obtenu votre diplôme en économie?

Barnard Oui et non : c'est à Harvard que j'ai terminé mes études, mais je n'y ai complété que trois ans et je n'ai pas eu mon diplôme.

Dubreuil Manque d'argent?

Barnard Non, manque de chimie !

Dubreuil De chimie?

Barnard Durant mes études antérieures, je n'avais pas fait beaucoup de sciences et la chimie était une matière obligatoire pour obtenir une licence en économie ; donc pas de diplôme !

L'hôte Peut-être, mais plus tard vous avez obtenu toute une série d' honoris causa!

Barnard En effet, mais mon vrai diplôme, je l'ai eu d'une manière ardue (à Woodward) : I earned it. (À l'hôte) Je l'ai «gagné » dans le monde des affaires.

L'hôte À la Bell Telephone.

Barnard Oui. J'y suis entré à 23 ans, en 1909, au département des statistiques où j'ai étudié les tarifs internationaux, ce qui m'a permis d'apprendre le français, l'allemand et l'italien.

L'hôte Encore des études ! 
Barnard Je ne m'en plaignais pas, ça m'a été très utile dans la vie... et encore aujourd'hui, ici même !

L'hôte Et ensuite, à la Bell ?

Barnard J'ai lentement monté en grade : adjoint au vice-président et directeur général en Pennsylvanie en 1922, vice-président au même endroit en 1926, puis président de Bell, New Jersey, de 1928 à 1948.

Woodward Toute votre carrière à la Bell Telephone, pas étonnant que vous vous soyez penché sur la communication!

Barnard Merci madame de changer de sujet ; il y a déjà trop longtemps que monsieur (nom de l'hôte) me fait parler de moi !

L'hôte D'accord, mais vous allez quand même continuer de parler puisque je vais vous demander de nous dire ce que sont les communications dans une organisation.

Barnard Pour bien le comprendre, il faut d'abord comprendre ce qu'est une organisation.

L'hôte Qu'est-ce qu'une organisation, cher Aristote?

Barnard Aristote?

L'hôte Mais oui, on a dit de vous que vous étiez l'Aristote du management !

Barnard C'est trop d'honneur ! (Temps) Une organisation est un système d'activités coopératives consciemment coordonnées, composé d'au moins deux personnes ; pour qu'une organisation puisse exister, il faut que les personnes qui en font partie 1) soient capables de communiquer entre elles ; 2) consentent à mettre leurs talents à contribution ; et 3) qu'elles visent un but commun.

Woodward Vous faites des communications une condition de l'existence d'une organisation, mais vous ne nous dites pas ce qu'elles sont!

Barnard Patience, j’y viens ! Dans toute organisation, il doit y avoir un système de communication, (à Woodward) et en voici la définition : un système de communication est un système d'autorité formelle.

Woodward C'est plutôt vague ! 
Barnard Encore une fois, patience, j'y viens ! Voici comment ce système doit fonctionner :

1. les canaux formels de communication doivent être connus de tous ;

2. ces canaux doivent rejoindre chacun des membres de l'organisation ;

3. la ligne de communication doit être aussi directe et aussi courte que possible ;

4. une information doit, en principe, circuler en empruntant toute la ligne de communication ;

5. les personnes en autorité qui agissent comme centres de communication doivent être qualifiées et adéquatement choisies ;

6. la ligne formelle de communication ne doit pas être interrompue ; et

7. chaque communication doit être authentifiée.

L'hôte Authentifiée?

Barnard Authentifier une communication, c'est donner à celui qui la reçoit l'assurance qu'elle est vraiment de l'auteur auquel on l'attribue et la certitude que son autorité et sa vérité ne peuvent être contestées.

L'hôte Pourquoi les communications sont-elles si importantes?

Barnard Parce que la possibilité que des personnes diverses atteignent un but commun repose sur la communication. Les techniques de communication déterminent la structure, l'étendue et la portée de l'organisation.

Mayo entre par l'allée à la droite de l'hôte et, tout en s'avançant vers la table.

Mayo Non, non, non ! C'est tout à l'envers !

Barnard (Éberlué) Pardon?

Mayo Vous commencez par la fin, mon pauvre Chester.

Barnard Que voulez-vous dire? 


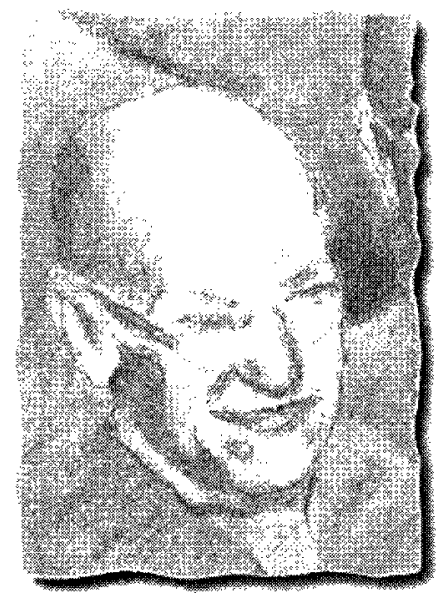

GEORGE ELTON MAYO

$1880-1949$

L'hôte Monsieur Mayo, avant de continuer, je voudrais...

Mayo Ne m'interrompez pas ! Vous m'avez déjà oublié trop longtemps dans les coulisses. Je vais répondre à monsieur Barnard et quand j'aurai terminé, vous parlerez!

Il s'assoit à côté de Woodward.

L'hôte Je ne voulais que vous présenter !

Mayo Plus tard! ('̇ Barnard) Ce que je veux dire, c'est qu'avant d'être une fonction des organisations, les communications sont à la base du talent social, elles font partie de la vie quotidienne de tous les humains !

Barnard Je ne le nie pas !

Mayo Non, mais vous ne le dites pas non plus !

Barnard Parce que ce n'était pas mon propos, mais passons, et puisque vous êtes là, dites-nous ce que vous entendez par le talent social.

Mayo Le talent social s'oppose au talent technique ; l'équilibre entre ces deux talents permet à l'individu de conserver sa santé mentale, ce qui est une réussite en soi. 
Barnard Je veux bien, mais je ne sais toujours pas ce qu'est le talent social!

Mayo Je vais d'abord vous définir ce qu'est le talent technique.

Barnard Je n'ose pas m'obstiner avec vous, mon cher Elton!

Mayo Le talent technique est la capacité pour les humains de manipuler des objets qui leur permettent d'atteindre leurs buts. Le talent social, lui, est la capacité de recevoir des communications d'autrui, de réagir aux idées et aux attitudes des autres de façon à promouvoir une participation agréable à la tâche commune. Or, l'éducation moderne met l'accent sur le développement du talent technique !

Woodward Il n'y a rien de mal à ça.

Mayo Au contraire, amis, il serait préférable que l'on accorde tout autant d'importance au talent social. On doit enseigner aux étudiants que le talent social commence par l'art de provoquer et d'entretenir des communications avec les autres.

Barnard Si on le faisait, qu'est-ce que ça donnerait ?

Mayo Quand on le fera, les idées et les attitudes communiquées formeront la base d'une compréhension plus vaste, plus efficace. Habitués à communiquer, les gens comprendront mieux les ordres émis par votre système de communication et la paix régnera dans la société et dans les organisations.

Dubreuil Je suis d'accord, monsieur Mayo, mais ce que je ne comprends pas, c'est ce qui nous vaut votre mauvaise humeur.

Mayo (Il regarde l'hôte puis Dubreuil.) Si on vous avait laissé poireauter en coulisses comme ce fut mon cas, vous comprendriez facilement mon humeur. Mais passons, et dites-moi plutôt pourquoi vous êtes d'accord avec mes propositions.

Dubrenil Parce que je crois qu'il vaut mieux dialoguer que discuter.

Mayo Y a-t-il une différence entre ces deux termes ?

Dubreuil Il y a au moins une nuance : « dialoguer » signifie qu'au lieu d'adopter le ton polémique de la discussion, on est disposé à examiner les raisons que l'on pourrait avoir de s'entendre. Mais continuez donc avec vos deux talents ! 
Mayo Le déséquilibre entre le développement du talent technique et celui du talent social a été désastreux pour la société.

Dubreuil Comment ça ?

Mayo Parce que ce déséquilibre affecte autant les États que les sociétés et les organisations ; si le talent social du monde avait avancé au même rythme que son talent technique, il n'y aurait pas eu de Deuxième Guerre mondiale.

Barnard (Pacifique) C'est un point de vue !

Mayo (Un tantinet agressif) Valable, non ?

Barnard (Toujours serein) Pourquoi pas!

L'hôte (Il regarde Mayo un moment pendant que personne ne parle.) Maintenant que monsieur Mayo a réglé le sort du monde...

Mayo J'aurais bien voulu!

L'hôte (Il continue.)... je vais enfin vous le présenter. (Il prend une feuille et lit.) George Elton Mayo est né en 1880 à Adélaïde, en Australie, le deuxième enfant et l'aîné des garçons d'une famille de sept enfants. Après des études primaires et secondaires brillantes, il entre à l'Université d'Adélaïde en médecine. Il trouve la routine des études médicales ennuyeuse et...

Mayo (Il le coupe.) Soporifique ! Insupportable ! À un tel point que j'ai quitté l'université.

L'hôte (Il abandonne sa feuille.) Mais ça ne vous a rien donné : vos parents vous ont envoyé étudier la médecine à Londres.

Mayo Ça ne leur a rien donné non plus : j'ai encore quitté !

L'hôte Qu'est-ce que vous avez fait?

Mayo Euh ! j'ai tâté du journalisme, de l'enseignement, je cherchais.

L’hôte Qu'est-ce que vous avez trouvé ?

Mayo Rien ! Alors je suis retourné à Adélaïde où je suis devenu copropriétaire d'une imprimerie, mais les affaires n'étant pas mon affaire, je suis retourné à l'Université d'Adélaïde.

Dubreuil (Blagueur) Pas en médecine?

Mayo Certainement pas ! En philosophie et en psychologie. 
L'hôte (Il consulte, réfère à sa feuille.) Après avoir obtenu votre maîtrise, vous avez enseigné la logique, l'éthique et la psychologie, puis le pays a requis vos services durant la Première Guerre mondiale.

Mayo Exact, et c'est là que j'ai vraiment trouvé ma voie. J'étais en charge de la psychothérapie des soldats traumatisés. L’expérience et les idées que j'ai acquises durant mon stage avec les militaires ont orienté le reste de ma vie et de mes travaux.

L'hôte (Toujours la feuille) On vous confie la nouvelle chaire de philosophie à l'Université du Queensland, puis en 1922, à 42 ans, vous émigrez aux États-Unis...

Mayo Où je voyais la possibilité d'approfondir mon étude des problèmes sociaux et industriels.

L'hôte Vous avez été recueilli par l'Université Harvard et ce fut le début de la période la plus glorieuse de votre carrière, la publication de vos trois célèbres livres qui traitent tous de la civilisation industrielle...

Mayo Oui, bon. On ne va pas s'étendre là-dessus, que les gens les lisent!

L'hôte $\quad$... et votre légendaire recherche à l'usine Hawthorne de la Western Electric.

Mayo Comme c'est mon intervention la plus célèbre, je veux bien en dire quelques mots. Au fait, monsieur (nom de l'hôte), quel effet croyezvous qu'a l'éclairage sur la productivité au travail ?

L'hôte Je dirais qu'un bon éclairage est susceptible de favoriser la productivité.

Mayo C'est une position logique et c'est elle qui avait incité une célèbre compagnie d'ampoules électriques à faire leur promotion dans diverses entreprises. Pourtant, des chercheurs qui voulaient valider cette relation entre l'éclairage et la productivité observèrent que, dans certains cas, la productivité augmentait malgré une diminution de l'éclairage !

L'hôte Il devait bien y avoir une explication ?

Mayo Ça va de soi, il y a toujours une explication. Encore faut-il la découvrir!

L'hôte Ce que vous avez fait, bien sûr! 
Mayo En effet.

Dubreuil Et quelle est cette explication?

Mayo Eh bien ! que les humains ne sont pas des êtres primaires qui réagissent simplement et toujours de la même façon à des stimuli externes. Ainsi, dans cette usine de la Western Electric, nous avons pu vérifier que, fiers (l'être les sujets d'autant d'attention, d'intérêt de notre part, les ouvriers ont réagi en augmentant leur productivité, et cela, nonobstant l'intensité de l'éclairage.

Woodward Au sujet de cette recherche, je tiens à mentionner qu'elle a confirmé la grande utilité des sciences sociales dans l'étude et l'analyse du comportement en milieu organisationnel.

Mayo Oui, et il était temps que cela se produise !

L'hôte $\quad$ Merci madame, merci monsieur Mayo. Maintenant...

Mayo (Le coupe) Avant de vous laisser passer à autre chose, je tiens à vous dire que je suis heureux de me retrouver au Québec.

L'hôte Ce n'est pas votre première visite ici ?

Mayo Non, j'ai donné en janvier 1945, à l'Université McGill, une conférence intitulée «Supervision and What It Means » dans le cadre de la série « Studies in Supervision ». L'hospitalité québécoise est aussi chaleureuse que dans le temps et je suis heureux de m'y retrouver. (À la caméra) Merci Québec!

L'hôte Merci à vous ! Le ministère du Tourisme sera ravi ! (À la caméra) J'ai promis à monsieur Dubreuil que nous reparlerions de la joie pour les ouvriers, un idéal qui a inspiré toute sa vie syndicale et sa vie d'auteur.

Dubreuil Je veux introduire dans le travail moderne des éléments qui rendent la vie digne d'être vécue : la joie, la poésie, la beauté.

L'hôte Qu'est-ce qui constitue la joie pour l'ouvrier selon vous ?

Dubreuil La joie, la vraie joie, est la joie qui découle directement du travail, de l'effort et qui apporte une récompense et une satisfaction immédiates et permanentes.

Woodward Vous voulez dire le plaisir?

Dubreuil Non, non, le plaisir n'est qu'un artifice imaginé par la nature pour assurer la conservation de la vie. La joie, elle, annonce que la vie 
a réussi, qu'elle a remporté une victoire: toute grande joie a un accent triomphal. Partout où il y a joie, il y a création; plus riche est la création, plus profonde est la joie !

Barnard Vous n'êtes pas syndicaliste, vous êtes philosophe !

Dubreuil Le philosophe ce n'est pas moi, c'est Henri Bergson à qui j'ai emprunté ces pensées.

Mayo Il n'est pas philosophe, il est psychologue : il a reconnu, comme moi, l'ennui, la lassitude qui assaille l'ouvrier moderne soumis à la monotonie, à la répétition perpétuelle des mêmes gestes.

Dubreuil Là, vous avez raison!

L'hôte Vous devez bien avoir un moyen pour sortir l'ouvrier de l'ennui et lui donner la joie?

Dubreuil Oui : éliminer les salaires !

L'hôte Quoi?

Barnard Ça n'a pas de sens !

Mayo Communiste !

Woodward Utopie!

Dubreuil Mais laissez-moi donc m'expliquer !

Mayo Ça s'impose !

Dubreuil Le salaire est, en somme, un louage de services et, en tant que tel, il ne fait qu'assurer la survivance de l'esclavage. D'autre part, il repose sur une erreur qui consiste à réclamer une quantité infinie, l'activité de l'ouvrier, en échange d'une quantité finie, le salaire.

Barnard Comment proposez-vous de remédier à cette erreur ?

Dubreuil Au lieu de fixer une valeur au temps de l'ouvrier, il faut fixer une valeur au produit à créer...

Woodward (Scandalisée) C'est le salaire à la pièce !

Dubreuil Pas du tout !

Mayo (Mordant) Vous avez dû étudier chez les jésuites !

Dubreuil (Pris au dépourvu) Euh ! Comment ça ?

Mayo (Encore mordant) Établir le salaire à partir du produit créé est la hase même du salaire à la pièce ; seul un jésuite oserait le nier. 
Dubreuil Ça dépend des circonstances dans lesquelles on établit ce critère !

Mayo (Toujours mordant) De plus en plus jésuite!

Dubreuil (À Mayo) Je reviendrai sur les circonstances (retour à Barnard), mais je veux ajouter qu'en établissant cette règle, on redonne à l'ouvrier sa dignité.

Barnard (Doutant) Ah ! comment?

Dubreuil Ce n'est plus l'individu qu'on surveille mais la matière, c'est-à-dire le produit du travail ; ses actes et sa personne ne font plus l'objet d'une inspection et d'une surveillance dégradantes, il est maître de son temps et son rendement n'en est que meilleur, parce que l'homme qui se fait le serviteur d'un autre ne donne jamais tout l'effort dont il est capable !

Mayo (Toujours mordant) Et vos circonstances... jésuistiques?

Dubreuil C'est dans la liberté totale qu'on trouve la plus haute expression du travail en même temps que le rendement optimum. La liberté est le moteur de l'activité et de la créativité. L'effort le plus efficace est celui qui est donné clans la liberté par tous ceux qui agissent de leur propre gré.

Woodward Par exemple?

Dubreuil Les alpinistes, les navigateurs à voile, les sportifs, les artistes, les paysans et (Il pointe l'index vers le haut)... les employeurs ! Tous motivés par l'espoir et la chance! Placé entre la crainte de perdre et l'espoir de gagner, l'homme a toujours donné son effort maximum. La marge d'espoir, que ne donne pas le salaire, est le secret de l'activité de l'employé.

Woodward C'est très matérialiste !

Dubreuil Très humain : plusieurs ouvrages sur le travail et le travailleur suggèrent qu'un de ses principaux besoins est celui de se réaliser, c'est-à-dire d'utiliser son potentiel pour conquérir quelque forme d'indépendance. « Il faut donner au travailleur la chance de changer la besogne en œuvre, la profession en vocation, car la meilleure récompense de l'homme est du domaine de l'esprit », a dit je ne sais plus qui.

Barnard En somme, vous voudriez que les ouvriers deviennent des patrons? 
Dubreuil Exact! Il faut qu'ils sortent de la position d'exécutants passifs et qu'ils aient des responsabilités. Il faut leur dire : «Vous êtes libres d'appliquer vos facultés inventives à votre travail et d'en transformer l'exécution à votre convenance, à condition, bien entendu, que ce soit dans le sens du progrès. »

Woodward Ces messieurs avaient tort : vous n'êtes ni philosophe ni psychologue, vous êtes révolutionnaire !

Dubreuil Et je m'en flatte ! Il $y$ a un principe révolutionnaire qui dit : " On ne détruit que ce qu'on remplace. " C'est pourquoi je soutiens que les ouvriers ne réussiront à transformer le régime dont ils se plaignent que lorsqu'ils formuleront des propositions positives pour une nouvelle organisation du travail.

Barnard En avez-vous à l'esprit, vous, des propositions positives pour une nouvelle organisation du travail?

Dubreuil Bien sûr, et j'ai des faits...

L'hôte (Il le coupe.) Monsieur Dubreuil, puisqu'il faut laisser la chance aux autres de s'exprimer, nous reviendrons plus tard à vos propositions.

Dubreuil Si c'est ce que vous voulez, j'attendrai!

L'hôte Merci monsieur Dubreuil...

Dubreuil Mais avant de me taire, je tiens à affirmer ceci : (avec véhémence) « $\mathrm{Il}$ faut supprimer le salariat... à perpétuité ! Chaque travailleur doit aspirer à devenir producteur indépendant et à se débarrasser de l'impression démoralisante d'être miséreux jusqu'à la fin de ses jours ! »

L'hôte Encore une fois, merci monsieur...

Dubreuil (Toujours avec véhémence) L'ouvrier n'a qu'une propriété : celle de son métier !

L'hôte Madame Woodward, votre recherche sur les industries du South Essex est un classique de l'histoire du management, voulez-vous nous en parler?

Woodward J'ai bien peur que le temps dont je dispose ne me permette pas d'en révéler les principaux détails. Je résumerai en indiquant que nous cherchions à mieux comprendre les relations qui existent entre les facteurs techniques et les facteurs sociaux des entreprises. 
Par ailleurs, ce que j'aimerais dire à ceux qui nous écoutent, c'est que nous avions commencé cette recherche avec des idées préconçues, tirées de nos connaissances académiques. Or, les premiers résultats contredisaient toutes nos prévisions et toutes nos hypothèses théoriques.

L'hôte Qu'est-ce que vous avez fait?

Woodward Table rase ! Nous avons analysé les données recueillies et à partir de là, nous avons établi une nouvelle base de travail, puis recommencé à zéro.

L'hôte Le conseil de Boileau vaut autant pour la recherche que pour la littérature : «Cent fois sur le métier remettez votre ouvrage, polissez-le sans cesse et repolissez-le. »

Woodward (À la caméra) Voilà une leçon qu'il ne faut jamais oublier !

L'hôte J'aimerais que vous nous parliez de l'influence de la technologie sur le comportement des membres des organisations, une chose importante que votre recherche a mise en évidence.

Woodward Ce n'est pas une notion que j'ai inventée. Déjà Weber, à la fin du siècle dernier, et Veblen, au début de celui-ci, ont soutenu que les conditions technologiques d'un système social déterminent de façon importante la structure d'une organisation et les comportements de ses membres. Aujourd'hui, on emploie couramment l'expression « système sociotechnique » pour expliquer l'interaction entre les facteurs sociaux et les facteurs techniques dans les milieux de travail. Notre recherche nous a permis de conclure qu'on peut démontrer empiriquement ce postulat énoncé par Veblen en 1904.

Barnard C'est une théorie très intéressante, je vous en prie, donnez-nous des détails.

Woodward Avec plaisir, mais avant de le faire, je voudrais revenir sur une affirmation que monsieur Barnard a faite plus tôt et que j'ai laissée passer pour ne pas l'interrompre.

Barnard À quel sujet?

Woodward La communication. Vous avez dit que les techniques de communication déterminent la structure, l'étendue et la portée de l'organisation. 
Barnard Je l'ai dit et c'est vrai !

Woodward C'est vrai, mais dans le contexte, ça pouvait donner l'impression que seules les techniques de communication sont un facteur déterminant ; or, tel n'est pas le cas.

Barnard J'en suis parfaitement conscient, il y a de nombreux autres facteurs : l'autorité, les buts, le contrôle...

Woodward (Elle l'interrompt.) Et la technologie. C'est une des choses que nous avons découvertes à South Essex et que je tenais à dire au départ pour que tous soient conscients de l'importance de la technologie dans l'organisation.

L'hôte Alors, nous vous écoutons avec grande attention!

Woodward Il faut d'abord se mettre dans la tête que toute théorie sur les organisations industrielles est incomplète et relativement inutile si elle se limite soit à l'aspect technique, soit à l'aspect social de l'organisation sans se pencher sur l'interaction entre ces deux aspects. ('A tous) D'accord?

Mayo Bien sûr!

Barnard Sans aucun doute.

Dubreuil Oui, oui.

Woodward Bien! Du point de vue de la technologie, de nouveaux outils changent la tâche...

Dubreuil (Il la coupe.)... et ils modifient les sentiments et le comportement. Parce que l'ouvrier vit auprès de sa machine, et quand elle atteint normalement le but pour lequel elle a été construite, elle devient pour l'ouvrier son alliée, une véritable amie! Combien lui donnent un nom, plus souvent un prénom, afin de marquer à quel point elle leur est familière ; ils lui parlent comme un cavalier parle à son cheval.

Mayo Ça démontre avec éloquence l'importance de la relation entre l'homme et l'outil, mais tout aussi importantes sont les relations entre les hommes eux-mêmes !

Dubreuil Même plus importantes, et c'est le premier problème qu'il faut régler.

L'hôte Bon, bon, c'est très intéressant, mais nous nous éloignons de la technologie ! Vous disiez donc, madame Woodward, que... 
Woodward De nouveaux outils changent la tâche et la nouvelle tâche change l'organisation et les qualités requises pour la mener à bon port.

Barnard Si les nouveaux outils changent la tâche, ils doivent inévitablement changer le comportement.

Woodward Bien sûr, mais ils ne sont pas les seuls à déterminer le comportement d'un individu, qui dépend de bien d'autres choses : de la force et de la nature des influences provenant de l'environnement de l'organisation, de sa manière de les percevoir et de les interpréter, de son attitude au travail et d'autres facteurs personnels dont certains, d'ailleurs, sont inconscients.

Mayo C'est exactement ce qu'aurait dit Freud!

Woodward Freud! Vous retournez bien loin en arrière !

Mayo Je mentionne Freud pour rappeler la contribution de la psychanalyse à notre compréhension des comportements humains. Il ne fait aucun cloute, selon moi, qu'il faudra s'inspirer de cette discipline pour mieux comprendre les attitudes des humains dans les organisations.

Woodward Va pour Freud. Donc plusieurs facteurs affectent le comportement individuel, mais celui-ci affecte à son tour le comportement organisationnel. Aussi faut-il, en étudiant le comportement, tenir compte de la technologie, mais à la fois étudier et classifier les procédés de contrôle parce que, non seulement la nature de la tâche, mais aussi la manière dont elle est planifiée et contrôlée sont des éléments déterminants du comportement organisationnel.

Barnard Comment cet exercice peut-il aider un cadre ?

Woodward De deux manières :

1. le lien entre la technologie, l'organisation et le succès permet au cadre de développer des nouvelles manières d'évaluer la structure organisationnelle ;

2. d'un point de vue plus général, en couplant les changements organisationnels aux changements techniques, on facilite leur introduction.

Dubreuil Peu importe la manière dont il a été planifié, le travail peut conduire l'ouvrier, soit à l'abrutissement, soit à l'intelligence, et 
ce n'est pas l'outillage qu'il faut mettre en cause : ce sont les hommes qui déterminent les conditions dans lesquelles il faut s'en servir.

Woodward Raison de plus pour que les cadres planifient méticuleusement les changements technologiques.

Barnard Moi qui gérais une entreprise de téléphonie, une technologie de pointe à l'époque, je peux confirmer que la technologie a plus d'importance qu'on lui en prête habituellement !

Woodward C'est pour cette raison qu'en exerçant ses fonctions, le cadre doit toujours tenir compte du fait que la technologie cause des variations de structure et de comportement, en particulier dans le monde manufacturier.

Mayo Les conséquences nombreuses et complexes de la technologie doivent en rendre l'étude extrêmement difficile.

Woodward Surtout quand on étudie son influence sur le comportement. Il faut alors analyser deux aspects :

1. examiner d'abord les contraintes qu'elle impose aux individus qui lui sont directement associés, puis les changements de comportement qu'elles peuvent entraîner; et

2. définir, parmi les caractéristiques saillantes de la technologie, celles qui commandent de modifier la structure de l'organisation.

Mayo Comment peut-on expliquer le comportement ?

Woodward En analysant la situation de travail et, surtout, en concevant la technologie comme une des premières variables dont dépend le comportement. On peut alors arriver à déterminer des conditions dans lesquelles le comportement devient standard et prévisible.

Barnard La connaissance et l'utilisation de la technologie est donc un outil, ce n'est pas un jeu de mots, un outil précieux pour le cadre!

Woodward Exact! La technologie influence l'organisation dans le choix des tâches ; il s'ensuit qu'elle influence le comportement, parce que la manière dont une personne réagit dépend des exigences de sa tâche et des conditions dans lesquelles elle l'accomplit, autant que de sa personnalité. 
Mayo Vous nous avez clairement démontré que la technologie est un facteur capital du comportement, mais il n'est pas le seul!

Woodward Vous avez tout à fait raison! Tout ce qui nous reste à faire, à nous chercheurs, c'est d'établir et d'isoler toutes les variables, autres que la technologie, qui affectent le comportement à l'intérieur d'une organisation ! Ça veut dire les recherches de toute une vie ! ('̀ la caméra) Voilà un projet fascinant pour la prochaine génération de chercheurs!

L'hôte Merci beaucoup madame Woodward. (À la caméra) Plus tôt durant notre rencontre, monsieur Barnard nous a dit qu'une organisation doit être conçue comme un système coopératif. La coopération est donc un élément primordial de toute organisation et il me semble important de savoir ce que nos invités ont à dire là-dessus. (À la table) Messieurs, madame?

Mayo Il n'y a pas que les organisations, toute société doit miser sur la coopération. Dans une société civilisée, la coopération repose sur la compréhension et la volonté de travailler ensemble plutôt que sur la force. Dans les groupes primitifs, le désir de travailler ensemble est aussi très présent, mais la peur et la force occupent une place plus importante que dans une société civilisée.

Dubreuil Comme les organisations sont des sociétés civilisées, elles doivent comprendre que la route du succès n'est pas celle de la guerre, mais celle de la coopération entre ouvriers et employeurs.

Barnard Avant de considérer la coopération comme élément essentiel des organismes, il me semble utile d'établir que la forme la plus universelle et la plus complexe de coopération humaine est la parole et qu'elle ne sert que dans des situations sociales.

Woodward Que faites-vous des ermites, des solitaires...

Barnard (Il la coupe.) Ils ont déjà vécu en société ! Un être humain qui, miraculeusement, naîtrait et survivrait seul sur une île n'aurait pas l'usage de la parole et n'en aurait pas besoin. La parole ne s'acquiert que par contact social et n'a de sens que dans son utilisation sociale.

Dubreuil (⿳亠丷厂 Barnard) Vous, Aristote le philosophe, dites-nous quelle est la cause de la coopération? 
Barnard La coopération se justifie parce qu'elle est une manière de surmonter les limites qui restreignent les capacités individuelles. Elle suppose l'adoption d'un but commun par deux personnes ou plus et elle n'a rien de personnel.

Mayo (Il continue de répondre à Dubreuil.) La perpétuation de la coopération au travail suppose aussi un code qui règle les relations entre les personnes concernées et leurs attitudes les unes envers les autres. Mais trop souvent, hélas ! la logique purement économique qui régit pour ainsi dire toutes les organisations contrecarre ce code, et cela engendre dans le groupe une impression de défaite humaine.

Dubreuil Qu'est-ce qu'il faudrait faire pour remédier à cette situation ?

Mayo Suivre la règle selon laquelle tout groupe social doit assurer à ses membres :

1. la satisfaction de ses besoins matériels et économiques ; et

2. le maintien de la coopération spontanée à travers toute l'organisation.

Dubreuil Ça m'a l'air facile, pourquoi ne le fait-on pas ?

Mayo Parce que toutes nos méthodes administratives actuelles pointent vers ce qui est matériellement efficace, aucune vers le maintien de la coopération.

Dubreuil Donc, il faut changer nos méthodes administratives !

Mayo Je ne vous le fais pas dire!

Dubreuil Dans quelle direction faut-il les changer?

Barnard La meilleure manière de faciliter la coopération est d'agir sur les facteurs sociaux, c'est-à-dire d'inventer des modes efficaces de relations humaines. Ce faisant, on atteint le but de l'effort coopératif, qui est de changer pour le mieux toute une situation en ne modifiant qu'une partie de cette situation.

Mayo Comme l'ont démontré Le Play et Durkheim, dans une société industrielle, on ne peut pas laisser la coopération au hasard.

Barnard Au lieu de la laisser au hasard, il faut la susciter et la faciliter, et pour y arriver, il faut l'envisager sous les points de vue des deux parties en présence : les individus et les systèmes coopératifs. 
Il faut comprendre que la volonté de coopérer est l'effet :

1. de l'incitation à le faire, avec les sacrifices que ça comprend; et

2. de la satisfaction que le coopérant entend retirer de cette coopération, cette satisfaction l'encourageant naturellement à coopérer de nouveau.

Cette volonté de coopérer est donc entièrement individuelle, personnelle et subjective. Cela étant compris, le cadre doit faciliter la coopération en favorisant le maintien d'un système coopératif qui fasse qu'en orientant leurs efforts dans le sens des objectifs de l'organisation, les employés aient à la fois le sentiment d'atteindre leur propre objectif.

Dubreuil Il faut un cadre, un chef, un leader très fort pour comprendre tout ça et pour l'exécuter!

Barnard Le leadership est l'indispensable détonateur des grandes forces de la coopération. Le leadership donne son sens au but commun, inspire la conviction personnelle qui produit la cohésion vitale sans laquelle la coopération est impossible. Il oriente la volonté des hommes vers l'accomplissement de buts différents et plus larges que leurs buts personnels. Cela étant dit, il faut bien comprendre que dans ces circonstances, le chef tire son leadership, sa véritable autorité, du consentement des employés à le suivre, à coopérer.

Mayo J'ai toujours maintenu et je maintiens encore, avec véhémence, que la coopération et sa survie sont le but le plus important auquel l'administrateur moderne doit aspirer.

Barnard Pourquoi avec tant de véhémence ?

Mayo Parce que les universités, les institutions et les politiciens n'en parlent jamais !

L'hôte Voilà un reproche qu'on ne peut pas faire à monsieur Barnard, comme le démontre le dernier paragraphe de son livre The Functions of tbe Executive. (Il prend le même livre qu'au début de la rencontre, trouve la page et le tend à Barnard.) Monsieur Barnard, je vais vous demander de le lire pour le bénéfice des cadres présents et futurs qui nous regardent. 
Barnard Avec plaisir. (Il prend le livre puis lit.) Ce livre est l'histoire de l'homme dans la société, une histoire qui me dicte un acte de foi. je crois que la coopération des hommes libres a le pouvoir de leur donner la liberté de coopérer ; que les hommes libres ne peuvent atteindre la plénitude de leur développement qu'en choisissant de travailler ensemble ; que ce n'est que lorsque chacun d'eux accepte la responsabilité du choix commun qu'ils peuvent entrer dans cette communion des hommes d'où surgissent les objectifs les plus élevés du comportement, aussi bien individuel que coopératif. Je crois que l'expansion de la coopération et le développement de l'individu sont des réalités mutuellement dépendantes et qu'un juste équilibre entre les deux est une condition nécessaire du bien-être humain. Je ne pense pas que la science puisse déterminer quel est cet équilibre parce que c'est un équilibre subjectif, aussi bien du point de vue de la société que de celui de l'individu. C'est une question qu'il faut poser à la philosophie et à la religion. (Il ferme le livre et le rend à l'hôte. Ce dernier et les autres applaudissent.)

Mayo Bravo ! Bravo! (Quand les applaudissements sont terminés, à l'hôte.) Monsieur (nom de l'hôte), depuis longtemps je n'ai plus l'occasion de communiquer ma pensée aux hommes, j'aimerais profiter de mon passage ici pour ajouter à ce que monsieur Barnard vient de dire.

L'hôte Profitez, profitez donc monsieur Mayo !

Mayo (À Barnard) Mon cher Chester, croyez bien que je ne veux pas vous voler la vedette ni neutraliser votre émouvant éloge de la coopération ; au contraire, je veux y ajouter parce que j'y crois autant que vous.

Barnard Mon cher Elton, pour une fois que nous sommes d'accord, je vous en prie, allez-y : il est toujours profitable d'écouter ce que les autres ont à dire et puis... je ne suis pas du tout cabotin !

Mayo Merci. (À la caméra) La coopération n'est pas nécessaire que dans les organisations, elle l'est dans les nations et entre les nations. Quand les hommes travailleront ensemble vers un but commun, la confiance nationale et la confiance internationale reviendront. La mésentente qui règne depuis un siècle entre employeurs et travailleurs, dans tous les pays civilisés, illustre que le manque de coopération est un symptôme de la désorga- 
nisation sociale beaucoup plus significatif que l'augmentation du crime, de la drogue et du suicide. La propagation de la coopération efficace est ce vers quoi nous devons encore tendre à la fin du $\mathrm{XX}^{\mathrm{e}}$ siècle. Nous avons appris à détruire des centaines de milliers d'humains en quelques instants, mais nous ne savons toujours pas inciter les groupes et les nations à coopérer à des tâches qui améliorent la civilisation. La société civilisée se détruira elle-même si elle ne trouve pas les moyens d'accroître la coopération et de contrôler ceux qui s'y opposent.

L'hôte Après ces deux remarquables apologies de la coopération, j'aimerais entendre ce qu'en pense notre syndicaliste.

Mayo Les syndicats savent beaucoup mieux faire la guerre contre les employeurs que coopérer avec eux. Ils répètent aujourd'hui les erreurs que les employeurs ont faites autrefois.

L'hôte On sait que c'est ce que vous pensez, vous venez de nous le dire ! Ce qu'on veut savoir, c'est ce qu'un syndicaliste en pense ; monsieur Dubreuil ?

Dubreuil La même chose que monsieur Mayo. (Réaction étonnée de tous; onomatopées)

Mayo Etes-vous syndicaliste ou capitaliste ?

Dubreuil Syndicaliste, mais ça ne m'empêche pas de me servir de ma tête ni de voir clair. J'ai constaté que la plupart du temps certains syndicats n'enseignent aux travailleurs que la haine, l'envie et l'avidité, ce qui est une grave erreur.

Mayo Il faut bien qu'ils sèment la haine des patrons pour ensuite récolter des grèves efficaces qui mobilisent tous les travailleurs qu'ils contrôlent ! C'est leur force !

Dubreuil La route de l'intelligence est plus efficace que celle de la force.

Woodward Est-ce à dire que vous êtes contre la grève ?

Dubreuil Fermement!

Woodward Drôle de syndicaliste : contre les syndicats, contre la grève !

Dubreuil Pardon madame, je ne suis pas contre les syndicats, mais contre certaines de leurs tactiques que je trouve démagogiques, certaines de leurs politiques que je ne trouve pas intelligentes, pas éclairées. Quant à la grève, elle est totalement illogique. (Il pointe l'index vers elle.) Qu'est-ce que le droit de grève? 
Woodward Euh... le droit de grève, c'est...

Dubreuil Ne cherchez pas, je vais vous le dire : le droit de grève, c'est le droit de ne pas travailler, un droit négatif, comparable au droit de se suicider. C'est un droit dépourvu de toute valeur constructive. Les législateurs qui ont donné le droit de grève à la fin du XIX ${ }^{\mathrm{e}}$ siècle n'ont pas beaucoup réfléchi!

Woodward Vous n'exposez qu'un côté de la médaille!

Dubreuil S'il y en a un autre, montrez-le nous !

Woodward Vous savez comme moi qu'il y a une multitude d'exemples où il a fallu des grèves longues, pénibles et même parfois violentes pour que les travailleurs obtiennent enfin une convention collective.

Dubreuil (Agressif) Les conventions collectives n'établissent jamais qu'une paix provisoire, c'est-à-dire précaire. De plus, en acceptant une convention collective, le travailleur s'engage à travailler pour untel, tant d'heures par semaine à tant de l'heure; il accepte un salaire et, je l'ai dit tantôt, le salariat, c'est de l'esclavage. De l'esclavage où le travailleur se vend luimême au lieu d'être vendu par un négrier.

Barnard On ne peut quand même pas ignorer le salaire, il fait partie des récompenses qui motivent les travailleurs.

Dubreuil Pour ceux qui croient encore au salariat, c'est vrai, mais ce n'est pas la seule récompense à leur offrir. Les chefs syndicaux et les patrons n'ont pas compris que les purs problèmes de salaire ou de conditions de travail n'animent plus l'enthousiasme des travailleurs.

Barnard Qu'est-ce qu'il faut pour les enthousiasmer?

Dubreuil Comprendre que nous ne vivons ni pour produire ni pour consommer, mais pour être heureux.

Barnard (Sourire) Monsieur Dubreuil, tout ça, c'est de la bien belle philosophie, mais en pratique, qu'est-ce qu'il faut faire?

Dubreuil D'abord, si je pouvais encore écrire, je ferais comme Zola, je ferais publier un nouveau « J'accuse » contre les « mauvais bergers » qui font profession de s'instituer les guides de la classe ouvrière.

Barnard Amusante répartie, mais ça ne répond pas à ma question : Qu'est-ce qu'il faut faire? 
Dubreuil Ce que les syndicats devraient faire, c'est éclairer leurs membres sur la coopération. La coopération est possible et souhaitable pour les humains puisqu'elle ne réclame pas vraiment de sacrifices : elle exige une contribution, mais en retour, elle est source de nombreuses satisfactions, comme vous disiez plus tôt.

Barnard De la part des « mauvais bergers », ça serait du nouveau!

Dubreuil Il y a déjà longtemps, les Romains disaient : Nihil novi sub sole, il n'y a rien de nouveau sous le soleil. C'est encore vrai : dans bien des domaines, dont celui du management, il n'y a rien à inventer ; le nouveau est simplement ce qui a été oublié, comme l'écrivait Le Play.

Barnard Croyez-vous que la coopération a déjà existé et qu'elle est simplement oubliée?

Dubreuil En effet, au Moyen Âge, il y avait les corporations, les apprentis, les compagnons, les artisans! Tous ces gens-là s'entraidaient, coopéraient et travaillaient dans la paix, la compréhension et la joie. C'est cette atmosphère qu'il faut ramener clans le monde du travail.

Mayo Tout le long de ma carrière, j'ai constaté que lorsque la coopération est maintenue entre l'individu et son groupe, entre le groupe et l'organisation, entre le syndicat et le management, le sens de sécurité est très élevé, tout comme l'absence de mécontentement individuel.

L'hôte Amen! Madame, messieurs, c'est tout le temps dont nous disposons...

Dubreuil (Il l'interrompt.) Vous m'avez dit que nous reviendrions à mes propositions positives pour une nouvelle organisation du travail!

L'hôte Je sais bien, mais nous n'avons plus le temps aujourd'hui. Cependant, nous aurons l'occasion de nous rencontrer à nouveau pour discuter de vos idées à tous, y compris de vos propositions à propos d'une nouvelle organisation du travail monsieur Dubreuil. (À la caméra) Après l'expérience d'aujourd'hui, je suis persuadé que cette deuxième rencontre sera fascinante ; ne la manquez pas ! Merci d'avoir été des nôtres. (Aux invités) Merci d'avoir accepté notre invitation. À toutes et à tous, à la prochaine heure et au revoir ! 



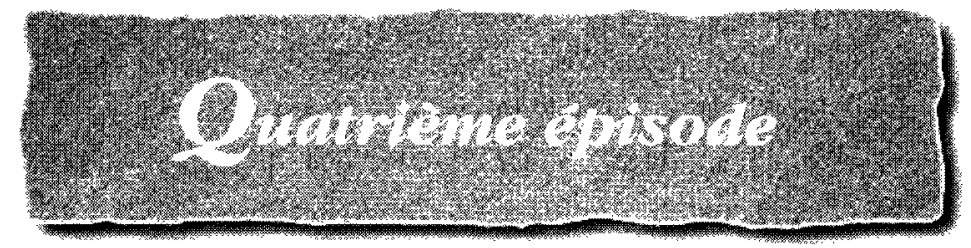

L'hôte et les quatre invités sont sur le plancher des vaches devant le praticable sur lequel sont placés la table et les fauteuils. Ils causent, sotto voce, mais on n'entend pas ce qu'ils disent : leurs voix sont couvertes par le murmure de l'auditoire. L'hôte aperçoit le signal que lui fait le régisseur, hors champ, il élève la voix.

L'hôte Ça y est, les techniciens et le réalisateur sont prêts ; si vous voulez prendre place.

Tous montent sur le praticable, l'hôte le premier; pendant que les autres prennent les mêmes places que durant le premier épisode et s'assoient, il commence sa présentation. Pendant ce déplacement, nous aurons un plan très éloigné qui nous montrera, ce sera la seule fois durant l'émission, les cameraman et les perchistes plaçant leurs appareils en position.

L'hôte Mesdames, messieurs, soyez les bienvenus à cette deuxième rencontre avec les mêmes invités, que je vais présenter aux malheureux qui n'ont pas assisté à la première.

Il se tourne vers chacun d mesure qu'il les présente en consultant ses feuilles.

Diplomée d'Oxford en administration sociale et publique, elle a fait carrière de professeur. Deuxième femme à devenir titulaire d'une chaire à l'Imperial College de Londres, elle a été la première à y obtenir le titre de doyenne de la faculté de sociologie industrielle. C'est à ce titre qu'elle a dirigé une importante recherche dans les industries du South Essex portant sur les impacts de différents systèmes techniques sur les structures et les arrangements sociaux dans les organisations. Madame Joan Woodward. 
Woodward (Vers le public) Bonjour!

L'hôte Né en Australie, notre prochain invité a obtenu sa maîtrise en philosophie et psychologie après de nombreuses tergiversations et pérégrinations. Il a enseigné la psychologie dans deux universités de son pays, puis émigré aux États-Unis pour y approfondir son étude des problèmes sociaux et industriels. En plus d'enseigner à l'Université de Pennsylvanie et de diriger la recherche industrielle à Harvard, il est associé aux célèbres études des comportements humains à l'usine de la Western Electric à Hawthorne. Monsieur Elton Mayo.

Mayo Bonjour.

L'hôte Seul Américain de naissance de notre panel, notre prochain invité a connu une carrière typiquement américaine : trente-neuf ans dans l'industrie de la téléphonie dont vingt comme président de New Jersey Bell. Après trois années d'études en économie à Harvard, il a dû abandonner pour manque de connaissances en chimie. (Il laisse ses notes un moment.) Je me demande bien ce que la chimie vient faire dans l'économie! (Haussement d'épaules) Enfin! (Retour aux feuilles) Ça ne l'a pas empêché d'avoir une carrière très fructueuse et de recevoir plus de sept doctorats honoris causa. Contrairement à nos deux premiers invités, il n'a pas enseigné, mais son livre sur les fonctions des dirigeants est un must, comme on dit chez Cartier, dans l'enseignement du management et l'étude des organisations. Monsieur Chester Barnard.

Barnard Bonjour.

L'hôte Enfin, un invité inattendu : Français, syndicaliste, autodidacte, il n'a reçu qu'une éducation primaire, ce qui ne l'empêche pas d'être l'auteur d'une quinzaine de livres. Sa longue expérience de la vie des ouvriers en usine et des syndicats en fait un interlocuteur qui sait tenir son bout devant des diplômés d'université et des présidents de compagnies comme nous avons pu le constater lors de notre première rencontre. Monsieur Hyacinthe Dubreuil.

Dubreuil Bonjour! N'oubliez jamais que l'ouvrier n'a qu'une propriété, celle de son métier! 
L'hôte Monsieur Dubreuil vous avez prononcé, lors de notre première rencontre, une phrase improbable dans la bouche d'un syndicaliste : " Il faut éliminer les salaires. »

Dubreuil Je l'ai dit, je le répète et je le répéterai tant que les salaires ne seront pas abolis à perpétuité !

L'hôte Pourquoi cet acharnement?

Dubreuil Parce que le salaire n'est pas une formule d'association, mais une formule d'antagonisme et que tout système qui oppose l'intérêt individuel de l'employé à celui de l'entreprise qui l'emploie est un système absurde.

Mayo Pas absurde, juste ! Le salaire en échange des services de l'employé. Il s'agit que le salarié comprenne qu'il a intérêt à être actif puisque cette activité assure la continuité de son salaire.

Dubreuil Et celle de son esclavage! Le salariat c'est de l'esclavage; la seule base pratique de la liberté est le contrat. Il faut éliminer le salariat et établir le système du contrat, du contrat où le bénéfice de la production n'est pas encaissé par un seul, mais réparti entre tous ceux qui l'ont produit.

Mayo Ça y est! Le communisme qui essaie de s'infiltrer dans nos industries capitalistes !

Dubreuil Non, non, non. Je sais que vous avez la phobie du communisme, mais il ne faut pas le voir là où il n'est pas ! Ma proposition est une saine application du capitalisme. L'employeur investit son capital, l'ouvrier investit sa seule propriété : son métier, et chacun récolte proportionnellement à sa mise de fonds.

Woodward Monsieur Dubreuil, n'êtes-vous pas un peu rêveur ? Vous avez vousmême fait face à l'indifférence des ouvriers devant des projets semblables que vous leur avez soumis. La liberté est un fardeau devant lequel beaucoup d'hommes hésitent. La liberté ne convient qu'aux forts, qui sont et seront encore longtemps une minorité. Les autres, les faibles, tremblent devant la liberté et préfèrent la sécurité du salariat aux émotions fortes de l'homme qui ose tenter la chance.

Dubreuil Vous parlez d'indifférence, je crois qu'il s'agit plutôt d'une méfiance qui vient des règles traditionnelles du travail obtenu par la contrainte. 
Indifférence ou méfiance, peu importe, rien ne m'empêchera de continuer d'attirer les salariés vers le chemin de la liberté.

Woodward Par quel moyen comptez-vous y arriver?

Dubreuil Par la décentralisation des connaissances techniques, du budget et de la responsabilité clans les entreprises. C'est la seule manière d'incorporer dans l'ensemble du travail humain les travailleurs qui, jusqu'ici, lui ont refusé leur adhésion totale. C'est la seule manière de voir réapparaître chez eux le goût du travail et même le goût du bon travail, ainsi que l'énergie, l'audace, l'esprit d'invention, et toutes les qualités viriles, pardon madame, des hommes indépendants.

Woodward Comment faire comprendre et accepter cela par les travailleurs indifférents... ou méfiants?

Dubreuil Oh ! ce ne sera pas facile : je sais que les hommes résistent aux nouveautés qui dérangent leurs habitudes et que l'amour de la tradition n'est souvent que le paravent de la paresse d'esprit !

Woodward Je suis d'accord, mais vous n'avez pas répondu à ma question: comment leur faire comprendre?

Dubreuil C'est aux chefs syndicaux et aux chefs d'industrie de convaincre les travailleurs.

Barnard Va pour les chefs syndicaux, mais pourquoi les chefs d'industrie iraientils prêcher aux travailleurs qui se méfient déjà tellement d'eux?

Dubreuil Parce que c'est leur intérêt de faire cesser le gaspillage incalculable qu'engendre l'affreuse flânerie au travail qui exaspérait tellement Frederick Taylor.

Barnard L'époque de Taylor est finie depuis longtemps !

Dubreuil Peut-être, mais pas le gaspillage : nous savons tous qu'il coûte une fortune, des dizaines de milliards juste en Amérique du Nord.

Mayo (Condescendant) Admettons toute cette belle théorie. Vous nous avez dit la dernière fois que vous aviez des propositions positives pour une nouvelle organisation du travail ; quelles sont-elles ? 
Dubreuil Enfin, j'ai fini d'attendre ! Merci monsieur Mayo. Ma proposition est plus que positive, elle existe déjà depuis longtemps. Elle a été éprouvée à Zlin, en Tchécoslovaquie, à la fin du siècle dernier par Tomas Bat'a quand il a fondé l'entreprise de fabrication et de vente de chaussures qui porte son nom et qui est devenue un empire mondial.

Barnard Toute entreprise doit avoir une structure, un mode d'opération; comment la vôtre est-elle organisée ?

Dubreuil Comme une sorte de fédéralisme industriel dont les différents « départements » sont indépendants pour tout ce qui concerne leurs activités internes, lesquelles s'harmonisent cependant avec celles des autres départements avec lesquels la production les met en rapport direct.

Barnard C'est la décentralisation dont vous nous parliez plus tôt !

Dubreuil Exact ! À la base, l'entreprise est constituée de nombreuses unités de travail autonomes. Chaque unité a une autonomie, non seulement au chapitre des techniques utilisées, mais aussi au plan budgétaire, de sorte que les hommes qui la forment sont clans une situation personnelle comparable à celle que leur offrirait une entreprise indépendante.

Barnard En quelque sorte, une série de cellules juxtaposées?

Dubreuil Oui, et c'est beaucoup plus facile d'atteindre, à l'intérieur d'une cellule, l'équilibre tant recherché entre l'intérêt personnel de chaque individu et l'intérêt collectif de l'entreprise.

Mayo (Agressif, parce qu'incrédule...) Ah! Ah ! Voilà ! L'individu est isolé dans sa cellule et la cellule est isolée des autres cellules, n'est-ce pas?

Dubreuil En effet.

Mayo Et les communications ? (Ironique) Éliminées peut-être ?

Dubreuil Les relations intérieures de l'entreprise, tant entre l'individu et son groupe qu'entre le groupe et l'entreprise, prennent la forme de relations purement commerciales. Ça élimine la notion de subordination, qui est une intarissable source de conflits.

Mayo Comment ça ?

Dubreuil Parce que l'autonomie du groupe fait que l'entreprise-mère n'a plus de relations avec les membres individuels du groupe. 
Mayo Mais il faut qu'il y ait coordination entre tous ces groupes! On ne peut pas laisser chaque petite cellule en faire à sa tête ; une organisation ne peut pas se passer de communications ni d'autorité !

Dubreuil Ce sont les chefs des groupes autonomes qui reçoivent une tâche collective déterminée. Puis chaque groupe se voit confier une partie du travail à faire, qui est ensuite livré à un autre groupe selon des critères préétablis. Chaque groupe est donc libre de s'acquitter du travail qui lui est confié comme il l'entend, à condition qu'il respecte les critères de qualité et les délais de livraison.

Mayo Qui désigne le chef de groupe ?

Dubreuil Les ouvriers du groupe choisissent leur chef et organisent librement l'exécution du travail qui leur est confié.

Woodward Les cadres n'ont donc rien à faire !

Dubreuil Au contraire! Ils s'occupent de l'organisation générale de l'entreprise, mais ils se déchargent des détails de l'exécution sur le groupe et mettent à sa disposition les locaux, l'outillage et la matière première nécessaire.

Barnard En somme, une coopérative?

Dubreuil Pas vraiment! Constituer une coopérative de production est très difficile parce que deux choses manquent généralement aux travailleurs : les capacités administratives et les capitaux. C'est pourquoi le système Bat'a est une forme de coopérative, mais sans capital.

Barnard Allons donc, monsieur Dubreuil, vous savez bien qu'aucune entreprise ne peut fonctionner sans capital et vous savez également que les ouvriers ne peuvent pas le fournir : ils n'en ont pas !

Dubreuil Les travailleurs possèdent un capital particulier qui est leur capacité de travail, leur savoir, leur compétence professionnelle. C'est seulement ce capital qu'ils investissent.

Barnard Oui, mais l'autre capital, (Il frotte son pouce contre son index.) le vrai?

Dubreuil Il vient de l'entreprise qui, comme je viens de vous le dire, met à la disposition des divers groupes les locaux, l'outillage et la matière 
première nécessaire. Au cas où vous ne l'auriez pas déjà compris, Bat'a illustre ma proposition positive pour une organisation nouvelle du travail et en respecte les règles.

Barnard Qui sont?

Dubreuil 1) Le libre recrutement des travailleurs par leur collectivité constituée en coopérative de main-d'œuvre ;

2) l'acquiescement collectif à un travail déterminé pour un prix convenu, déterminé entre l'entreprise et le délégué de la coopérative de main-d'œuvre ;

3) comme je viens de vous le dire, les ouvriers groupés dans l'entreprise collective choisissent eux-mêmes leur chef et organisent librement l'exécution du travail qui leur est confié ;

4) et la répartition du prix global du travail entre les ouvriers se fait selon le partage qu'ils jugent eux-mêmes convenable.

Barnard À première vue, il ne m'apparaît pas facile d'intégrer autant d'éléments divers : les individus autonomes, les groupes autonomes et les cadres, ou la hiérarchie, comme vous l'avez appelée tout à l'heure.

Dubreuil Pourtant c'est facile : il faut prendre modèle sur les êtres vivants dont les organes sont autonomes et parfaitement intégrés dans l'ensemble.

Barnard Vous embrouillez les choses !

Dubreuil Mais non, regardez la vie animale : les organes fonctionnent chacun pour leur compte en vue d'entretenir la vie d'un être complexe. Ils travaillent et se nourrissent, donnant et recevant en même temps, dans cet admirable équilibre du phénomène de la vie. (À la caméra) Il serait utile que ceux qui aspirent à des positions de responsabilité dans l'industrie possèdent une connaissance spéciale des principes de la biologie ! Ça les aiderait à traiter l'industrie comme un organisme et non comme une machine !

Mayo Ils seraient meilleurs administrateurs !

L'hôte Vous n'êtes pas satisfait de nos administrateurs?

Mayo Sûrement pas ! L'administration de la société, autant au plan gouvernemental qu'au plan industriel, est notre problème le plus aigu et le plus urgent. 
L'hôte Pourquoi?

Mayo Parce que nous souffrons d'anomie.

L'hôte D'anomie ?

Mayo L'anomie, c'est l'absence d'organisation.

L'hôte Il me semble pourtant que notre société est organisée.

Mayo Non, elle est désorganisée. Désorganisée parce qu'elle n'a pas su s'adapter aux découvertes scientifiques ni à la mutation intellectuelle qui nous sont tombées dessus avec une rapidité sans précédent. Et si la société n'a pas su s'adapter, c'est que les anciens administrateurs n'ont pas su suivre l'évolution de la civilisation.

L'hôte Et pourquoi n'ont-ils pas suivi?

Mayo Parce qu'ils n'ont pas su apprécier les valeurs humaines contenues dans notre code social de comportement. C'est pourquoi les administrateurs d'aujourd'hui sont coincés dans une bataille entre le développement d'innovations de toutes sortes et leur désir de conserver des valeurs humaines.

L'hôte Avez-vous un remède à suggérer ?

Mayo (Impatient) Mais bien sûr que j'en ai un monsieur (nom de l'hôte) ! D'ailleurs, je tiens à vous faire remarquer que vous n'avez pas devant vous une victime de l'anomie, un travailleur envahi par une impression de futilité personnelle et pris dans la rêverie au lieu d'être pris par son travail ou quelqu'un qui ne croit plus en sa fonction sociale, en sa solidarité avec les autres humains ni en sa capacité de collaboration au travail. Bref, je ne suis pas un humain typique du $\mathrm{XX}^{\mathrm{e}}$ siècle !

L'hôte (Époustouflé) Mais... je...

Mayo Je ne suis rien de tout ça et j'ai un remède. Les administrateurs appartiennent à une aristocratie. Or, les aristocraties ne durent pas : l'histoire est un cimetière d'aristocraties. Mon remède : changer les administrateurs !

Woodward Et les remplacer par qui ?

Mayo Par des nouveaux arrivants dont la qualité et l'énergie revivifient la capacité administrative générale. Sous peine de voir l'équilibre social complètement troublé, il faut maintenir la " circulation de l'élite ", 
c'est-à-dire favoriser l'ascension d'individus vigoureux et capables issus des classes inférieures et nous réjouir du déclin de l'aristocratie décadente.

Woodward C'est draconien!

Mayo Ça s'impose madame! Dans une société qui change rapidement, il faut des administrateurs, publics et privés, qui aient un esprit généraliste, ou systémique comme on dit aujourd'hui, capable de saisir une multitude de relations complexes.

Woodward Quelles qualités, quel état d'esprit doivent-ils avoir selon vous?

Mayo Notre besoin immédiat est de restaurer la coopération humaine ; pour y arriver, l'administrateur doit avoir une grande capacité d'écoute. Plusieurs ont les qualités pour l'être, mais ne peuvent pas relier les différents « échos » qu'ils reçoivent à autre chose que leur expérience personnelle. Ils n'ont pour tout bagage que leurs études spécialisées et ignorent l'aspect humain et social de l'organisation industrielle.

Woodward Là, je suis d'accord : il ne faut pas enseigner les principes de gestion comme s'ils étaient des lois scientifiques quand, en fait, ce ne sont que des expédients qui ont fonctionné dans certaines circonstances mais qui n'ont jamais été systématiquement testés.

Mayo C'est malheureusement ce que font trop d'universités, partout à travers le monde. Trop d'entre elles sont admirablement équipées pour découvrir et entraîner des scientifiques, trop peu pour découvrir et entraîner des nouveaux administrateurs. Conséquemment, trop d'administrateurs croient faire face à un problème économique et trop peu sont conscients d'avoir à régler un problème social humain.

L'hôte Qu'est-ce que vous suggérez que les universités fassent?

Mayo Qu'elles mettent en pratique les conseil d'Hippocrate et de sir Francis Bacon. Hippocrate recommandait à ses élèves un travail dur, persistant, intelligent et responsable... dans les chambres des malades et non pas à la bibliothèque! Sir Francis, lui, disait que le talent et l'expérience, l'observation et la logique sont les trois stades de l'avancement. 
Dubreuil C'est-à-dire qu'il faut faire comme madame Woodward a fait à l'Imperial College et envoyer les étudiants apprendre dans les ateliers et les usines.

Mayo Et je conclus en disant que les connaissances de seconde main n'engendrent que la médiocrité !

L'hôte Monsieur Barnard...

Barnard (Il sursaute, brusquement sorti d'une profonde réflexion.) Hein?

L'hôte Vous êtes bien silencieux !

Barnard Je réfléchissais à ce que messieurs Dubreuil et Mayo viennent de dire.

L'hôte Et...?

Barnard Il manque bien des éléments dans leurs raisonnements.

Dubreuil Ah oui ! Comment ça?

Mayo Que voulez-vous dire?

Barnard À l'exclusion des autres êtres, des autres éléments qui constituent la société ou une organisation, vous n'avez considéré que (pour Maya) l'humain typique et (pour Dubreuil) l'ouvrier.

Dubreuil Avec raison : il faut adapter l'industrie à l'homme et non l'inverse !

Barnard Vous avez raison...

Dubreuil (Vainqueur) Ah!

Barnard ... mais rien que partiellement, et cela pour deux raisons :

1) d'une part, parce que l'adaptation, comme la coopération, est un jeu qui se joue à deux ;

2) et d'autre part, parce qu'en plus des membres reconnus de l'organisation, travailleurs, contremaîtres, cadres, il y a aussi les " contributeurs ", si vous me permettez ce mot, les contributeurs de l'extérieur : le client qui achète, le fournisseur, l'investisseur qui fournit le capital. Autant de gens dont il faut tenir compte.

Dubreuil Autant de personnes auxquelles il faut que l'industrie s'adapte !

Barnard Et vice versa,... mais là n’est pas mon propos. Écoutez-moi bien ! 
Dubreuil Je ne fais que ça!

Barnard L'organisation est un système d'activités humaines ; les personnes sont les agents de l'action, mais dans l'étude des systèmes coopératifs, on ne doit pas considérer l'action comme personnelle.

Mayo Ah! tiens donc! pourquoi?

Barnard Il faut considérer l'organisation comme un tout parce que chaque partie est reliée aux autres parties. Toutes sont inter-dépendantes, ce qu'on oublie trop souvent et que vous semblez avoir oublié tous les deux.

Mayo Non, je ne l'ai pas oublié et je n'ai pas oublié non plus que le travailleur est une personne et que ce qu'il veut, c'est

1) entretenir des relations sociales harmonieuses avec les autres,

2) avoir une fonction économique dans le groupe, une fonction qui ajoute de la valeur au groupe.

Dubreuil C'est exactement ce qu'il obtient avec le système Bat'a!

Barnard Et voilà, nous sommes d'accord! Cependant, en dépit de votre intervention sur les désirs des travailleurs, mon cher Elton, je veux revenir sur le fait que dans les organisations, il ne faut pas considérer l'action comme personnelle.

Mayo J'attends toujours que vous m'expliquiez pourquoi !

Barnard Il ne faut pas considérer l'action comme personnelle, d'abord parce que toutes les parties de l'organisation sont interdépendantes, nous sommes bien d'accord là-dessus?

Mayo et

Dubreuil

(Acquiescent par une onomatopée.)

Barnard Et ensuite, parce que la personne dans l'organisation, c'est-à-dire à son travail, n'est pas la même que la personne chez elle ou durant ses loisirs quels qu'ils soient. Je ne veux pas entrer dans les détails de cette idée, (à la caméra) s'il y en a que ça intéresse, j'ai réfléchi sérieusement à cette question et ai fait part de mes observations et de mes convictions clans un livre intitule The Functions of the Executive.

L'hôte Un livre remarquable qui a déjà éclairé plusieurs personnes et qui n'a pas fini d'en éclairer. 
Barnard Je n'ai pas la prétention de dire que tout y a été dit, bien au contraire. Aussi, tous ceux et celles qui s'intéressent à ces questions sont invités à compléter les réponses contenues clans mon ouvrage. Malheureusement, bien des gens ne s'intéressent qu'aux aspects superficiels de l'organisation et ne saisissent pas ses éléments vraiment significatifs. Comprendre les organisations et leur fonctionnement requiert de la rigueur mais également une sensibilité à des dimensions qui relèvent davantage de l'art que de la science proprement dite. La structure de la symphonie, l'art de sa composition, le talent de son exécution échappent à plusieurs parce qu'ils ne peuvent pas distinguer les tons.

Mayo Je ne vous savais pas poète, mon cher Chester!

Barnard Pas poète, musicien!

L'hôte Peut-être... mais je m'en voudrais à ce moment-ci de ne pas permettre aux autres... euh... de jouer leurs propres gammes! (Il regarde autour de la table.) Il y a quelqu'un qui a quelque chose à ajouter sur l'organisation? (Joan Woodward lève la main.) Madame Woodward!

Woodward Je crois qu'une des erreurs, courante et grave, est de croire que l'élaboration d'une structure organisationnelle est une fin en soi plutôt qu'un moyen d'arriver à une fin.

L'hôte D'où vient cette erreur?

Woodward Du fait qu'une grande partie de la pensée et de l'enseignement du management se fait en dehors de situations réelles, de sorte qu'il est extrêmement difficile pour les diplômés, une fois en situation réelle de travail, de considérer une organisation en relation avec les objectifs qu'elle sert.

L'hôte Vous avez des exemples?

Woodward Oui : le livre de monsieur Barnard, The Functions of the Execulive.

Barnard Mais tout un chapitre de mon livre traite des buts et des objectifs !

Woodward Je le sais et c'est très bien, mais ce n'est pas contre ça que j'en ai. Ce qui me gêne, c'est que votre livre a été écrit à partir de vos connaissances personnelles et de votre expérience spécifique, avec lesquelles peu de lecteurs sont familiers. Ils doivent donc évaluer votre livre dans un vacuum ou en regard de leur propre expérience. 
Barnard Je tiens d'abord à clarifier une chose : mon livre n'a été inspiré ni par mon expérience personnelle ni par les travaux de mon confrère Elton ici présent, comme certains ont prétendu. Mon livre est le résultat de ma réflexion et de mon analyse personnelle, il est issu de mon cerveau. Cela dit, il reste que, selon vous, le livre en question ne vaut pas cher?

Woodward Non, non, ce n'est pas ce que j'ai dit. Votre livre est extrêmement valable en tant que point de départ pour une pensée spéculative sur le management, mais pas en tant que guide d'action pour un cadre placé dans des circonstances précises.

Barnard Vous ne pouvez pas nier qu'il y ait des règles de base...

Woodward (Elle le coupe.) Je ne connais personne qui se soit penché sérieusement sur le management et qui ait prétendu qu'il y ait « une » meilleure façon d'organiser une entreprise. Il faut enseigner le management à partir de règles flexibles.

Barnard Règles flexibles, c'est une contradiction clans les termes !

Woodward Une contradiction qui indique qu'il faut abandonner le déterminisme qui est une caractéristique de la conception classique du management !

Dubreuil Classique, classique ! Pas tant que ça ! Taylor, un classique s'il en est un, adaptait les applications de ses principes aux conditions et aux besoins de chaque situation à laquelle il faisait face.

Woodward Étant donné l'époque où il a vécu, il était certainement à la fois une exception et un avant-gardiste ! Ce que j'essayais de vous dire, c'est qu'il faut être conscient des théories différentes de la sienne et en tenir compte. C'est pourquoi, quand on enseigne, on ne doit pas confier aux étudiants des cas réels avant qu'ils aient tout ce qu'il faut pour en faire une analyse rigoureuse, les comprendre à partir de perspectives différentes, pour juger de l'à-propos des décisions prises et proposer des solutions. La base, c'est l'analyse!

Barnard Comment abordez-vous l'étude et l'analyse d'une organisation ?

Woodward En définissant le genre de travail qu'elle fait et la technologie spécifique qu'elle utilise pour accomplir ce travail. Une fois ce premier pas fait, on peut explorer la structure de l'organisation en utilisant une variété de modèles. 
Barnard Pourquoi tant d'importance à la technologie spécifique ?

Woodward Je vous l'ai dit lors de notre première rencontre : parce que la technologie utilisée par un système de production est une variable primordiale dans la détermination de la structure organisationnelle. Ce qui revient à dire que chaque système de production a sa propre forme idéale d'organisation.

L'hôte Vous nous avez aussi parlé de comportement...

Woodward La technologie détermine le comportement, comme je vous l'ai dit, et si on l'introduit correctement dans l'organisation, le comportement de ses membres devient prévisible.

L'hôte Qu'est-ce que ça donne de pouvoir prévoir le comportement ?

Woodward Deux choses :

1) la possibilité de satisfaire les besoins humains et sociaux des travailleurs, besoins si chers à messieurs Mayo et Dubreuil, et

2) la possibilité d'évaluer la justesse de l'organisation eu égard à ses buts et à ses besoins.

Barnard Madame Woodward, vous avez affirmé qu'il faut abandonner la conception classique du management; par quoi la remplacer?

Woodward Tellement de théories du management existent que l'ensemble s'apparente à une jungle, une jungle dans laquelle on peut distinguer quatre pistes ou courants principaux :

1) l'approche sociologique qui repose sur le concept de "système social ». Le sociologue détermine les parties du système et étudie leur interdépendance. C'est l'approche que nous avons utilisée dans notre recherche dans le South Essex ;

2) l'approche de la psychologie individuelle qui repose sur la présomption d'antagonisme entre les buts des individus et ceux de l'organisation. Le psychologue évalue l'habileté qu'a l'organisation d'atteindre ses buts tout en permettant aux individus de s'autoréaliser ;

3) l'approche décisionnelle repose sur la théorie économique. Au début, elle se limitait à la rationalité économique des décisions, puis elle a élargi la portée du concept pour inclure tous les ingrédients de la prise de décision : les facteurs sociaux, psychologiques, etc., et finalement, 
4) l'approche mathématique qui réduit l'organisation à un ensemble de procédés mathématiques. Elle est trop complexe pour que je vous l'explique ici. Je me contenterai de vous dire qu'elle ne se suffit pas à elle-même. Pour la rendre efficace, il faudrait la compléter avec les concepts et les méthodes des autres approches.

Barnard Laquelle de ces approches favorisez-vous ?

Woodward Aucune!

Mayo (Enthousiaste) Bravo!

Barnard Pourquoi aucune?

Woodward Quand on adopte une approche, on y croit, on la vit et on ne l'analyse plus ; on n'admet même pas qu'elle puisse être analysée. Une telle attitude est une barrière au progrès parce qu'aucune idéologie n'est uniquement ni entièrement vraie et valable, ni immuable ni éternelle.

L'hôte Mais c'est une attitude tellement humaine !

Woodward Humaine et bête puisqu'elle est à l'origine de l'argument fallacieux selon lequel un système est adéquat parce qu'il existe !

Barnard Alors, qu'est-ce qu'il faut conclure?

Woodward Que tant qu'il n'y aura pas une science complètement intégrée du management, - et c'est pas demain la veille ! -, la vie des cadres continuera d'être extrêmement difficile !

L'hôte Les cadres! Il y a probablement autant de conceptions du mot «cadre » que de théories du management ; j'aimerais que chacun de vous nous donne sa définition d'un cadre, nous dise les qualités qu'un cadre doit avoir.

Barnard Entendez-vous par «cadre » ce que j'ai appelé dans mon livre un executive?

L'hôte Oui, oui, ce que vous appelez executive, que d'autres appellent manager ou administrateur; enfin, celui qui dirige effectivement une entreprise, une industrie, une organisation. Monsieur Dubreuil ? 
Dubreuil Les qualités nécessaires au chef sont l'esprit d'entreprise, l'initiative, la confiance en soi, l'audace, en un mot tout ce qui fait réellement un homme.

\section{L'hôte Monsieur Mayo ?}

Mayo Le cadre doit avoir une familiarité intime, habituelle et intuitive avec les hommes et les choses, une connaissance systématique des hommes et des choses et finalement une manière efficace de réfléchir aux uns et aux autres.

L'hôte Monsieur Barnard ?

Barnard La première qualité universelle d'un cadre est la loyauté et la capacité d'être dominé par la personnalité de l'organisation. Viennent ensuite les habiletés spécifiques personnelles que je divise en deux : les habiletés relativement générales, la vivacité, la compréhension de l'intérêt, la flexibilité, la faculté de s'ajuster, le sang-froid, le courage, etc., et puis les habiletés spécialisées basées sur les aptitudes particulières et sur les techniques acquises.

L'hôte Madame Woodward?

Woodward Les qualités et l'attitude requises d'un cadre varient selon les organisations et les circonstances. Un chef qui est bon dans une situation donnée ne l'est pas nécessairement dans une autre.

L'hôte Monsieur Barnard. tout votre livre traite des fonctions du cadre, quelles sont-elles ?

Barnard Le travail du cadre n'en est pas un d'organisation, c'est le travail spécialisé de maintenir l'organisation en activité, en fonctionnement. Ça se traduit par trois fonctions essentielles :

1) formuler et définir les grandes orientations que poursuivra l'organisation ;

2) contribuer à mettre en place et à assurer l'efficacité d'un système de communication, et

3) obtenir des membres de l'organisation qu'ils fournissent les efforts essentiels au bon fonctionnement de l'organisation.

L'hôte Voilà donc ce qu'il faut faire pour bien gérer une organisation!

Barnard Attention! Le cadre ne gère ni un groupe de personnes ni un système d'efforts coopératifs; le système se gère lui-même. 
L'hôte Comment ça, il se « gère » lui-même ?

Barnard Comme monsieur Dubreuil, je ferai une comparaison avec la biologie. Les fonctions du cadre sont comme celles du système nerveux en regard de celles du reste du corps. Le système nerveux maintient le système corporel en fonctionnement en dirigeant certaines actions qui permettent au corps de s'ajuster efficacement à l'environnement ; on ne peut pas dire qu'il gère le corps pour autant. Plusieurs fonctions du corps sont indépendantes du système nerveux; en revanche, le système nerveux dépend de certaines de ces fonctions.

Dubreuil C'est une comparaison intéressante sauf que, étant donné les qualités requises du cadre et les fonctions qu'il a à exécuter, il doit être drôlement plus intelligent que le système nerveux !

Barnard Encore une fois, attention ! Le cadre doit... euh... « sentir » ... intuitivement l'organisation. Son rôle transcende la capacité des méthodes uniquement intellectuelles. Au sujet de son rôle, il faut employer les mots 《 sensation », « jugement », « bon sens », « proportion », « équilibre », « opportunité », « justesse ». Gérer est un art plus qu'une science, c'est plus esthétique que logique. C'est un rôle qu'on peut plus facilement observer que définir précisément. On apprend à en connaître les différents aspects à force d'exercice et d'expérience plutôt que d'analyse objective.

Mayo Mais monsieur Barnard, on ne peut procéder ainsi si on veut vraiment comprendre ce que c'est que gérer! Je m'objecte à votre méthode, car tout comme le scientifique, pour analyser objectivement un phénomène, il faut que l'observateur s'impose une certaine distance par rapport au phénomène.

Woodward Vous avez raison : comme le sociologue, le cadre qui veut tirer des connaissances valables de ses observations ne doit pas s'engager personnellement dans une situation, parce que sa simple présence ou son attitude personnelle peuvent affecter ou altérer cette situation. Et nous savons tous qu'il est très difficile de faire abstraction de ses propres inclinations!

Mayo Très juste ! Et j'ajouterai que le cadre ne peut faire abstraction de ses émotions et de ses préjugés que grâce à un entraînement méticuleux qu'il n’a généralement pas. 
Woodward Le cadre doit également être conscient qu'une organisation n'est pas un système aux seules dimensions sociale et économique, mais qu'elle a aussi un caractère politique. La politique au sein de l'usine joue souvent un grand rôle dans la détermination du prestige et du statut des cadres. C'est cette dimension des organisations qui doit rappeler au cadre qu'il doit se méfier des nombreux assistants et secrétaires qui exercent trop souvent plus d'autorité que celle que leurs postes ne leur donnent...

L 'hôte (Il interrompt madame Woodward, puis les regarde, elle et monsieur Mayo.) J'aimerais bien qu'on laisse la chance à monsieur Barnard de réagir à vos propos. Monsieur Barnard.

Barnard Tous ses conseils me paraissent bien sensés... de la part de gens qui n'ont jamais gérer une organisation. (Il arbore un large sourire auquel Woodward et Mayo réagissent en grommelant.) En fait, je comprends très bien leurs réserves à l'égard des connaissances en gestion que j'ai acquises par l'expérience. Et je suis prêt à reconnaître que ma méthode ne respecte pas les canons de la science moderne. (Au tour de Mayo d'arborer un large sourire ; celui de Woodward est plus discret.) Cependant, (Les deux interlocuteurs sont surpris et perdent leur sourire.)... je maintiens que ma méthode me permet d'accéder à des connaissances dont vous prive la vôtre, toute scientifique qu'elle soit. (Mayo veut intervenir mais l'hôte l'en empêche d'un signe de la main.) Voyez-vous, on peut apprendre énormément sur la natation à regarder des nageurs et à observer minutieusement leurs mouvements. Pourtant, le nageur a développé des connaissances, des façons de faire qui vous échappent à moins qu'il vous les révèle, ou mieux, que vous ayez été nageur vous-même !

Woodward Je veux bien me rallier, monsieur Barnard, mais ne croyez-vous pas que cette façon de développer des connaissances en gestion comporte des risques quant à leur validité ?

Barnard Bien sûr qu'il y a des risques! Toute méthode n'en comporte-t-elle pas ? D'ailleurs, je n'hésite pas à mettre en garde les cadres qui ont tendance à généraliser trop facilement à l'ensemble des organisations ce qu'ils ont appris dans la leur! Les organisations humaines sont tellement complexes, vous savez... 
L'hôte Comment résumer ce... dialogue, comme dirait monsieur Dubreuil, sur le cadre, ses qualités, ses fonctions et l'acquisition des connaissances en gestion?

Barnard Avant de répondre à votre question, je tiens à répéter qu'en dépit des conseils de mes camarades, je reste convaincu que le cadre doit avoir et utiliser de l'intuition. Ce n'est pas le moment de le démontrer, mais je l'ai fait abondamment dans mon livre. (À la caméra) Avis aux intéressés. (À l'hôte) Pour ce qui est du dialogue, je le résumerais, ou plutôt je le condenserais, en disant que la fonction essentielle du cadre est d'inculquer à tous les membres de l'organisation la foi en l'existence d'un but commun, parce que sans but commun, une organisation ne peut ni fonctionner ni survivre.

L'hôte $\quad$ Est-il si important que les membres croient en un but commun ?

Barnard Sans aucun cloute ! Souvenez-vous que je propose de concevoir l'organisation comme un système coopératif, dont les activités sont, en somme, les efforts des membres de l'organisation. Si les membres ne croient pas aux buts de l'organisation, pourquoi fourniraient-ils les efforts qui en assurent la survie ? C'est la foi en l'objectif qui est importante, pas sa compréhension. La compréhension en soi est un élément qui paralyse et divise parce qu'elle prête flanc à la discussion et à la ratiocination; toutes les religions ont compris ça depuis longtemps !

Dubreuil Après cette... ratiocination, voulez-vous nous donner votre définition philosophique du ou des buts d'une organisation?

Barnard Certainement ! Le but est un pont entre le passé et le futur, mais il n'est efficace que lorsqu'il repose sur le présent.

Dubreuil Mon cher Chester, votre réponse est plutôt énigmatique !

Barnard (À Dubreuil, sourire compréhensif) Je vais essayer de rendre ma réponse plus claire : il n'y a pas de futur qui ne commence après le présent, ni de passé qui ne soit terminé avant le présent, ni aucun but qui ne soit un but dans le présent!!!

L'hôte Ouais ! Nous n'avons sûrement pas assez de temps pour l'analyser et la digérer celle-là ! Si nous revenions à Bat'a. Vous ne nous avez pas beaucoup parlé de la rémunération chez Bat'a, monsieur Dubreuil. 
Dubreuil J'ai déjà indiqué les deux points les plus importants:

1) le bénéfice de la production n'est pas encaissé par le seul propriétaire mais réparti entre ceux qui l'ont produit; et

2) chaque cellule négocie le prix de son travail.

L'hôte Ça, c'est la théorie, mais dans le monde réel, comment cette belle théorie s'applique-t-elle?

Dubreuil Chaque équipe, ou cellule, achète de celle qui la précède dans le processus de production et vend à celle qui la suit. Comme le client et le vendeur de chaque côté du comptoir, ses membres discutent du prix de la transaction.

L'hôte Exemple?

Dubreuil Le chef de l'équipe qui s'occupe de la première opération de production des chaussures fait ses achats au magasin de peaux. Le chef et le vendeur sont deux experts qui négocient le prix des peaux selon leur qualité et la quantité requise.

Mayo Vos négociations, c'est de la frime : ils sont tous deux de la même maison et dans la même maison! Tout le monde sait tout !

Dubreuil Justement pas ! Chaque équipe a sa propre comptabilité, qu'elle n'a ni l'obligation ni l'intérêt de divulguer aux autres. Chaque équipe est un commerce autonome : elle achète les matières qui lui sont nécessaires ainsi que la force motrice et la lumière, paie ses ouvriers et son chef et vend ensuite ce qu'elle a fabriqué. Chez Bat'a, l'autonomie dans la gestion du budget s'ajoute à l'autonomie clans l'exécution des tâches.

L'hôte Une équipe peut donc faire des profits.

Dubreuil Bien sûr!

L'hôte Comment?

Dubreuil De cieux manières : en vendant à un prix plus élevé que celui prévu dans son budget ou en tirant meilleur parti de ses matières premières.

L'hôte Dans le premier cas, le vendeur roule son client !

Dubreuil Oui, mais jusqu'à un certain point seulement, car les abus ont été prévus. Si l'obstination d'un vendeur empêche de conclure finalement un accord, il s'expose à une amende. S'il trompe son client sur la qualité, il devra lui payer une indemnité. 
L'hôte Et l'utilisation optimale des matières premières ?

Dubreuil Il y a bien des façons d'y arriver. Par exemple : si un découpeur dispose les pièces qu'il découpe dans une peau plus ingénieusement que les études ne l'ont prévu et réduit ainsi d'autant le déchet, lui et son équipe se partagent un pourcentage des économies ainsi réalisées.

L'hôte La rémunération, ça fonctionne comment ?

Dubreuil Il y a un salaire de base qui est...

Mayo (Il le coupe.) Un salaire! Je pensais que vous étiez contre! (Il se moque de Dubreuil.) Il faut abolir le salariat à perpétuité...

Dubreuil (Il coupe à son tour.) J'ai dit un salaire de base, ce n'est pas la même chose ! C'est un point de départ à partir duquel on calcule les émoluments qui sont variables. Avant que vous ne m'interrompiez, j'allais dire un salaire de base qui est augmenté de bénéfices lorsque l'équipe atteint $100 \%$ de la production prévue, et aussi augmenté des bénéfices que l'équipe a pu réaliser par les moyens que je vous ai exposés plus tôt.

Barnard Donc, un salaire de base plus des bénéfices basés sur le rendement ?

Dubreuil C'est ça : la rémunération totale réelle est fonction du rendement de l'équipe. Elle est ensuite répartie entre les ouvriers, conformément à une règle de partage proportionnel qui tient compte de la contribution de chacun d'eux.

Barnard Qu'est-ce qui arrive au chef qui a beaucoup plus de responsabilités et de qui dépendent certains bénéfices?

Dubreuil Le chef reçoit le double de la part de l'ouvrier qui touche le plus dans son équipe.

Barnard Quel privilège !

Dubreuil Ce privilège compense la responsabilité dont vous parliez! Il compense aussi la perte, car le chef supporte seul, sur son compte personnel, toute perte attribuée à son équipe.

Mayo Toute la perte!

Dubreuil Oui, mais il y a une limite : la perte ne peut dépasser la moitié de la somme que le chef a gagnée l'année précédente.

L'hôte Après la rémunération, nous allons... 
Dubreuil (Il l'interrompt.) Pardon, il reste la troisième catégorie de travailleurs, les aides dont le travail n'est pas directement lié à la production du groupe.

L'hôte Qu'est-ce qui leur arrive?

Dubreuil Tout ce qu'ils ont, c'est une rémunération fixe : le salaire de base. Ils ne participent pas aux bénéfices.

Barnard C'est inhabituel et ça me semble injuste.

Dubreuil Inhabituel, d'accord, mais pas injuste, au contraire! Ces aides sont des faibles, mal armés pour la lutte. Leur salaire est relativement médiocre, j'en conviens, mais il leur assure la sécurité dont ils ont besoin. Chez Bat'a, la sécurité est en bas et non en haut de l'échelle.

L'hôte Voilà qui suffit. Avec votre permission, monsieur Dubreuil...

Dubreuil (Étonné) Quoi ?... Déjà ! J'avais pourtant encore bien des choses à dire sur Bat'a! (Haussement d'épaules de résignation) Bon! (À la caméra.) C'est une organisation si avant-gardiste et si efficace que je vous recommande de tout apprendre à son sujet en lisant mon livre, $L$ 'exemple de Bat'a.

L'hôte Votre livre a été publié en 1936 ; bien des choses se sont passées depuis ce temps-là, entre autres en Tchécoslovaquie et chez Bat'a ! Êtes-vous certain que Bat'a fonctionne toujours de la même manière?

Dubreuil Sans aucun doute !

L'hôte Comment le savez-vous ?

Dubreuil J'ai communiqué avec eux! L'évolution du monde les a forcés à faire certains changements, mais les principes de base sont toujours les mêmes. Bat'a est encore comme Tomas Bat'a l'a fondée en 1894 : une entreprise décentralisée constituée de centres autonomes dont les membres participent aux bénéfices. Si les communistes n'avaient pas aboli la démocratie en Tchécoslovaquie, Bat'a aurait fait encore beaucoup plus de progrès.

Mayo $\quad \mathrm{Ah} ! \mathrm{ah} ! \mathrm{ah}$ ! La démocratie et le progrès, deux de mes dadas à moi !

Dubreuil Qu'est-ce que vous avez contre le progrès ? 
Mayo Pas à pas, avec notre progrès économique, nous avons détruit le sens individuel de la vie pour la majorité des citoyens.

Dubreuil Mais on a amélioré leur sort : en 1880, les paysans marchaient pieds nus, plus maintenant. Aujourd'hui, le dernier des citoyens voyage plus facilement et plus confortablement que les ministres de Louis XIV !

Mayo Vous venez de justifier magistralement mon point de vue ! On ne s'attend pas à ce que ce soit l'homme qui progresse, mais seulement son confort physique, son environnement matériel. On a confondu le confort et la civilisation !

Barnard Je constate que depuis le temps qu'on se connaît, vous n'avez pas changé de marotte, mon cher Elton!

Mayo Avec raison ! Nous avons fait avancer les sphères matérielles et scientifiques, mais dans le domaine humain et sociopolitique, nous nous sommes contentés d'agir sur la base de conjectures et de tâtonnements opportunistes.

L'hôte Conjectures et tâtonnements sont le propre d'une société qui évolue rapidement ; on ne peut pas tout prévoir ni tout organiser à la perfection du premier coup !

Mayo Peut-être pas, mais notre attitude a plongé notre monde moderne dans une situation sérieuse. Les scientifiques ont développé de manière formidable nos connaissances scientifiques et les ont appliquées trop rapidement pour que la société puisse s'y ajuster. On n'a qu'à regarder un peu partout les effets désastreux. Nous sommes passés d'une société organisée sur des bases plus ou moins rationnelles à une société tout à fait désorganisée, en bonne partie à cause d'un excès de rationalité ! Bravo!

L'hôte Alors là, si vous vous mettez à philosopher !

Mayo Moi philosopher, jamais ! J'ai vu trop de psychologues qui ont fait de la philosophie l'objet de leur dévotion ! Ils deviennent de terribles métaphysiciens et s'engagent dans des discussions qui durent toute la nuit, ne mènent nulle part et ne guérissent rien. Le spectacle de ces malheureux me fait me demander si la spéculation philosophique n'est pas simplement une maladie du cerveau humain ! 
Woodward L'objet de notre dévotion à nous, ce n'est ni la sociologie ni la philosophie, c'est le management qui, pour être efficace, doit faire progresser les organisations.

Mayo Progresser, qu'est-ce que c'est pour vous ?

Woodward C'est avoir la volonté de faire tout ce qui est possible, dans les limites imposées par les objectifs et la technologie, pour augmenter l'efficacité et le contrôle des opérations d'une organisation. Nous allons continuer à faire du management ; vous, continuez à faire de la politique !

Mayo Je ne fais pas plus de politique que de philosophie ! Le contrôle politique est le seul contrôle social dont nous admettions encore l'existence. Nous avons renversé le pouvoir de l'aristocratie et celui de l'Église, il nous faut maintenant renverser celui des politiciens... Ce sera une dure bataille !

L'hôte Mais, c'est une vraie révolution que vous suggérez !

Mayo Ils l'ont bien méritée !

L'hôte Comment?

Mayo En s'accaparant trop de pouvoir et en se mêlant de ce qui ne les regarde pas ou de ce qu'ils ne peuvent pas régler.

L'hôte Expliquez-vous!

Mayo Dans toute société, la vie sociale doit s'organiser. Comme l'État a tendance à tout organiser, il s'est graduellement mêlé de l'organisation de toutes les activités à caractère social. Or, l'État ne peut pas organiser effectivement la vie intime quotidienne des citoyens.

L'hôte Pourquoi?

Maya D'abord, parce que c'est une tâche impossible étant donné la complexité de nos sociétés modernes. Ensuite, parce que son activité est trop générale pour qu'il puisse comprendre et s'occuper de la réalité vivante, de la collaboration intime entre les gens. Ces choses-là doivent rester pour toujours en dehors de la sphère du contrôle politique. En s'immisçant dans ce domaine, l'État n'accomplit rien et engendre le déséquilibre social.

L'hôte Avez-vous trouvé un moyen de le rétablir, l'équilibre?

Mayo Oui, il faut étudier et comprendre les facteurs qui agissent sur le développement ou le déclin de l'organisation sociale. 
L'hôte En somme, l'État est une autre des choses dont vous n'avez pas une bien haute opinion!

Mayo Quand on pense à l'État, il faut se souvenir de deux choses : les hommes peuvent avoir des amis, l'État n'a que des intérêts ; ensuite, le clan est une communauté de groupes, tandis que l'État est une communauté d'individus, il y aura donc toujours une inévitable hostilité mutuelle entre le clan et l'État.

L'hôte Même en démocratie?

Mayo Surtout en démocratie !

L'hôte Ça aussi, vous êtes contre?

Mayo Pas vraiment, mais je ne peux pas m'empêcher de constater qu'il existe trois conditions qui limitent l'applicabilité d'un gouvernement démocratique.

L'hôte Qui sont?

Mayo Pour que la démocratie fonctionne,

1) il doit y avoir, dans la société, un niveau suffisamment élevé de talent technique et d'alphabétisation ;

2) il faut que les différents groupes sociaux aient des niveaux de vie relativement équivalents si le gouvernement représentatif veut pouvoir assurer le bien général de la société ; et

3) le gouvernement représentatif ne peut s'exercer efficacement que si la société n'est pas divisée par des hostilités et des haines de groupe. L'inhabileté des groupes à coopérer et l'hostilité qui s'ensuit ont en effet détruit de grandes civilisation.

L'hôte En somme, la démocratie n'est pas facile à vivre et ne vaut pas cher !

Mayo Elle n'est pas facile à vivre ni à appliquer, mais il reste qu'elle est incommensurablement supérieure à toutes les autres formes de gouvernement, de la monarchie au communisme !

L'hôte Merci monsieur Mayo. Politique, démocratie, gouvernement, tout cela implique la notion d'autorité dont monsieur Barnard a une conception étonnante, qui me semble différer de celle de nos invités des deux premières rencontres. Monsieur Barnard... 
Barnard Quelle qu'ait été la conception de vos précédents invités, voici ce que j'en pense. L'autorité est le caractère d'un ordre qui fait que cet ordre est accepté par le membre de l'organisation à qui il est destiné. L'autorité d'un ordre dépend donc de la personne à laquelle il s'adresse et non de la personne qui l'émet.

Dubreuil J'abonde clans votre sens. Il faut que celui qui donne des ordres sache les faire accepter pleinement par celui à qui il les adresse, qu'il obtienne sa confiance, son adhésion. Il n'existe pas d'autre manière de commander.

Barnard D'accord, il ne faut jamais émettre d'ordres qui ne seront pas respectés, ça détruit l'autorité, la discipline et le moral.

Woodward Ça me semble paradoxal : l'autorité ne vient-elle pas d'en haut ?

Barnard Il y a quelque chose de bien plus paradoxal, même les militaires pensent comme moi. Plusieurs grands généraux, dont le maréchal Foch, comprenaient bien ce fait et n'ordonnaient jamais à leurs troupes de charger ou d'avancer sans être certains qu'ils avaient le consentement de leurs soldats.

Woodward Quand et pourquoi un ordre est-il accepté ?

Barnard Un ordre est accepté quand la personne à qui il est destiné

1) l'a bien compris parce qu'il a été bien communiqué ;

2) croit que l'ordre est compatible avec le but de l'organisation;

3) croit qu'il est compatible avec son intérêt personnel; et

4) peut s'y conformer, mentalement et physiquement.

Mayo Si vous avez raison, pourquoi continue-t-on de croire que l'autorité est supérieure, qu'elle vient d'en haut?

Barnard La notion de l'autorité supérieure est une fiction, mais une fiction nécessaire, parce que c'est le procédé par lequel l'individu délègue vers le haut la responsabilité de la décision organisationnelle.

Dubreuil Trop d'ouvriers sont prêts à accorder ou à reconnaitre de l'autorité à d'autres parce qu'ils ne veulent pas assumer de responsabilité personnelle.

Barnard Vous l'aviez déjà dit et c'est juste. Une autre raison pour laquelle la fiction de l'autorité supérieure est nécessaire, c'est qu'elle rappelle à tous que c'est le bien de l'organisation qui est en cause. 
Mayo Qu'est-ce qui arrive quand un membre n'obéit pas ?

Barnard Manquer intentionnellement à une obligation est un acte d'hostilité qu'aucune organisation ne peut permettre. Dans ces cas, l'organisation doit réagir par une action punitive. Quand il s'agit de l'État, cette action peut aller jusqu'à l'incarcération et même jusqu'à l'exécution !

L'hôte Quelle décision à prendre pour un cadre ! C'est une épouvantable responsabilité qui relève de la morale !

Barnard Attention! Il ne faut pas confondre morale et responsabilité.

L'hôte Qu'est-ce qui les distingue?

Barnard La morale est une force personnelle, une propension qui tend à inhiber et à contrôler les désirs et les impulsions qui lui sont incompatibles et à intensifier ceux et celles qui s'y conforment.

L'hôte Et la responsabilité ?

Barnard La responsabilité est le pouvoir qu'a la morale de contrôler la conduite d'un individu quand il fait face à de forts désirs ou à des impulsions contraires à sa morale. La responsabilité véritable ne saurait exister si elle ne peut s'appuyer sur un code moral solide.

L'hôte Pourrait-on posséder un tel code tout en étant irresponsable ?

Barnard Bien sûr! Ceux qui ont de grandes valeurs morales ne sont pas nécessairement en mesure de les utiliser dans l'exercice de leurs responsabilités.

L'hôte Le cadre doit être à la fois moral et responsable, ce qui n'est pas facile !

Barnard D'autant moins qu'il peut y avoir conflit entre son propre code moral et celui de l'organisation. Quand ça arrive, c'est un affreux dilemme qui place le cadre devant le choix de détruire ou bien sa probité personnelle ou bien la cohésion et l'efficacité de 1'organisation.

L'hôte Voilà une illustration des complexités du processus décisionnel !

Barnard Oui et non! Il est relativement rare que la morale entre en ligne de compte dans une décision à prendre. C'est une circonstance à laquelle il faut faire face quand elle se présente mais que je préfère ne pas considérer quand je pense au procédé de prise de décision en général. 
L'hôte Alors, qu'est-ce que vous considérez ?

Barnard Que pour choisir, il faut limiter les possibilités. En conséquence, et aussi bizarre que cela puisse paraître, la manière la plus courante de décider est de se demander si on ne peut pas éviter de prendre une décision!

L'hôte Toujours énigmatique ! Comment diable faites-vous donc pour décider?

Barnard L'art de prendre des décisions consiste

1) à ne pas prendre des décisions qui ne sont pas immédiatement pertinentes ;

2) à ne pas décider prématurément ;

3) à ne pas prendre des décisions qui ne peuvent pas être exécutées; et

4) à ne pas prendre des décisions que d'autres peuvent prendre !

L'hôte Voilà ce qu'il faut «ne pas faire »! Qu'est-ce qu'il faut faire ?

Barnard Il ne faut jamais oublier que le succès d'une décision est souvent incertain et qu'il dépend en bonne partie du contrôle qu'on a sur sa réalisation. Prendre une décision efficace, c'est aller au-delà du choix, c'est exercer un contrôle au bon moment, au bon endroit. en bonne dose et de manière appropriée de sorte que la décision, une fois réalisée, atteigne les buts qu'elle visait.

L'hôte Les effets d'une décision sont donc reliés aux buts?

Barnard Pas uniquement. Certaines décisions prises par l'organisation en altéreront l'environnement ou certains facteurs stratégiques. Mais le cadre, habituellement, prend des décisions qui lui permettront d'atteindre des buts. Or, comme le présent toujours changeant d'une organisation engendre continuellement des nouveaux buts, le procédé décisionnel ne s'arrête jamais.

L'hôte Ce qui peut être encourageant ou décourageant !

Barnard Jamais décourageant ! Il faut croire en l'organisation et toujours continuer de contribuer à son efficacité et à sa survie !

L'hôte Quelle sagesse, quelle lucidité dans vos propos! On a eu raison de vous appeler l'Aristote du management ! 
Barnard Je vous en prie, n'insistez pas. Je n'ai voulu que faire profiter mes successeurs de mes réflexions!

L'hôte Merci, monsieur Barnard (Il se tourne vers Joan Woodward.) Madame Woodward, votre étude dans le South Essex a contribué à ce qu'on appelle aujourd'hui la théorie de la contingence.

Woodward Merci, mais ce fut une découverte surprise pour moi et pour tous ceux qui ont participé à cette étude.

L'hôte Comme la contingence est un principe important, pouvez-vous nous résumer ce que vous entendez par là ?

Woodward Que les mêmes règles peuvent produire des résultats différents dans des circonstances différentes.

Barnard Donc, il n'y a plus de règles ?

Woodward Si, mais leur utilisation en tant que guides est limitée.

Barnard Que voulez-vous dire?

Woodward Je vais vous donner un exemple qui va vous faire comprendre. On dit que l'eau bout à $100^{\circ} \mathrm{C}$. C'est une règle, mais elle n'est pas toujours vraie, elle est flexible. Nous savons tous que l'altitude, la pression atmosphérique et plusieurs autres facteurs font varier la température à laquelle l'eau bout. Eh bien, il en va de même des prescriptions en matière de management : elles doivent être utilisées avec beaucoup de circonspection... parce que toutes les marmites ne bouillent pas infailliblement à $100^{\circ} \mathrm{C}$ !

Barnard En somme, selon vous, il n'y a pas de règles rigoureuses qui s'appliquent dans tous les cas?

Woodward C'est juste. Mais ça n'empêche pas que des informations recueillies dans des situations différentes peuvent être systématisées et qu'on peut dégager des tendances générales. Ce que je voudrais que vous reteniez de mes recherches, c'est que la structure organisationnelle est le produit d'un nombre inconnu ou mal connu de variables.

L'hôte Merci madame Woodward. Il ne nous reste presque plus de temps ; avant de terminer cet entretien, je vais demander à chacun de vous de laisser à notre public une dernière pensée qui puisse le guider dans ses réflexions sur le management. Monsieur Dubreuil. 
Dubreuil Pensez que l'ouvrier n'a qu'une propriété, celle de son métier, et qu'il a le désir et le droit de travailler dans la joie, comme son patron!

L'hôte Monsieur Mayo.

Mayo Pensez que les situations humaines sont infiniment plus compliquées que les descriptions des manuels !

L'hôte Madame Woodward.

Woodward Pensez que toutes les règles, tous les principes sont flexibles.

L'hôte Monsieur Barnard.

Barnard Pensez!

L'hôte (Au moins souriant) Merci à tous les quatre. (À la caméra) Merci à vous tous d'avoir été des nôtres et nous espérons que ces entretiens vous ont été profitables et le seront pendant encore longtemps. Au revoir à tous ! 


\section{Épilogue}

\section{À propos de l'actualité des idées qui font l'objet de discussion dans cet ouvrage}

Les lecteurs auront peut-être été étonnés du choix des auteurs que nous avons fait revivre dans cet ouvrage. En effet, ils ont probablement entendu parler à plus d'une occasion du modèle bureaucratique de Max Weber, de l'organisation scientifique de Frederick Winslow Taylor, des fonctions de gestion énoncées par Henri Fayol et des recherches d'Elton Mayo mettant en relief l'importance des aspects humains dans l'étude des organisations. Moins nombreux, peut-être, sont ceux qui, déjà, connaissaient Mary Parker Follett et son point de vue sur la gestion des conflits, Chester Irving Barnard et sa conception des organisations comme " systèmes coopératifs ", Joan Woodward et ses études sur les implications de différentes technologies sur les structures de l'organisation ou encore Hyacinthe Dubreuil et ses propositions avantgardistes sur le fonctionnement des groupes de travail dans les organisations.

Quoi qu'il en soit, on peut se demander si les développements technologiques, sociaux, économiques et politiques qui ont marqué le monde depuis les vingt-cinq dernières années ne rendent pas caduques les idées émises par des auteurs réagissant au contexte de leur temps, soit la fin du $\mathrm{XIX}^{\mathrm{e}}$ siècle et la première moitié du $\mathrm{XX}^{\mathrm{e}}$ siècle. Leurs idées valent-elles toujours dans le contexte des nombreux changements technologiques qui se multiplient à un rythme incessant dans pratiquement tous les champs de l'activité scientifique et humaine ? Comment, par exemple, ces auteurs réagiraient-ils à l'informatisation systématique des organisations modernes, au développement d'Internat, du courrier et du commerce électroniques ? Les problèmes 
environnementaux, tels ceux créés par l'effet de serre ou encore la pollution atmosphérique, relativement moins aigus à leur époque mais de plus en plus préoccupants en ce début de troisième millénaire, les problèmes démographiques (la surpopulation dans certains pays, le vieillissement dans d'autres), ou encore de nouveaux phénomènes sociaux (la famille éclatée, l'émancipation du rôle des femmes, le travail autonome) les feraient-ils « changer »d'idées ou renforceraient-ils celles qu'ils ont émises ? La libéralisation des échanges commerciaux, l'extraordinaire fluidité des transactions financières, l'émergence de l'économie du savoir et la vague récente de fusions résultant en des mégaentreprises multinationales ne les amèneraient-ils pas à remettre en question leur conception de l'organisation somme toute assez peu « ouverte » et « sensible » à l'environnement ? Et que dire des modifications aux rôles des États, de moins en moins en mesure d'assumer leurs fonctions de régulateurs de l'activité sociale et économique ? Dans quelle mesure le postmodernisme et le poststructuralisme qui, l'un et l'autre, rejettent la prétention scientifique du management pour mieux insister sur la primauté du symbolisme et du langage organisationnels, auraient-ils ébranlé les discours de ces auteurs ? Auraient-ils pu développer, dans le contexte sociopolitique actuel, une sensibilité postmoderne ou poststructuraliste?

Plus précisément, que penser du modèle bureaucratique de Max Weber que plusieurs jugent inadéquat en ces temps où l'entreprise moderne doit faire preuve de créativité, de flexibilité et de rapidité d'action ? Comment Weber lui-même réagirait-il au procès que ne manqueront pas de lui faire les tenants du postmodernisme, critiques d'une rationalité trop réductrice de la réalité et d'une approche exagérant l'importance des structures formelles d'organisation ? Et pourtant, la bureaucratisation, si souvent dénoncée, semble en pratique, et malgré les nouvelles technologies des communications et de l'information, n'épargner que les organisations de petite taille, encore à un stade préliminaire de développement. Au-delà des inconvénients bien connus des bureaucraties que personne ne cherche à nier, les propos de Weber nous invitent à réfléchir aux conséquences qui découlent des formes modernes d'exercice de l'autorité. Rien n'empêche 
de penser à de nouveaux modes d'organisation, bien au contraire, et plusieurs auteurs s'y emploient. Cependant, leurs conceptions peuventelles faire abstraction du fait que des forces importantes, notamment dans les organisations publiques et les grandes organisations privées, semblent pousser vers la bureaucratisation ? Que penserait Weber des tentatives de « débureaucratisation », enclenchées par la plupart des États modernes ? Les jugerait-il futiles devant la rationalisation et la bureaucratisation poussées à l'extrême qui caractérisent nos organisations actuelles, voire nos sociétés ? De même, pour tout soucieux que soit le poststructuralisme de vaincre les caractères autoritaire et rigide du modèle bureaucratique de Weber en privilégiant un projet d'émancipation collective, encore faut-il bien reconnaître que celui-ci demeure toujours indéfini, donc toujours plus une utopie qu'une alternative concrète ${ }^{1}$.

De la même façon, comment ne pas être tenté de rejeter l'approche de Frederick Winslow Taylor à l'organisation du travail, d'autant plus que, pour plusieurs, Taylor a contribué à exacerber des conditions de travail aliénantes. Durant les années 1970, on chantait les vertus du marxisme-léninisme et du maoïsme. Taylor, lui, apparaissait comme l'un des ennemis jurés du syndicalisme, des ouvriers et des intellectuels bien pensants. On se plaisait à faire du taylorisme le complément du capitalisme sauvage, tout en omettant d'expliquer pourquoi, malgré tout, Taylor avait eu de l'influence non seulement aux États-Unis et dans d'autres pays occidentaux, mais également dans l'U.R.S.S. d'alors, notamment sous Lénine ! Rares sont ceux qui prenaient alors la peine d'expliquer dans quel contexte favorable du début du siècle le taylorisme s'était développé alors que bien des travailleurs, non scolarisés, illettrés et souvent nouvellement immigrés, ne demandaient pas mieux que d'augmenter substantiellement leurs revenus. Pas étonnant que Peter F. Drucker ait prétendu dans un ouvrage récent que l'augmentation de la productivité découlant de l'étude du travail manuel selon les méthodes de Taylor explique la totalité des progrès économiques et sociaux du $\mathrm{XX}^{\mathrm{e}}$ siècle $^{2}$. 
Et pour ne pas être en reste, on doit rappeler que l'examen rigoureux des processus de travail prescrit par Taylor constitue une caractéristique importante d'approches modernes comme la qualité totale ${ }^{3}$ ou la " réingénierie du travail ${ }^{4}$ ». En ce sens, et malgré les prétentions d'enrichissement et de distinction élevées qui accompagnent tout nouveau discours managériel, force est d'admettre que le management est toujours redevable à Taylor de certaines de ses idées et méthodes! Seule une lecture attentive des discours de ces auteurs classiques permet de mettre à nu cette dette intellectuelle du management contemporain et, de là, leur caractère nettement plus conservateur et statique que ne le suggèrent nombre d'auteurs à succès 5 .

Et que dire des propositions d'Henri Fayol sur les fonctions de gestion, propositions contestées par Henry Mintzberg ${ }^{6}$ au début des années 1970, mais qui inspirent toujours les offres d'emploi adressées aux cadres. On n'a qu'à consulter les journaux de fin de semaine pour s'en convaincre ! Il faut d'ailleurs préciser que le point de vue de Mintzberg est lui-même contesté aujourd'hui ${ }^{7}$. On oublie trop souvent qu'Henri Fayol fut le premier à proposer une série de fonctions propres à l'exercice de la gestion, à suggérer les qualités que devraient posséder les cadres

Drucker, Peter F. (2000). L'avenir du management selon Drucker Paris, éditions Village Mondial, p. 13a. Le chapitre 5 de l'ouvrage qui débute par cette reconnaissance de la contribution de Taylor porte sur le défi que pose l'amélioration de la productivité du travailleur du savoir.

Schmidt, Warren et Jerome P. Finnigan (1992). The Race Without a Finish fine, America's Quest for Total Quality, San Francisco, CA, Jossey-Bass.

4.

Hammer, Michael et Steven A. Stanton (1995). The Reingineering Revolulion, a Handbook, New York, Harper Business.

Nous pensons tout particulièrement, pour n'en nommer qu'un, à Thomas J. Peters, auteur de nombreux best-sellers sur le management au cours des années 1980 et 1990.

6. Mintzberg, Henry (1984). Le manager au quotidien : les dix rôles du cadre, Paris, Les Éditions d'Organisation.

7. Pour un point de vue critique sur la perspective de Mintzberg et une appréciation du point de vue d'Henri Fayol, nous suggérons Lemaitre, Pierre (1994). À propos des recherches d'Henry Mintzberg sur le travail du managery, Revue française de gestion, janvier-février, n 97 , p. 67-74 (l'article comprend une réplique de Mintzberg). 
et à se faire le promoteur du développement et de l'enseignement du management, à une époque où on ne se préoccupait que des fonctions commerciales, techniques et financières des organisations.

L'incident à l'usine d'Hawthorne ${ }^{8}$ a permis à Elton Mayo de développer ses thèses bien connues sur l'importance de tenir compte de la dimension humaine et de celle des groupes dans la compréhension des comportements clans l'organisation. C'est d'ailleurs à Mayo qu'on doit les débuts de ce qu'il est convenu d'appeler « l'école des relations humaines » dont les contributions sont toujours d'actualité. Il faut aussi prendre conscience du fait que la démarche d'observation directe des phénomènes organisationnels, largement critiquée à l'époque, est abondamment utilisée aujourd'hui. En effet, comment ne pas reconnaître l'influence de Mayo sur le discours managériel de la qualité totale qui, ainsi, serait une espèce d'hybride de deux courants par trop souvent considérés comme mutuellement exclusifs, à savoir " l'école des relations humaines » et « l'organisation scientifique du travail Dans un même ordre d'idées, comment pourrait-on nier la récupération des travaux de Mayo que font systématiquement les discours contemporains sur la culture organisationnelle en tant que facteur d'accroissement de l'efficacité et de l'efficience') ?

Mary Parker Follett, une intellectuelle certes utopique mais non dénuée de sens pratique, a émis des idées très avancées pour l'époque sur nombre de phénomènes organisationnels ${ }^{10}$. H. Waterman Jr. (1999). Le prix de l'excellence, nouvelle édition, Paris. Dunod ; Ouchi, William G. (1982). Theorie Z-faire face au défi japonais, Paris. Interéditions ; Serge, Peter (1991). La cinquième discipline. Paris, First ; Osborne, David et Ted Gaebler (1992). Reinventing Government - How the Entrepreneurial Spirit is Transforming the Public Sector, Reading (MA), Addison-Wesley Publishing Company.

10. Le lecteur pourra en juger lui-même en consultant un ouvrage récent rééditant les écrits de Mme Follet' et faisant état de nombreux témoignages sur le caractère contemporain de ses idées : Graham, Pauline (1995). Mary ParkerFollett. Prophet of Management : A Celebration of Writings from the 1920s, Boston, MA. Harvard Business School Press. 
Ainsi, elle est une pionnière par l'avant-gardisme de ses idées, mais également du fait qu'elle était une femme. En effet, l'époque, très peu de femmes étaient admises dans cet univers masculin de la gestion. Aussi étonnant que cela puisse paraître, son discours ne laisse cependant transparaître aucune idéologie à caractère féministe. Il faut dire que ce n'était pas encore à la mode... Parmi les thèmes abordés par Follett, mentionnons les conflits, qu'elle ne considère pas comme pathologiques mais comme inévitables et générateurs d'idées et dont la résolution optimale doit reposer sur une stratégie " gagnant-gagnant » et la recherche d'une solution originale répondant pleinement aux attentes des parties. On ne peut s'empêcher ici de faire un lien avec la négociation raisonnée, une méthode de négociation fort à la mode ces dernières années $^{11}$. Signalons également l'autorité hiérarchique et le pouvoir en général dont Follett rappelle l'importance qu'ils soient exercés par ceux qui, dans l'organisation, sont les mieux placés pour ce faire. Cette « loi de la situation "> s'apparente, à bien des égards, au principe de subsidiarité qui fait un retour en force, ces dernières années, dans la pratique de la gestion ${ }^{12}$. Rappelons enfin sa critique des aspects dominateurs associés à l'exercice du contrôle qui témoigne, de façon limitée mais réelle, d'une certaine communauté d'esprit avec le courant poststructuraliste en études managérielles. Privilégiant une approche psychologique, elle se prononce également sur l'importance de la participation des employés aux décisions qui les concernent dans l'organisation, de la réconciliation et de l'arbitrage des points de vue divergents et sur l'exercice du leadership. Parions que plagier les idées de madame Follett ferait passer l'auteur du méfait pour un esprit avantgardiste... même en ce début de millénaire. La lecture de ses textes est convaincante à cet égard.

Gestionnaire chevronné d'une entreprise de téléphone (un secteur de haute technologie à l'époque), Chester Barnard émet (19R2). Comment réussir une négociation, Paris, Éditions du Seuil.

12. Pour en savoir plus sur le principe de subsidiarité Million-Delson, Chantal (1993). Le principe de subsidiarité, Paris, Presses universitaires de France. 
une idée apparemment simple mais finalement fort évocatrice sur la façon de concevoir les organisations : selon lui, les organisations doivent être conçues comme des systèmes coopératifs dont les objectifs ne peuvent être réalisés avec succès que si les dirigeants tiennent compte des objectifs et des intérêts individuels des employés. C'est ce postulat de départ qui donne aux propos de Barnard sur l'exercice de l'autorité, la prise de décision et le travail des administrateurs toute leur originalité. Proposée clans les années 1930, cette idée de la coopération comme dynamique de succès pourrait constituer une piste de développement fort pertinente dans de nombreuses organisations modernes. De plus, Barnard pourrait certainement se vanter d'avoir fait germer l'idée d'une conception systémique de l'organisation, conception encore largement utilisée aujourd'hui pour mieux comprendre les dynamiques organisationnelles.

Parmi les auteurs présentés, Joan Woodward incarne le plus l'image du chercheur universitaire dont les thèses reposent sur des recherches rigoureuses et empiriques. Les études de Woodward sur les implications de diverses technologies sur les structures des organisations font d'elle un précurseur dans la mesure où, aujourd'hui, l'informatique, la bureautique et la robotique perturbent la structuration des organisations contemporaines $^{13}$. On peut donc voir un lien entre la primauté des technologies clans l'organisation sur laquelle insiste Woodward et le discours récent sur la réingénierie qui repose, entre autres choses, sur le rôle névralgique des nouvelles technologies de l'information et des communications (NTIC) pour reconfigurer d'une manière (prétendument) optimale l'organisation du travail ${ }^{14}$. transformations profondes découlant de la révolution numérique, une révolution non amorcée à l'époque de Joan Woodward mais qui renforce ses idées concernant l'impact des technologies sur le tissu social de l'entreprise, voire sur la société dans son ensemble. Nous proposons au lecteur les chapitres 3 «L'entreprise en réseau » et 4 « La transformation du travail et de l'emploi » du premier ouvrage de la trilogie : La société en réseaux, l'ère de l'information, Paris, Payard. 1998.

14. Hammer, Michael et James Champy (1993). Le rengineering - Réinventer l'entreprise pour une amélioration spectaculaire de ses performances. Paris, Dunod, p. 97-115. 
Hyacinthe Dubreuil a d'abord été un ouvrier. Syndicaliste français sympathique aux idées socialistes, il étonne par ses propos sur le changement et la résistance persistante des humains aux idées nouvelles et aux innovations. Dans l'introduction de son ouvrage sur l'entreprise de chaussures Bat'a, Dubreuil débute avec les deux anecdotes suivantes.

On raconte que lorsque les chevaliers français eurent perdu la bataille de Crécy en 1346, ils protestèrent avec indignation contre l'emploi que leurs adversaires avaient fait d'une nouveauté technique avec laquelle ils n'étaient pas encore familiers. Traditionnellement hardés de fer, ils s'étaient présentés en ce lourd équipage, devant les canonniers d'Édouard III qui leur avaient envoyé à grand bruit leurs gros boulets de pierre. On dit alors que, si les boulets ne firent, paraîtil, guère de mal, les chevaux - et sans doute les hommes aussi - eurent grand peur de ce bruit terrifiant et nouveau, ce fut la principale cause de leur panique. Ce qui est certain, c'est que cette déroute vint annoncer au monde que l'usage de l'armure allait tomber en désuétude, comme étant inefficace devant un nouvel engin. [...] les combattants surpris protestèrent, en déclarant que l'emploi du canon n'était pas chevaleresque.

[...] Bayard, qui devait mourir deux siècles plus tard d'un coup d'arquebuse, estimait encore qu'une arme à feu , « qui atteignait l'ennemi de si loin, ne convenait qu'à des gens sans courage ${ }^{15} »$.

Dubreuil veut ainsi illustrer la traditionnelle résistance au changement qui, sur le plan commercial, se manifeste ''lorsqu'un concurrent étranger fait tout à coup irruption sur le marché, en surprenant tout le monde

15. Dubreuil, Hyacinthe (1936). L'exemple de Bat'a ; la libération des initiatives individuelles dans une entreprise géante, Paris, Éditions Bernard Grasset. Les extraits sont tirés des pages 13 et 14 . 
par l'efficacité supérieure de ses méthodes $^{16}$ ". À titre d'exemple, Dubreuil rappelle que l'industrie française de l'automobile du temps, qui jusqu'alors dominait ce secteur, a ressenti brusquement le choc des méthodes américaines. Comment ne pas sourire à la lecture de ces quelques lignes à propos de la réaction de ces mêmes Américains, quelques décennies plus tard, aux méthodes nippones! Et comment ne pas s'étonner du caractère supposé moderne de la qualité totale lorsque le même auteur attribue à " la perfection incessante du travail, l'amélioration continue de la qualité du produit et des services rendus au public... ${ }^{17}$ » le fait que l'industrie du caoutchouc soit devenue un modèle d'organisation pour toutes les autres.

Par ailleurs, la remise en question que fait Dubreuil, un syndicaliste, du salaire comme mode de contrôle du temps du travailleur plutôt que comme reconnaissance de la production qui en découle pourra en étonner plusieurs. Qui sait si cette quasi-obsession pour la liberté créatrice du travailleur ne trouverait pas satisfaction aux yeux de cet auteur devant cette nouvelle réalité que sont les travailleurs autonomes! D'un côté, parce que leur contrat psychologique ne les lie plus à une organisation au sens traditionnel, mais renvoie plutôt à une entente ponctuelle portant sur des résultats, ces travailleurs incarnent peut-être l'idéal de Dubreuil. D'un autre côté, la précarité des conditions de travail de ces nouveaux travailleurs et l'incertitude du nouveau contrat psychologique qui lie l'individu à une activité donnée ne concourent peut-être pas à accroître cette liberté créatrice du travailleur, tant souhaitée par Dubreuil, mais plutôt à accentuer, sous une forme nouvelle, l'inféodation du travailleur ${ }^{18}$.

16.

17.

18.
Idem, p. 14.

Idem, p. 15.

Pour plusde détails sur la notion de « contrat psychologique », le lecteur est invité à consulter Margaret M. Blair et Thomas A. Kochan (sous la direction de) (2000). The New Relationship - Human Capital in the American Corporation. Washington (DC), Brookings Institution Press. 
Weber, Taylor, Fayol, Mayo, Follett, Barnard, Woodward et Dubreuil ont tous contribué, chacun à leur façon, à l'avancement des connaissances — théoriques et pratiques - en management. Sans prétendre que l'ensemble des idées qu'ils ont défendues est encore d'actualité, il importe de reconnaître que plusieurs d'entre elles sont toujours pertinentes pour le management contemporain. Qui plus est, nous l'avons vu, plusieurs des idées présentées constituent en fait les prémisses de concepts à la mode de nos jours. Ignorer le passé peut nous condamner à le répéter bêtement. D'ailleurs, on reproche souvent à l'administration publique — et probablement à l'ensemble des sciences de la gestion - de n'être pas suffisamment cumulative ${ }^{19}$. En d'autres mots, plutôt que de bâtir sur des fondations existantes, on repart souvent à zéro. Souhaitons que cet ouvrage contribuera au moins à éviter un tel piège. Et, s'il était permis d'émettre un autre souhait, il consisterait à espérer que les Grands Esprits permettent à plusieurs de distinguer l'essentiel de l'accessoire et de départager le fondamental du superficiel dans les nombreuses approches, théories et techniques qui sont proposées, chaque année, pour mieux comprendre les organisations et agir sur elles.

Julie Fortin,

étudiante au doctorat, ENAP

Daniel Maltais et Christian Rouillard, professeurs, ENAP 


\section{Bibliographie}

\section{Ouvrages et articles écrits par les « Grands Esprits »}

Note: Les bibliographies présentées pour chacun des "Grands Esprits 》 ne contiennent que des ouvrages ou articles écrits par eux. En outre, nous ne prétendons pas que la liste des ouvrages et articles présentés est exhaustive puisque nous n'avons retenu que les écrits traitant plus ou moins directement des organisations, de leur fonctionnement ou de leur gestion. Enfin, nous avons privilégié les titres en français lorsqu'ils étaient disponibles. Les [ ] indiquent l'année de parution de l'ouvrage ou l'article original.

\section{Ouvrages et articles par Chester I. Barnard}

Barnard, Chester I. ([1938], 1968). The Functions of the Executive, nouvelle édition pour le $30^{\mathrm{e}}$ anniversaire de la publication originale (1938), Cambridge, Ma., Harvard University Press, 334 pages.

Barnard, Chester I. (1939). Dilemmas of Leadership in Democratic Process. Fondation L. Baker, Princeton University.

Barnard, Chester I. ([1948], 1969). " Organization and Management », Selected Papers, Cambridge, Harvard University Press, 244 pages.

Barnard, Chester I. (1962). « Functions and Pathology of Status System in Formal Organizations ", Organization and Management, Cambridge, Harvard University Press.

Barnard, Chester I. (1962). "The Nature of Leadership ", Organization and Management, Cambridge, Harvard University Press.

Barnard, Chester I. (1962). "Education for Executives », Organization and Management, Cambridge, Harvard University Press. 


\section{Ouvrages et articles par Hyacinthe Dubreuil}

Dubreuil, Hyacinthe (1925). La coopérative de main-d'œuvre : la liberté et l'éducation ouvrière, une production abondante et loyale, une rétribution juste des rapports de paix, par une organisation coopérative du travail, Paris, Association pour le développement des contrats coopératifs de travail, 17 pages.

Dubreuil, Hyacinthe (1931). Nouveaux standards: les sources de la productivité et de la joie, Paris, Grasset.

Dubreuil, Hyacinthe (1934). Les codes de Roosevelt et les perspectives de la vie sociale, Paris, Grasset.

Dubreuil, Hyacinthe (1935). À chacun sa chance : l'organisation du travail fondée sur la liberté, Paris, Grasset, 324 pages.

Dubreuil, Hyacinthe (1936). L'exemple de Bat'a, la libération des initiatives individuelles dans une entreprise géante, Paris, Grasset.

Dubreuil, Hyacinthe (1941). La chevalerie du travail, Paris, Grasset.

Dubreuil, Hyacinthe (1953). Le travail et la civilisation: esquisse de l'histoire et de la philosophie du travail, Paris, Pion.

Dubreuil, Hyacinthe (1956). Le campagnonnage : extrait des comptes rendus de l'Académie des sciences morales et politiques, Paris, Imprimerie de Campagnonnage.

Dubreuil, Hyacinthe (1956). Des robots et des hommes : l'ouvre et l'influence de l'ingénieur Taylor, Paris, Grasset, 335 pages.

Dubreuil, Hyacinthe (1962). Si tu aimes la liberté, Paris, Nouvelles Éditions Latines, 156 pages.

Dubreuil, Hyacinthe (1963). Promotion, préface de Louis Armand, Paris, Éditions de l'entreprise moderne, 237 pages.

Dubreuil, Hyacinthe (1971). J'ai fini ma journée, Paris, Librairie du Campagnonnage. 


\section{Ouvrages et articles par Henri Fayol}

Fayol, Henri ([1916], 1970). Administration industrielle et générale : prévoyance, organisation, commandement, coordination, contrôle, Paris, Dunod, 151 pages.

Fayol, Henri (1919). "L'industrialisation de l'État », Bulletin de la Société de l'industrie minérale, deuxième livraison.

\section{Ouvrages et articles par Mary Parker Follett}

Follett, Mary Parker (1896). The Speaker of the House of Representatives, New York, Longmans, Green \& Co.

Follett, Mary Parker (1920). The New State : Group Organization, the Solution of Popular Governments, New York, Longmans, Green \& Co.

Follett, Mary Parker (1924). Creative Experience, New York, Longmans, Green \& Co.

Follett, Mary Parker (1942). Dynamic Administration : The Collected Papers of Mary Parker Follett, New York, Harper and Row, 320 pages.

Follett, Mary Parker (1987). Freedom and Coordination : Lectures in Business Organization, New York, Garland, 89 p.

\section{Ouvrages et articles par Elton Mayo}

Mayo, Elton (1919). Democracy and Freedom : An Essay in Social Logic, Melbourne, Macmillan.

Mayo, Elton (1923). «Irrationality and Revery », Personnel Journal, vol. 7, nº 10.

Mayo, Elton (1924). « Civilized Unreason », Harper's Magazine, vol. 148, mars.

Mayo, Elton (1924). « Civilization : The Perilous Adventure », Harper's Magazine, vol. 149 , octobre. 
Mayo, Elton (1924). « Revery and Industrial Fatigue », The Journal of Personnel Research, vol. $3, \mathrm{n}^{\circ} 8$, décembre.

Mayo, Elton (1925). « The Great Stupidity », Harper's Magazine, vol. 151, ${ }^{\circ} 902$, juillet, p. 230-231.

Mayo, Elton (1927). « Sin with Capital », Harper’s Magazine, vol. 154, avril.

Mayo, Elton (1929). " The Maladjustment of the Industrial Worker », Wertheim Lectures on Industrial Relations, Cambridge, Harvard University Press, 172 pages.

Mayo, Elton ([1933], 1986). The Human Problems of an Industrial Civilization, réimpression, Salem, Ayer, 194 pages.

Mayo, Elton (1937). (En collaboration avec L.J. Henderson et T.N. Whitehead) « The Effects of Social Environment ", Papers on the Science of administration, publié par Luther Gulick et Lyndall Urwick, New York, Institute of Public Administration.

Mayo, Elton (1937). « What Every Village Knows », Survey Graphic, vol. 26, n 12 , décembre.

Mayo, Elton (1937). " Psychiatry and Sociology in Relation Disorganization », American Journal of Sociology, vol. 42, mai.

Mayo, Elton (1939). " Routine Interaction and the Problem of Collaboration ", American Sociological Review, vol. 4, $\mathrm{n}^{\mathrm{o}} 3$.

Mayo, Elton (1939). « Changing Methods in Inclustry », Personnel Journal, vol. 8, $\mathrm{n}^{\mathrm{o}} 5$.

Mayo, Elton (1941). « Research in Human Relations », Personnel, vol. 16, $\mathrm{n}^{\circ} 4$, p. 267-268.

Mayo, Elton (1944). (En collaboration avec George F.F. Lombard) Teamwork and Labor Turnover in the Aircraft Industry of Southern California, vol. 31, $\mathrm{n}^{\circ}$ 6, Business Research Studies $n^{\circ} 32$, Boston, Harvard University Graduate School of Business, Bureau of Business Research. 
Mayo, Elton (1945). The Social Problems of an Industrial Civilization, avec, en annexe : The Political Problems of Industrial Civilization, Boston, Ma., Harvard University, Graduate School of Business Administration, 176 pages.

Mayo, Elton (1948). Some Notes on the Psychology of Pierre Janet, Cambridge, Harvard University Press.

\section{Ouvrages et articles par Frederick Winslow Taylor}

Taylor, Frederick Winslow (1894). " Notes on Belting ", American Society of Mechanical Engineers (A.S.M.E), vol. 15. Cet article est paru en français sous le titre : «L'emploi des courroies », Revue de métallurgie, mars 1907.

Taylor, Frederick Winslow (1895). « A Piece Rate System », American Society of Mechanical Engineers (A.S.M.E), vol. 16.

Taylor, Frederick Winslow (1906). " On the Art of Cutting Metals », American Society of Mechanical Engineers (A.S.M.E), vol. 28. Cet article est paru en français sous le titre : «La taille des métaux », clans la Revue de Métallurgie, mars 1907.

Taylor, Frederick Winslow (1909). « Why Manufactures Dislik College Graduates » Sibley journal of Engineering, vol. 24. Cet article est paru en français sous le titre : « Pourquoi les industriels n'apprécient pas les diplômés des Universités et des Écoles techniques », dans la Revue de métallurgie, 1910.

Taylor, Frederick Winslow (1919). « Publications posthumes de Frederick Winslow Taylor », Revue de métallurgie, 37 pages.

Taylor, Frederick Winslow (1947). Shop Management, New York, Harper \& Brothers.

Taylor, Frederick Winslow (1965). La direction scientifique des entreprises (cette édition comprend aussi une traduction du témoignage de Taylor lors de sa comparution devant un comité de la Chambre des Représentants), Paris, Dunod, 309 pages.

Taylor, Frederick Winslow (1972). Scientific Management Comprising Shop Management. The Princip/es of Scientific Management and Testimony Before the Special House Committee, Londres, Greenwood Press. 


\section{Ouvrages et articles par Max Weber}

Weber, Max ([19491, 1964). The Methodology of the Social Sciences, traduction de Edward A. Shils et Henry A. Finch, New York, Free Press of Glencoe, 188 pages.

Weber, Max (1958). From Max Weber : Essays in Sociology, New York, Oxford University Press, 490 pages.

Weber, Max (1959). Le savant et le politique, Paris, Édition Plon, coll. Recherches en sciences humaines.

Weber, Max (1964). The Theory of Social and Economic Organization, édité par Talcott Parsons, New York, Free Press, 436 pages.

Weber, Max (1965). Politics as a Vocation, Philadelphia, Fortress Press. Weber, Max (1967). Études de sociologie de la religion, Paris, Pion.

Weber, Max (1967). L'éthique protestante et l'esprit du capitalisme, suivi d'un autre essai comprenant Études de sociologie de la religion, Paris, Plon, 340 pages.

Weber, Max (1968). Max Weber on Charisma and Institution Building : Selected Papers, textes rassemblés et présentés par Shumel N. Eisenstadt, Chicago, Ill., University of Chicago Press, 313 pages.

Weber, Max (1969). Basic Concepts in Sociology, traduit par H.P. Secher, Westport, Ct., Greenwood Press, 1969, 123 pages.

Weber, Max (1971). Économie et société, traduction de Julien Freund et autres, sous la direction de Jacques Chavy et Éric de Dampierre, Tomes 1 et 2, Paris, Plon.

Weber, Max (1981). General Economic History, New Brunswick, N.J., Transaction Books, 401 pages.

Weber, Max (1982). La ville (traduit de l'allemand par Philippe Fritsch), Paris, Aubier-Montaigne, 218 pages.

Weber, Max (1986). Sociologie du droit, Paris, Presses universitaires de France, 242 pages. 
Weber, Max (1991). Histoire économique: esquisse d'une histoire universelle de l'économie et de la société, traduit par Christian Bouchindhomme, Paris, Gallimard, 1991, 431 pages.

\section{Ouvrages et articles par Joan Woodward}

Woodward, Joan (1958). Management and Technology, London, Her Majesty's Stationery Office, 39 pages.

Woodward, Joan ([1965], 1980). Industrial Organization: Theory and Practice, $2^{\mathrm{e}}$ édition, London, New York, Oxford University Press, 281 pages.

Woodward, Joan (1970). Organizational Behavior Models, avec commentaires de Elmer Burack, édité par Anant R. Negandhi et Joseph P. Schwitter, Ohio, Kent State University, 148 pages.

Woodward, Joan (1970). Industrial Organization: Behavior and Control, New York, Oxford University Press. 



\section{LES GRANDS ESPRITS DU MANAGEMENT... DEVANT VOUS!}

Au moment de mettre sous presse, l'équipe des Productions Épisode, la compagnie de théâtre interactif, prépare en collaboration avec l'École nationale d'administration publique (ENAP) une version théâtrale d'une partie du texte publié ici.

Il s'agit, dans un premier temps, d'une représentation qui met en scène Mary Parker Follett, Frederick Winslow Taylor, Max Weber et Henri Fayol avec une animatrice (qui joue le rôle de «l'hôte » dans le texte).

Toutefois les comédiens ne font pas qu'interpréter leurs répliques telles que reproduites dans ces pages : sous la supervision de professeurs de l'ENAP, ils sont formés afin de faire vivre leurs personnages en dehors de leur texte.

C'est pourquoi la seconde partie de la représentation est effectuée en interaction impliquant les spectateurs et les personnages. On peut imaginer les débats qu'engendre ce type d'animation, de même que l'intérêt, voire l'émulation, créée par le dialogue entre des étudiants et ces personnages enfin sortis du carcan de l'histoire. Chez Épisode, on croit fermement que ce théâtre sert une pédagogie moderne, stimulante et pour le moins vivante.

Depuis 1987, Épisode, une compagnie théâtrale de Québec qui engage plus de 60 pigistes annuellement, a joué plus de 1000 spectacles exploitant de très nombreuses formes d'interaction avec le public. En 1994, ses créations l'ont amenée à déborder les frontières du Québec pour jouer également en Europe francophone.

La pièce proposée ici est d'une durée de 90 minutes, suivie d'une partie interactive de durée variable. Selon la tradition de la série "Les Grands Esprits » vue à la télévision, elle nécessite un espace scénique restreint, peu de décors, peu d'accessoires, et peut être présentée dans des types de salles très variés. Le but des promoteurs est de rendre le spectacle le plus accessible possible aux différentes institutions d'enseignement intéressées, sans égard à la région où elles sont situées.

Pour plus d'information, veuillez contacter :

\section{Les Productions Épisode}

$572,1^{\text {re }}$ avenue, Québec (Québec)

G1L 3J9 téléphone : $\quad 418-648-6760$

télécopieur : 418-648-8058

Responsable du projet : Stéphan Parent 


\section{- $)$ MARQUIS \\ Québec, Canada 2000}

